\title{
The political ecology of sustainable livelihoods in Kakisa, NWT: Fish waste composting for enhancing soil productivity and waste management capacity in northern Indigenous communities
}

By

\section{Erin Snider}

Bachelor of Arts with Honours in Environmental Studies, Trent University

A thesis submitted to the Faculty of Graduate and Postdoctoral Affairs in partial fulfillment of the requirements for the degree of

\author{
Master of Arts \\ In \\ Political Economy \\ Carleton University \\ Ottawa, Ontario \\ (C) 2021 \\ Erin Snider
}




\section{Abstract}

Climate change and inadequate waste management capacity disproportionately impact northern Indigenous communities, exacerbating existing food security concerns in the Northwest Territories. Climate change not only reduces the accessibility and availability of traditionally harvested or hunted foods, but also allows for expanded agricultural production farther North. However, a lack of fertile soil in the North limits agricultural expansion. In response to these challenges, the Ka'a'gee Tu First Nation (KTFN) from Kakisa, NWT, identifies fish waste composting to simultaneously increase agricultural productivity and waste management capacity.

This thesis explores the community-driven fish composting pilot project led by the KTFN, using participatory action research as a guiding methodology. It couples a Sustainable Livelihoods Approach (SLA) to generate practical recommendations to strengthen community assets, with a political ecology framework to explore underlying meaning and discursive constructions. This project uses participant observation, informal, semi-structured interviews and focus groups to answer: 1) why has KTFN expressed interest in fish composting; 2) how might fish composting work in Kakisa; and 3) how might the SLA and political ecology appropriately theorize this community initiative? Results indicate that the KTFN perceive various practical benefits for composting fish waste including increased soil productivity, increased waste management capacity, employment opportunities, knowledge sharing opportunities, and adoption of a proactive approach to climate change adaptation. The KTFN's worldviews and epistemologies articulate the perceived practical benefits through lenses of deeper significance including health, taking care of the land, self-sufficiency, and traditional knowledge. 


\section{Acknowledgements}

First and foremost, I extend my deepest gratitude to people of the Ka'a'gee Tu First Nation (KTFN). Thank you for granting me the opportunity to work with you on research topics I am passionate about, including climate change adaptation, food security, and waste management. Thank you for welcoming me into your community, and for helping me feel welcome and included. I appreciate the Elders who invited me into their homes for tea and stories. I appreciate the youth who worked alongside me throughout the summer days, and who helped entertained me on our days off. I appreciate the people who invited me to pick berries and gain on-the-land experiences. Without your support, and most importantly, your friendship, I could not have completed this project. Mahsi Cho. I would also like to thank various other community partners including Sambaa K'e First Nation, Ecology North, and Russel Chase for collaborating with me, not only on this thesis, but also for their dedication to larger projects I am a part of.

Next, a big thank you to Dr. Andrew Spring, for introducing me to your research partners, the KTFN, and your network of grad students. You provided me with a comfortable space to learn and explore the research topics I am passionate about. This project would not have existed without you. I appreciate all of your support and encouragement. I am also grateful for the support and guidance I received from my cosupervisors, Dr. Patricia Ballamingie and Dr. Peter Andrée. Your feedback was always constructive, and both my writing and perspective on research has improved a great deal in working with you. I appreciate the patience and encouragement you extended when things got tough for me. 
Finally, thank you to my family and friends for their unconditional love and support. To my friends, my cousin, and my sister for making me smile and helping me maintain some level of work-life balance. To my partner, for always believing in me, making me coffee when I needed it most, and for maintaining a positive attitude throughout this journey. Thank you to my father, for your unconditional support and for moving across the province with me while I continue to pursue my dreams. Last, but not least, a tremendous thank you to my mother, for reading every chapter of this thesis, for finding creative ways to help me stay motivated, and for nurturing and supporting me throughout my entire academic career - I would be lost without you. 


\section{Table of Contents:}

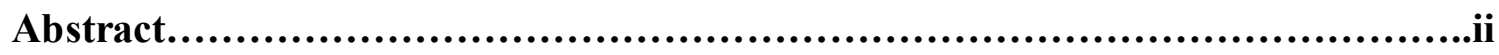

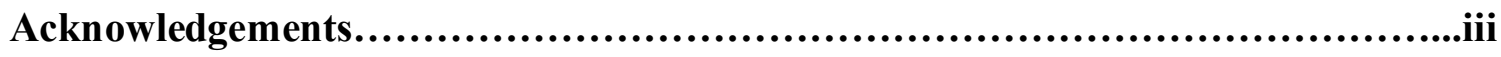

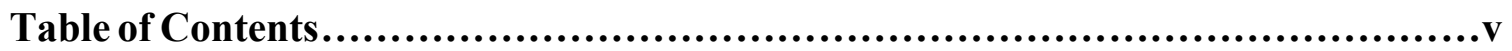

List of Tables.........................................................................

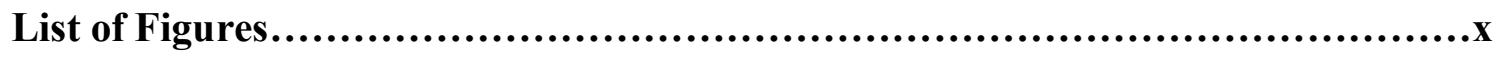

List of Appendices......................................................................

Chapter 1: Introduction..............................................................

1.1 Coming to a head: Climate change, waste management, and food security ............3

1.1.1 Literature review on climate change impacts and food security in the

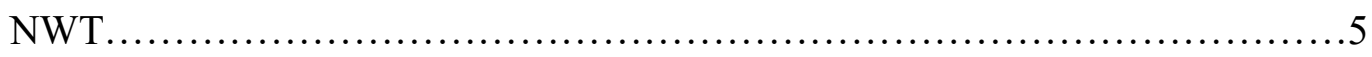

1.1.2 Literature review on waste management in the NWT.....................9

1.2 Indigenous communities take action......................................... 12

1.2.1 Introducing the research partners and community led projects.............13

1.3 Research questions and project objectives..................................... 15

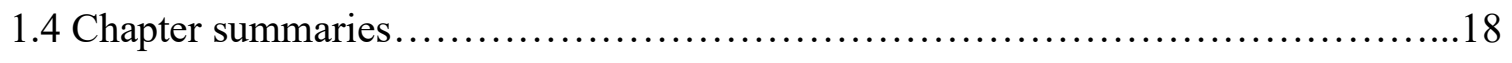

1.4.1 Chapter 2: Integrating the SLA and political ecology for a combined

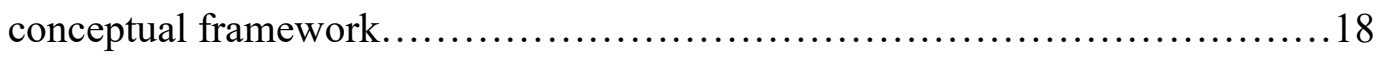

1.4.2 Chapter 3: Methodology, ethics, and methods...........................19

1.4.3 Chapter 4: Meaning and perceived benefits - Why fish composting?.........19

1.4.4 Chapter 5: Community assets and recommendations.....................20

1.4.5 Chapter 6: Learning from experience - SLA and political ecology

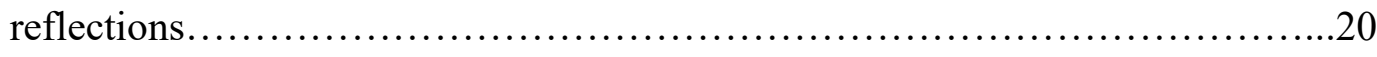


1.5 Conclusion

Chapter 2: Integrating the SLA and Political Ecology for a Combined Conceptual

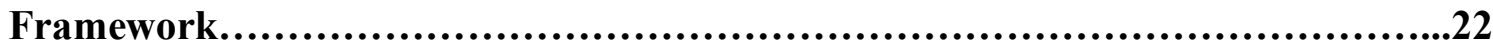

2.1 Sustainable livelihoods approach....................................... 23

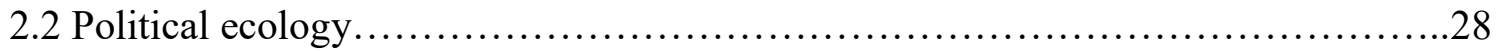

2.3 Political ecology critiques of the SLA: Gaps to address for a dual framework.......31

2.4 Framework summary and reconciling tensions.............................. 36

Chapter 3: Methodology, Methods, and Ethics..................................37

3.1 Community profile....................................................

3.2 Researcher positionality.............................................40

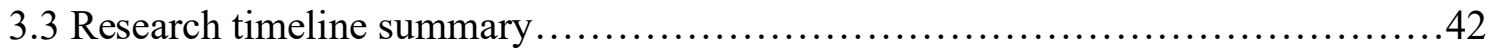

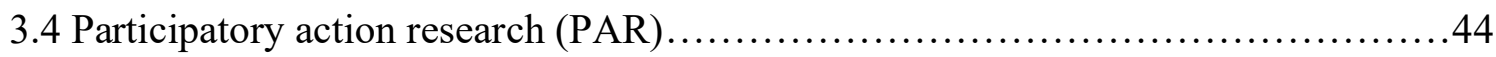

3.4.1 PAR and fish composting in Kakisa................................47

3.5 Ethics............................................................. 50

3.6 Methods ............................................................. 51

3.6.1 Focus Groups................................................51

3.6.2 Interviews................................................... 54

3.6.3 Participant Observation........................................55

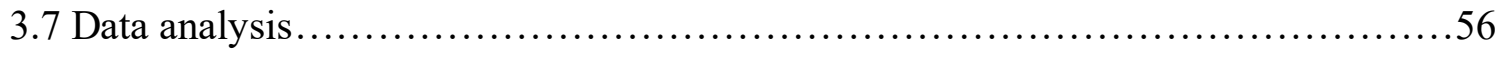

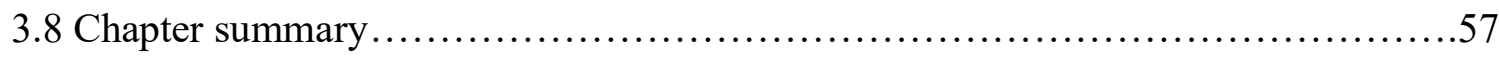

Chapter 4: Meaning and Perceived Benefits - Why Fish Composting?.......................59

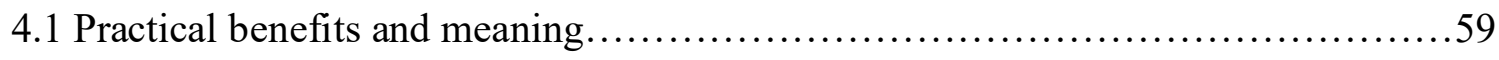

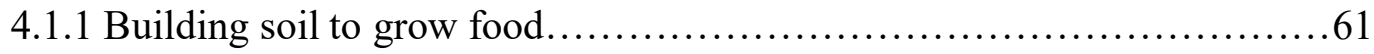


4.1.2 Increasing waste management capacity ..............................66

4.1.3 Creating employment............................................... 70

4.1.4 Taking a proactive approach to climate change adaptation.................72

4.1.5 Sharing knowledge with other communities...........................75

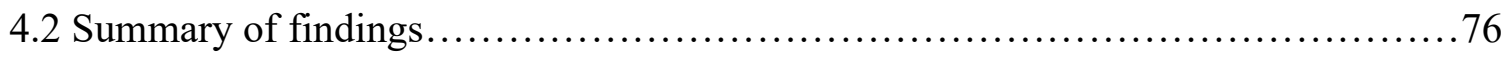

4.2.1 Political ecological analysis............................................ 80

Chapter 5: Community Assets and Recommendations..............................83

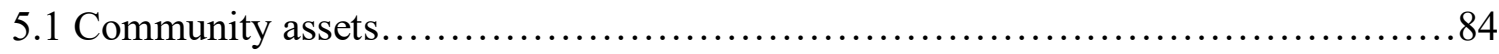

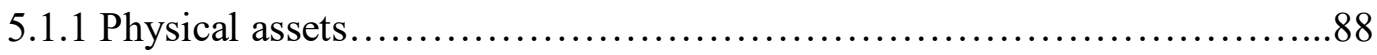

5.1.2 Cultural assets.......................................................... 93

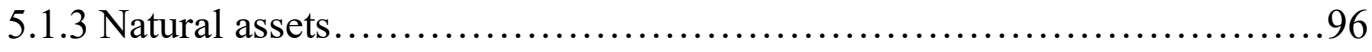

5.1.4 Economic assets................................................ 98

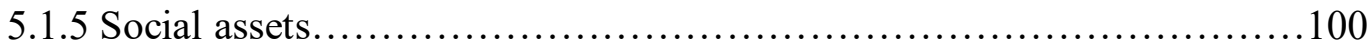

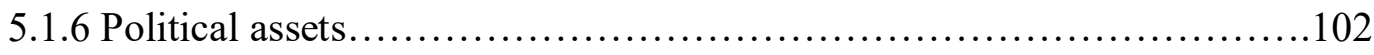

5.1.7 Human assets...................................................... 104

5.2 Challenges and barriers........................................................

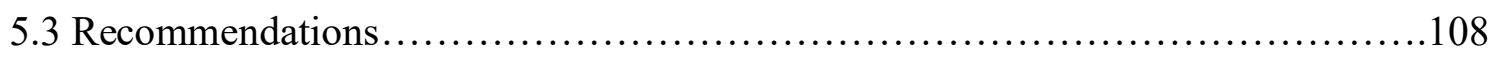

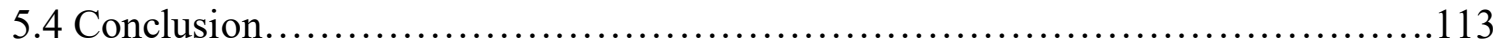

Chapter 6: Learning from Experience - SLA and Political Ecology Reflections...114

6.1 Framework Strengths and limitations....................................... 115

6.1.1 SLA: Strengths and limitations.........................................115

6.1.2 Political ecology: Strengths and limitations ...........................122

6.1.3 Combined framework: Strengths...................................126 
6.1.4 Reconciling tensions.............................................. 127

6.2 Summary: SLA and political ecology in a northern Indigenous context............132

Chapter 7: Conclusion.............................................................135

References..............................................................................140

Appendices............................................................................150 


\section{List of Tables}

Table 1. Research Timeline...................................................43

Table 2. Kakisa's Assets................................................ 87

Table 3. Kakisa's Identified Outstanding Needs \& Challenges.................... 107

Table 4. Results: Fish Composting Recommendations.......................... 109

Table 5. Recommendations for a Combined Framework........................133 


\section{List of Figures}

Figure 1. Community Profile Map: The KTFN's Traditional Territory..................23

Figure 2. Community Profile Map: Treaty No. 11 Range...........................39

Figure 3. Toward a Combined Conceptual Framework: Integrating Political Ecology and a Sustainable Livelihoods Approach...................................40

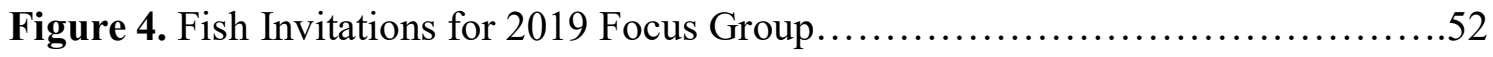

Figure 5. Paper Mâché Fish Composting Diorama..................................53

Figure 6. Fish Composting in Kakisa: Relationships Between Practical Benefits and

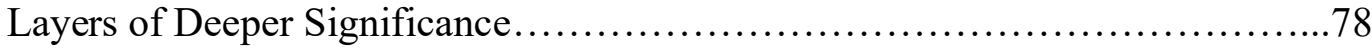

Figure 7. Map of Kakisa: Key Fish Composting Locations ......................... 90

Figure 8. Ka'a'gee Tu Candidate Area....................................... 103

Figure 9. Linda Tuhiwai-Smith's Representation of an Indigenous Research Agenda..131 


\section{List of Appendices}

Appendix A: Plain Language Document: Fish Composting Methods \& Locations

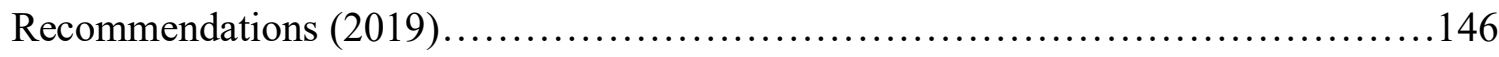

Appendix B: Wilfrid Laurier University Approved Ethics: Recruitment Letter \&

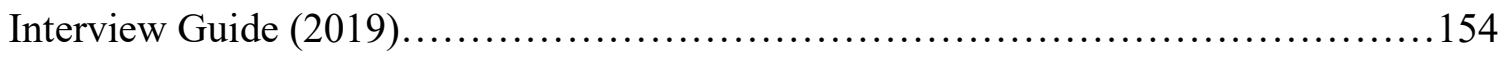

Appendix C. Aurora Research Institute License...............................157

Appendix D. Carleton University Approved Ethics: Recruitment Letter \& Interview

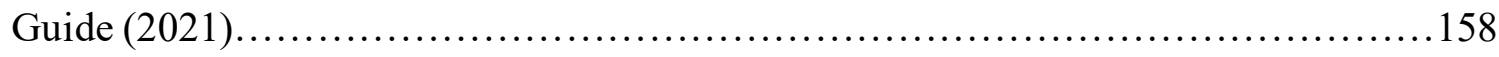

Appendix E. 13 Moons Poster - Indigenous Food Circle.........................162

Appendix F. Kakisa's Community Capitals Table (Spring et al., 2018)...............163 


\section{Chapter 1: Introduction}

Indigenous communities in Canada's Northwest Territories (NWT) disproportionately experience impacts of climate change, inadequate waste management practices, and food insecurity (Oyengunle, 2016; Zagozerwski et al., 2011; Spring et al., 2020; Rudolph \& McLachlan, 2013; Fieldhouse \& Thompson, 2012; Fiddler et al., 2012; Guyot et al., 2006; Anisimov et al., 2007). Indigenous communities in the North are very aware of how these issues impact their livelihoods, and many communities take on leadership roles to address these concerns through community-driven research projects and initiatives. For example, the Ka'a'gee Tu First Nation (KTFN), Kakisa NWT, lead the Northern Agriculture Futures (NAF) project to research agricultural best practices for addressing the impacts of climate change and increasing food insecurity. In response to growing concerns on the impacts of climate change, waste management, and food insecurity in the North, the KTFN identify composting as a tool for simultaneously enhancing soil productivity, expanding local food production, and increasing waste management capacity in their community. The KTFN have already taken steps to implement a fish composting pilot project in Kakisa, with the goal of expanding established composting infrastructure to include household organic waste.

This thesis project investigates the use of fish waste composting as a tool for overcoming livelihoods challenges associated with climate change, waste management, and food insecurity in the NWT. Since the KTFN already identify fish waste composting as a path forward, I investigate specific ways to successfully implement this project in Kakisa as principal investigator for this project. This thesis applies a participatory action research (PAR) methodology for better understanding the KTFN's values, goals, and 
motivations for undertaking the fish composting project. Applying a PAR methodology means working closely with community members to address community-identified research objectives and needs (Gilmore et al., 1986; McTaggart, 1999; Baum et al., 2006; Pearce et al., 2009; Spring et al., 2018). The recommendations outlined in this thesis will inform community action plans for implementing this project in Kakisa.

To generate both practical and meaningful recommendations for implementing the fish composting pilot project in Kakisa, I apply the sustainable livelihoods approach (SLA) and political ecology as a combined framework for data collection and analysis. The SLA uses an assets-based approach to enhance community livelihoods and promote sustainability (Chambers \& Conway, 1991; Morse \& McNamara, 2013; Scoones, 1998). The SLA's descriptive framework for mapping community assets identifies the KTFN's strengths, which ensures recommendations fit within the community's capabilities. Political ecology uses a theoretical approach to understand the socially constructed nature of environmental discourse, sustainability, dominant structures of power, and local significance (Escobar, 1996; Jarvenpa, 2008; Robbins, 2012). Political ecology’s emphasis on addressing meaning and discourse aligns the recommendations outlined in this thesis with the KTFN's worldview and ways of knowing.

This thesis supports three primary arguments. First, I argue that the KTFN's core cultural values, articulated through a wider ontology and epistemology, inform their goals for improving waste management capacity and expanding local agricultural production. The KTFN views agriculture and waste management holistically, meaning the two goals for improving livelihood sustainability cannot be disentangled. Second, I argue that complex capacity related challenges must be addressed in Kakisa to ensure long-term 
success for the fish composting project. The administrative and organizational needs within community projects must be equally considered alongside infrastructure development to promote successful project operation and management. Finally, I reflect on the experience of using the SLA and political ecology as a combined framework. I argue that the SLA's and political ecology's complementary differences actively strengthen one another. This combined framework allows researchers to bridge the gap between community realities and academic theory.

\subsection{Coming to a head: Climate change, waste management, and northern food insecurity}

In Canada's Northwest Territories, Indigenous communities and their livelihoods are disproportionately impacted by environmental and ecological changes. Climate change poses a major ecological threat, as warming in Canada's North continues to accelerate at a rate of up to 3 times the global average (Flato et al., 2019; Lenton et al., 2019; IPCC, 2018). The impacts of climate change in the North include, but are not limited to permafrost thaw, changes in weather and precipitation, unpredictable seasonal shifts, changes in surface water and ground water, changes in species migration, changes in species range and distribution, changes in species health, and warmer temperatures (Anisimov et al., 2007; Zhang et al., 2019; Bush et al., 2019; IPCC, 2014; IPCC, 2018; Lenton et al., 2019; Derksen et al., 2019).

In addition to climate change, northern Indigenous communities also experience increasing environmental contamination and the legacy of poor waste management strategies in the Northwest Territories (Golder, 2018; GNWT, 2019). Research on the 
impacts of poor waste management in the Northwest Territories is severely lacking. However, there exists a small body of literature on the state of waste management in northern Indigenous communities throughout Provincial Canada, which highlights growing concern about the state of waste management in Indigenous contexts (Oyengunle, 2016; Zagozerwski et al., 2011). This literature often cites inadequate waste management facilities and infrastructure, insufficient landfill design, historically poor waste management policy from the federal government, and inadequate funding for Indigenous communities to enhance waste management practices - contributing to growing concerns about the environmental impacts of waste.

The negative impacts of climate change and poor waste management in the Northwest Territories amplify one another. On one hand, poor waste management practices - such as the inclusion of organic waste in landfills - produces methane gas, which increases greenhouse gas $(\mathrm{GHG})$ emissions that contribute to climate change (Pan \& Voulvoulis, 2007; Goldsmith et al., 2012; Bogner \& Matthews, 2003; Bogner et al., 2007; Trapani et al., 2013). On the other hand, climate change contributes to permafrost thaw and increased ground water activity, which mobilizes poisonous leachate produced in landfills and threatens to contaminate the surrounding environment and surface water in the Territory (GNWT, 2019; Frugal \& Prowse, 2008).

In the North, both climate change and waste management issues contribute to increasing food insecurity in Indigenous communities - an exceedingly pressing issue. Food insecurity disproportionately impacts northern Indigenous communities compared to southern, provincial, and predominately white communities throughout Canada (Spring et al., 2020; Rudolph \& McLachlan, 2013; Fieldhouse \& Thompson, 2012; Fiddler et al., 
2012). Climate change threatens food security in northern Indigenous communities by reducing the availability and accessibility of traditional foods (Price et al., 2013; Guyot et al., 2006; IPCC, 2014; IPCC, 2018; Council of Canadian Academies, 2014; GNWT, 2008; Wesche \& Chan, 2010). Poor waste management practices also reduce the consumption of traditional foods by generating both real and perceived risks of ecological contamination (Zagozerwski et al., 2011). Since climate change disproportionately impacts northern Indigenous communities - and due to the sever underfunding of waste management programs - these two factors contribute to the disproportionately high rate of food insecurity experienced in these communities. Ultimately, climate change, waste management, and food insecurity intersect as deeply connected, interrelated issues affecting Indigenous communities in the NWT.

\subsubsection{Literature review on climate change impacts and food security}

Northern Indigenous food systems and wellbeing are threatened by various social, economic, political, and environmental factors rooted in colonialism (Lambden et al., 2007; Kuhnlein \& Chan, 2000), and climate change is one emerging factor that further threatens an already vulnerable food system in northern Indigenous communities. Climate change impacts both the accessibility and availability of traditional foods in the North (Guyot et al., 2006; Anisimov et al., 2007; Collings 2011; Lambden et al., 2007; Spring et al., 2018), which negatively impacts community and individual wellbeing, northern Indigenous cultural and spiritual identity, and social organization in the North by complicating relationships with the land and hindering the consumption of traditional foods (Receveur 
\& Kuhnlein, 1998; Kuhnlein \& Chan, 2000; Parlee et al., 2007; Jarvenpa, 2008; Spring et al., 2018).

Climate change impacts the quantity of culturally significant flora and fauna species used for food. Climate change also affects species health, distance travelled to obtain species, and the availability/distribution of species (Guyot et al., 2006; Anisimov et al., 2007). Culturally significant northern fauna are especially vulnerable to climate change because they are highly specialized for harsh northern environments, which means in addition to facing the challenges of a rapidly warming environment, they are ill-equipped to compete with southern animals increasing their ranges northward (Anisimov et al., 2007; IPCC, 2018; Turetsky et al., 2017). People in Fort Providence have observed expansion in the range of various predatory animals including cougars, eagles, and lynx, and changing migration times and patterns for migratory birds have limited people's access to traditional foods such as geese (Guyot et al., 2006). Other ecological changes documented in the North broadly include changes in water, ice, and weather (Guyot et al., 2006; Anisimov et al., 2007; IPCC, 2014; Derksen et al., 2019; Zhang et al., 2019; Bush et al., 2019; Lenton et al., 2018; Turetsky et al., 2017; Turetsky et al., 2019;). Many of these factors influence one another, further highlighting the complexity of local ecosystems and climate change impacts.

Changes to water quality, precipitation, and surface water levels also pose significant threats to traditional food systems in the North. Increased precipitation, flooding, and unpredictable fluctuations in water levels for rivers and lakes all impact the availability and accessibility of both terrestrial and aquatic species used for food (Guyot et al., 2006; Anisimov et al., 2007; Turetsky et al., 2019). Warmer weather, later arrival of 
seasons, and air temperatures increasing at an average of $5^{\circ}$ Celsius or more over the twentieth century also impact the North (Guyot et al., 2006; Anisimov et al., 2007; IPCC, 2018). In 2019, models predict that warming in Canada's North will accelerate to 3 times the global average (Flato et al., 2019; Lenton et al., 2018). As a result, animals will likely experience increased exposure to disease and decreased health (Guyot et al., 2006; Anisimov et al., 2007). Warmer water also makes ice travel less safe for hunters, ice fishers, and harvesters (Guyot et al., 2006). These documented changes will only continue to accelerate over time (Anisimov et al., 2007; IPCC, 2018; Turetsky et al., 2017; Turetsky et al., 2019). Habitat destruction through irreversible permafrost thaw, the drying of wetlands and ponds, increased flooding, and increased forest fires in addition to migratory disruptions will contribute to the reduction of native biodiversity (Anisimov et al., 2007; Zhang et al., 2019; Bush et al., 2019; Turetsky et al., 2019). Overall, these ecological changes to land-based resources will "alter local resource use and traditional and subsistence lifestyles" (Anisimov et al., 2007: 66). Since northern Indigenous communities' food systems rely heavily on knowledge and relationships with the land itself, the fact that climate change complicates being on the land directly impacts their ability to access traditional foods and maintain their overall wellbeing.

While some communities in the North resiliently adapt to the impacts of climate change (Guyot et al., 2006), adaptive capacity is by no means ubiquitous across communities. As previous work in northern Indigenous communities shows, adaptive strategies can be pursued provided they are collaborative, inclusive, considerate of Indigenous knowledge, and shaped in a manner that aligns with Indigenous cultural values (Spring et al., 2018; Power, 2008; Pearce et al., 2009; Pearce et al., 2010; Andrachuck \& 
Smit, 2012). However, there are often stark differences across Indigenous communities in terms of what types of adaptive strategies are culturally appropriate and acceptable (Anisimov et al., 2007). Adaptation in northern Indigenous communities also tends to be limited by "economic, social, and institutional circumstances" (Andrachuk \& Smit, 2012: 867).

Limited community capacity is another barrier to climate change adaptation strategies in the North (Spring et al., 2018), and will likely be a major obstacle throughout this project. For instance, as Spring et al. (2018:12) highlights, with a population of roughly 40 people in Kakisa, there is often "low participation and engagement" in traditional food procurement and community events. If low participation and engagement are general concerns regarding the food system in Kakisa, these concerns might also pose challenges for implementing a fish composting project. Building the capacity for active, on-going participation in the research phase of the project, constructing the composting site in Kakisa, conducting routine maintenance at the composting site, collecting waste in the community, and monitoring the composting process will be necessary for overcoming these challenges related to population size and engagement. The KTFN are currently investigating the possibilities for increasing human capacity in Kakisa. Youth employment from summer work programs for food security related work and community research offers one avenue for expanding community capacity. These ideas will be explored in more detail throughout this project.

Increasing community capacity for adaptation can also be improved by increasing regional knowledge sharing and social capital. Knowledge sharing as a form of social capital or social learning includes access to resources, participation of new or different 
actors across communities and institutions, trust building, conflict resolution, and networking (Berkes, 2009). Social learning as an on-going, reflective form of experiential learning, or "learning-by-doing" (Berkes, 2009) offers valuable insight for promoting fish composting on a regional scale. When communities engage with other institutions or other communities, they increase their opportunities for accessing knowledge and resources they might not have otherwise had in order to tackle problems (Natcher, 2015). Beneficial knowledge sharing relationships can become reciprocal, allowing multiple communities or institutions across larger scales to influence and assist one another in tackling problems or implementing adaptive strategies to broad issues such as climate change (Natcher, 2015; Berkes, 2009).

\subsubsection{Literature review on waste management in the NWT}

Waste management in the NWT, and in Canadian Indigenous communities in general, is not widely researched or discussed in academic literature (Assuah, 2020; Oyengunel, 2016; Zagosewski et al., 2011). Waste management literature for the NWT consists primarily of GNWT websites and documents, third party consulting publications, and grey literature. Thus, there is a considerable gap when it comes to the representation of waste management in northern Indigenous communities. This is problematic because it means monitoring and reporting on the status of waste management inadequately informs practices, which contributes to a lack of understanding for estimating the impacts of poor waste management practices and insufficient waste management capacity on Indigenous communities in the North. 
Some impacts of poor waste management in the NWT are vaguely addressed in government documents and third-party reports. For instance, as Golder Associates Ltd. (2016) explains, various risk factors including environmental contamination, water contamination, threats to wildlife, and threats to human health stem from insufficient waste management practices and infrastructure in the Territory. Many NWT landfills are adjacent to wetlands or surface water, both of which are connected to lakes and rivers through ground and surface water drainage. Leachate is cited as a critical concern throughout the reports, as many NWT landfills lack proper cell lining or covers to prevent leachate traveling through groundwater, or to prevent surface runoff. Climate change and permafrost thaw also increases water contamination concerns in the region (GNWT, 2019; Furgal \& Prouse, 2008). The report also identifies risks to wildlife, since many NWT landfills are not equipped with proper animal protection (such as electric fences or cell covers). Wildlife may ingest hazardous waste or become too reliant on waste as a food source - which means improving waste management practices could result in loss of food sources, leading to wildlife population fluctuation, particularly for scavenging predators. If landfill sites are not properly monitored, this increases the likelihood of direct human contact with hazardous waste. The increasing presence of bears and wolves at landfill sites also pose threats to human safety. Additionally, leachate can contaminate drinking water obtained from nearby lakes and rivers, impacting human health.

Golder Associates Ltd. (2016) also provides some insight into how the Territory and individual communities manage waste, however, it does not provide a significant level of detail regarding the impacts on the environment and communities. The report outlines specific details including the estimated amount of solid waste generated by each 
community in the NWT based on 2011 government and census data. The report estimates that Kakisa generates roughly 25 tonnes of solid waste per year, diverts roughly 1 tonne/year, and generates roughly $550 \mathrm{Kg}$ of solid waste/person/year. The landfill site in Kakisa comprises an area of $10,500 \mathrm{~m}^{2}$ and annual costs for dealing with solid waste amount to roughly $\$ 105,425.00$, or $\$ 2,095$ per capita. Kakisa's landfill currently does not have compaction infrastructure, cover materials, or landfill covers.

In the NWT, community governments are primarily responsible for waste management costs, not the GNWT or the federal government (Golder Associates Ltd., 2016). However, some funding may be available for communities through the Environmental Liabilities Fund or the Waste Reduction and Recycling Initiatives program (GNWT, 2019). Historically, funding for waste management in Indigenous communities has been severely lacking (Assuah, 2020; Oyengunle, 2016; Zagozerwski et al., 2011), and discrepancies between federal, provincial, territorial, and community jurisdiction make it difficult to navigate various responsibilities for ensuring adequate monitoring, enforcement, and support is provided to improve waste management practices in Indigenous contexts. In the NWT, responsibilities for overseeing waste management have recently shifted from the federal government to the GNWT and community governments (Golder Associates Ltd, 2016). In 2019, the GNWT published the Northwest Territories Waste Resource Management Strategy and Implementation Plan, to outline their strategy for increasing waste diversion and transitioning to a circular economy approach to waste management. Unfortunately, the plan offers vague practical guidance for how communities should approach improving waste management capacity, infrastructure, and practices, and instead, tends to focus more on government departments. 
In response to these issues, various communities in the NWT including the KTFN and the Sambaa K'e First Nation (SKFN) strive to implement community-based projects to improve waste management capacity and practices (Climate Change Adaptation Workshop, Kakisa, personal communication, February 12, 2021; Spring et al., 2020). Composting offers communities a chance to not only improve soil quality and productivity, but also significantly reduce the amount of organic material entering landfills, which would reduce toxic leachate production and methane emissions generated from decomposing organic material in landfills (Jenish, 1997; Government of Western Australia, 2018; Ayalon \& Shechter, 2001; Environment Canada, 2013). As such, this project focuses on finding ways to improve agricultural capacity while simultaneously addressing waste management concerns through composting.

\subsection{Indigenous communities taking action}

In response to the disproportionate impacts of climate change, poor waste management policy, and food insecurity, northern Indigenous communities take the lead in generating their own solutions to these problems by expanding local agriculture projects (Spring et al., 2017; ITI, 2015; GNWT, 2014). As temperatures in the North increase, climate change has the potential to allow agriculture to expand into northern environments (IPCC, 2014; Zable et al., 2014; Anisimov et al., 2007). While local agriculture does not directly address the issues of declining access and availability of traditional foods, it can provide communities with locally driven strategies for substituting expensive market-based goods with food grown on their land on their terms (Loring \& Gerlach, 2010). Agriculture in and of itself does not directly address concerns of waste management. However, as this project 
demonstrates, new waste management practices could be incorporated into local agriculture projects to serve a dual purpose of improving waste management in northern Indigenous communities while also bolstering agricultural productivity and food security.

A lack of fertile soil is one barrier to expanding food production in the North, since the types of soil present in the region consist primarily of bedrock, boreal forest peat lands, and wetlands (Day, 1968; ITI, 2015; Cook, 2017). In response to these challenges, the KTFN identify composting as a way to increase soil fertility in their community for expanding food production and to reduce the amount of waste that enters the community landfill. For this phase of the project, the community will focus on fish waste to kick off the pilot project - since fish waste is produced primarily from Kakisa's commercial fishery and traditional hunters, the community believes this will be a more manageable target material when establishing new infrastructure and waste collection systems. Once the project is successfully launched, the community hopes to expand their composting project to include kitchen and household compost.

\subsubsection{Introducing research partners and community led projects}

This research is part of the Northern Agriculture Futures (NAF) project led by the KTFN. The NAF project funded by Environment Canada's "Climate Change Preparedness in the North Program" intends for communities in the Dehcho and South Slave regions to develop small-scale agriculture and food production in ways that align with community needs and visions for the future. As northern climates warm, there will be more opportunities to grow food throughout the region. However, if steps are not taken to perform agriculture sustainably it could increase the amount of carbon emissions being released into the 
atmosphere, and potentially pose a threat to the surrounding boreal forest. As communities and traditional food systems in the North depend on the health of the land and waters for their wellbeing, ensuring agriculture develops in a way that supports clean air and healthy soil and water is important. Thus, the NAF project supports communities in developing local agriculture in a way that maintains the health of the surrounding ecosystems, stores carbon, and provides fresh, healthy food and economic opportunities for communities. The NAF project led by the KTFN is a multi-disciplinary project combining natural science and social sciences to develop best practice guidelines for expanding local agriculture in the North and for informing future agriculture policy. It is a multi-institutional project comprised of many community, academic, governmental, and not-for-profit partners.

As fish composting research informs my Master's thesis, I have taken a leading role investigating the use of fish composting for enhancing soil fertility and improving waste management in the North. During the summer of 2019, I lived in Kakisa for two months, building relationships with members of the community and working closely with community researchers and partners to investigate community-wide fish composting. Since the NAF project aims to expand local food production to increase adaptive capacity and resiliency in the face of climate change, this project seeks to lay the groundwork for doing so by using waste already generated within the community to increase soil productivity. Another goal of the NAF project seeks to strengthen relationships between communities in the North and to increase adaptive capacity on a more regional scale through knowledge sharing - which will also be investigated throughout this project. Currently, knowledge is shared between the NAF project's partnered communities through gatherings, workshops, and accessible language documents. The partnered community of the SKFN, from Sambaa 
K'e, NT has previously expressed interest in learning from the fish composting pilot project in Kakisa so they might implement their own composting site in their community. As such, knowledge sharing will make up an important component of this project.

\subsection{Research questions and project objectives}

This project applies a political ecological lens to qualitative data collected through interviews, focus groups, and participant observation in Kakisa. Using a political ecological lens emphasizing meaning and discourse enables an inductive approach to data analysis, where significant themes emerge from and are informed by the data itself. In Chapter 4 of this thesis, I apply this framework and method for data analysis to analyze the discourses employed by the KTFN. The application contributes to a better understanding of what fish composting means to the community, and how this meaning informs their livelihoods goals.

This project also applies the descriptive SLA framework for community asset mapping. Mapping community assets requires the use of deductive coding analysis, where themes are identified prior to analyzing the data itself. Typically, an SLA study organizes assets based on five categories including physical, social, economic, natural, and human. For this project, I have added political and cultural assets for analysis. In Chapter 5, I apply this framework and form of data analysis to map Kakisa's assets and generate recommendations on strengthening community capitals for implementing the fish composting project.

Finally, this project also seeks to examine the strengths and limitations of using the SLA and political ecology as theoretical lenses for approaching fish composting in a 
northern Indigenous context, and to examine how these frameworks might be strengthened if applied together as a combined theoretical framework. In Chapter 6, I reflect on the experience of using the combined framework as a lens for data analysis and generate recommendations for strengthening the use of this framework in Indigenous contexts.

Theis project is designed to respond to three guiding research questions and associated sub-questions:

1. How will fish composting increase the KTFN's capacity to address broader stresses, including climate change and food insecurity?

a. Where did the idea for fish composting come from? How is fish composting connected to the KTFN's overarching goals with expanding local agricultural production? What does fish composting mean to the community?

b. How might fish composting uphold or reflect traditional or cultural values and/or employ traditional or cultural practices?

c. What benefits have the KTFN identified in carrying out this project and how did they come to these conclusions?

2. How can the KTFN's identified assets help in generating practical recommendations for ensuring the success of the fish composting pilot project in Kakisa?

a. Which assets are currently applied in Kakisa for achieving community livelihoods?

b. What do outstanding needs reveal about possible challenges or barriers to implementing this project? 
c. What does this combined theoretical framework for this project reveal about the community's assets and possible ways to strengthen assets for supporting the implementation of this project?

3. How does the sustainable livelihoods approach (SLA) viewed through the lens of political ecology help us conceptualize the Ka'a'gee Tu First Nation's (KTFN) capacity for implementing a fish composting system in their community?

a. What are the possibilities and limitations of combining elements of the SLA and political ecology as the theoretical framework for this project? How can tensions and gaps be addressed?

b. How might this project inform the combined application of the SLA and political ecology in a northern Indigenous context?

Ultimately, the three goals of this thesis project can be summarized as: 1) to learn how the KTFN understands fish composting and its perceived benefits (why fish composting?); 2) to generate practical recommendations for implementing this project within Kakisa (how to do fish composting?); and, 3) to consider how best to work with two specific theoretical frameworks (SLA and political ecology) in this research context (how to theorize this community initiative?). 


\subsection{Chapter summaries}

\subsubsection{Chapter 2: Integrating the SLA and political ecology for a combined conceptual framework}

Chapter 2 outlines the two frameworks I use to guide my analysis in this project. I selected the sustainable livelihoods approach (SLA) as an analytical framework as it seeks to understand community capacity for adaptation and resiliency. The framework takes a descriptive approach to cataloguing and assessing community capitals (or assets) that can be strengthened in a fish composting context. Political ecology was selected as a complementary theoretical lens based on its emphasis on discourse and meaning in human relations with the more-than-human world. It is useful for understanding perceptions and meanings that inform people's livelihood choices.

The chapter begins with a brief overview of how these two frameworks are combined throughout the project. Then, it explains core principles for each framework individually, and provides examples of other projects that have applied the frameworks. Next, I cover various critiques of the SLA from a political ecology perspective and offer insight on how to overcome these tensions and differences throughout the project. I also explain how a participatory action research (PAR) methodology connects to each framework and explore ways that PAR can help overcome some of the tensions between the two frameworks. Ultimately, this chapter constructs a preliminary argument that the SLA and political ecology are complementary frameworks, and that each framework is relevant to a fish composting context in Kakisa. Chapter 6 considers whether or not this was actually the case in application. 


\subsubsection{Chapter 3: Methodology, ethics, and methods}

Chapter 3 provides a more detailed discussion of how PAR is applied in this project. I explain how community members contributed to various stages of the research process and reflect on the impacts of COVID-19 and remote research on applying a PAR methodology. Then, I explain ethics approval, obtaining informed consent, and data storage. The chapter concludes with a detailed discussion of my data collection methods, primarily focus groups, interviews, and participant observation. I explain how plans changed to adapt to new COVID-19 research protocols and provide a brief explanation of how data was analyzed.

\subsubsection{Chapter 4: Meaning and perceived benefits - Why fish composting?}

Chapter 4 addresses research question 1 for this project. It explores the KTFN's perceived benefits of the fish composting project - highlighting that, in addition to practical benefits, the KTFN identified various intertwined layers of deeper significance that reflect their broader worldviews and ways of knowing. In this chapter, I argue that the KTFN's goals for improving waste management capacity and agricultural expansion are interconnected and driven by their core cultural values for caring for the land, health, self-sufficiency, and applying traditional teachings to their livelihoods. Ultimately, applying a political ecological lens to the KTFN's stories allowed me to uncover and interpret these deeper meanings, which would help guide my recommendations in the following chapter. 


\subsubsection{Chapter 5: Community assets and recommendations}

Chapter 5 addresses research question 2 for this project - as cataloguing the KTFN's assets was necessary for creating recommendations for the project that play to their strengths and fit within the community's means. First, I describe the KTFN's identified assets, and briefly discuss some of the challenges they identified. Then, I apply these assets to generate various recommendations for the project including practical recommendations, recommendations for strengthening assets, and future considerations for ensuring longterm success of the project. I argue that, while practical steps need to be taken to implement this project, it will also be imperative to address broader, capacity related issues to ensure long-term success of the fish composting project, and other agriculture and waste management goals in general.

\subsubsection{Chapter 6: Learning from experience - SLA and Political Ecology Reflections}

Chapter 6 addresses research question 3 for this project. It reflects on the experience of applying the SLA and political ecology in this context. First, I explain the strengths and weaknesses of both the SLA and political ecology individually. Then, I explain the strengths of using the combined framework, while also reflecting on ways to strengthen the combined framework in future research. Ultimately, the chapter builds a case for why the SLA and political ecology work well together as a combined framework, However, I also argue that this framework needs to be refined in the future to fit appropriately within a northern Indigenous context. 


\subsection{Conclusion}

Understanding how the impacts of climate change, inadequate waste management, and food insecurity intersect in northern Indigenous contexts forms the central narrative of this thesis. It is important to view these issues holistically in relation to one another. As the KTFN's fish composting project illustrates, it is also important to view possible solutions to these challenges holistically, with emphasis on promoting health, caring for the land, self-sufficiency, and traditional Indigenous knowledge inclusion. Composting provides one actionable initiative to address some of the complex, intersectional impacts of climate change, waste management challenges, and food insecurity in the North. As such, this project offers wide-ranging application across communities in the North, and for research projects working closely with Indigenous communities, to increase livelihood sustainability. The following chapter further explains the theoretical framework guiding this project. 


\section{Chapter 2: Integrating the SLA and Political Ecology for a Combined Conceptual Framework}

This project combines the Sustainable livelihoods approach (SLA) - a descriptive analytical framework for cataloguing community assets - with political ecology, a framework centred around more abstract analytical concepts including discourse and meaning. Merging the two frameworks broadens this project's scope beyond a descriptive summary of community capitals. Understanding what various assets mean to the community is essential for understanding their perceived strengths and possible avenues of application in a fish composting context. Figure 1 illustrates how these two frameworks operate together throughout this project. Each framework is discussed in more depth in the paragraphs to follow. The chapter concludes with a discussion of how these frameworks complement one another to create a rich understanding of community assets and livelihoods in Kakisa. 


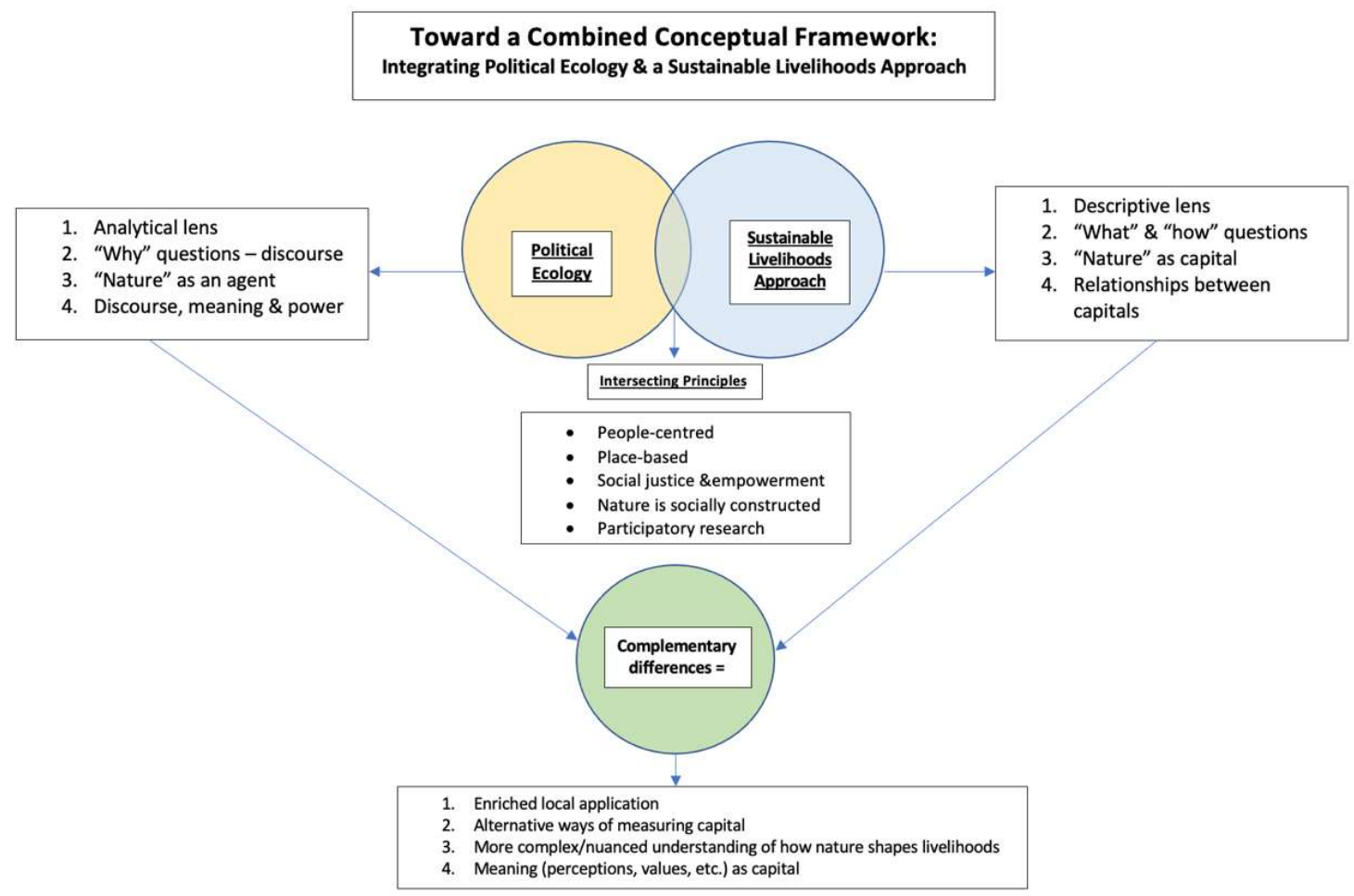

Figure 1. Diagram illustrating the key aspects of political ecology and the SLA, their intersecting principles, and how these two frameworks might come together to strengthen their application to a fish composting pilot project in Kakisa.

\subsection{Sustainable livelihoods approach}

This project uses the SLA to collect data, which is then analyzed through the lens of political ecology. The SLA was originally developed by Chambers \& Conway (1991) and is grounded in questions of community capability, equity, and sustainability - focused primarily on the local scale. The first key aspect of the SLA is the concept of sustainability, which is grounded in the idea that human actions in the present can either protect or threaten the ecological and environmental circumstances of future generations (Morse \& McNamara, 2013). Even though sustainability is comprised of three overlapping concepts - the "environmental," the "economic," and the "social" spheres of society - sustainability studies tend to overlook the significance of human relationships with their environments 
(Morse \& McNamara, 2013). The significance Morse \& McNamara (2013) refer to might include how human relationships with the environment combine elements of other forms of capital, or how they inform livelihoods decisions. The livelihoods aspect of the SLA is thus an attempt to reinsert the centrality of people back into conversations about sustainability.

Chambers \& Conway (1991: i) define a livelihood as comprised of people, "their capabilities, and their means of living”, the latter of which includes food, income, and assets (resources and/or capital). A sustainable livelihood maintains or enhances "local and global assets on which livelihoods depend" and has "a net benefit on other livelihoods" (Champers \& Conway, 1991: i). Put another way, the SLA "attempts to put sustainability into practice" by focusing on livelihoods (Morse \& McNamara, 2013: 6). As this project aims to investigate the ways in which fish composting in Kakisa can yield local and regional livelihood benefits for enhancing sustainability, the SLA pinpoints areas to strengthen for realizing these goals. The SLA uses a "multi-capital" approach to understanding community capacities for strengthening sustainability (Morse \& McNamara, 2013). Available capitals within a community are catalogued and assessed to identify assets that can be strengthened to increase overall sustainability (Chambers \& Conway, 1991; Morse \& McNamara, 2013; Scoones, 1998). For a typical SLA project, these capitals include natural capital (natural resources, environmental services), social capital (social networks, relations, associations, etc.), physical capital (infrastructure, equipment, means of production), human capital (people, occupations, skills, knowledge, labour, physical/mental health), and economic/financial capital (cash, income, debt, access to credit, assets) (Morse \& McNamara, 2013). SLA projects might also look at cultural 
capital and political capital as separate pillars comprising assets within a community (Morse \& McNamara, 2013; Scoones, 1998). SLA projects also consider capitals in relation to one another, as they are often intertwined and mutually constituted. Considering relationships between capitals means taking a reflexive approach to identify "what livelihood resources (or combinations of 'capitals') are required for different livelihood strategy combinations" (Scoones, 1998: 9).

Since this project takes place in an Indigenous context, cultural and political capital must be included with natural, physical, social, economic, and human capital as categories for analysis. Adding cultural and political capital makes this use of the SLA more consistent with a community capitals framework (CCF), another community assets-based approach developed by Emery \& Flora (2006) and applied in Kakisa by Spring et al., (2018). Despite these similarities, I made a conscious choice to use and modify the SLA framework based on the SLA's more extensive literature coverage. Having access to more literature was necessary for comparing and exploring possible intersections between the SLA and political ecology for a combined framework.

Cultural capital comprises the "underlying factors that provide human societies with the means and adaptations to maintain themselves in their environment" (Cochrane, 2006: 318). Culture plays an active role in the development of societal rules, belief systems, ethics, and traditional ecological knowledge (Cochrane, 2006; Daskon \& McGreggor, 2012). Cultural capital also plays a significant role in facilitating relationships between other forms of capital (Cochrane, 2006). Cultural capital's relationships with natural and social capital prove especially significant in Indigenous contexts, since the land influences spiritual beliefs, food systems, social organization, and epistemologies (McGregor, 2004; 
Receveur \& Kuhnlein, 1998; Parlee et al., 2007; Tuck et al., 2014; Ferguson \& Weaselboy, 2020). Since cultural capital influences various other capitals and shapes Indigenous worldviews and ways of knowing, excluding cultural capital in this research context would be inappropriate as it significantly facilitates how Indigenous communities conduct their livelihoods.

Political capital also plays a significant role in shaping Indigenous livelihoods because it either provides or restricts assets to traditional land and land management practices (Johnston \& Spring, 2021). Flora et al., (2005: 2) define political capital as "levels of community organization through the use of government" and "the ability of government to garner resources for the community." Political capital also includes access to power, inclusion in decision-making, and voice. In a community setting, an example of political capital might include the local level of government's relationships with the Territorial or federal government. These relationships become political capital when they impact a community's access to livelihoods resources such as land for development or funding for infrastructure development. Considering political capital will be necessary for acknowledging Indigenous self-determination, Indigenous rights, and for understanding how structures of power influence the KTFN's livelihoods.

Although SLA projects may differ in their approaches depending on context, there are at least seven key principles common throughout. These include: 1) being "peoplecentred" by involving participants actively in the construction and execution of the project; 2) being "holistic" by acknowledging the wide range of actors, stakeholders, and strategies that people or communities adopt in securing livelihoods; 3) being grounded in an understanding that livelihoods, capitals, and assets as they are dynamically informed by 
and shape one another; 4) being attentive to strengths and opportunities by focusing on positive assets as opposed to challenges and barriers; 5) being conscious of "micro-macro links" that shapes understanding on how policy and scale shape and are shaped by local livelihood strategies; 6) encouraging "broad partnerships" between wide ranging actors; and, 7) advocating for sustainability (Morse \& McNamara, 2013: 10). SLA projects should be action-oriented in nature and aim to generate practical solutions and direct benefits to the people or communities in question.

One example from Thompson et al. (2014) highlights these aspects of an SLA project in their analysis of the Island Lake Opakitawek Cooperative (ILOC) in the Garden Hill First Nation community in Manitoba, Canada. This three-year long project took a participatory community development approach to the research, where the primary goal was to assess livelihoods and identify ways to increase sustainability and economic viability for the ILOC. The authors stated that by working closely with commercial fishers, community members, and partnered stakeholders, they conducted a sustainable livelihoods assessment, community food security assessment, strategic business analysis, and a business plan. These outputs demonstrated the people-centred and holistic goals of an SLA project. Additionally, the project delivered practical outcomes and applications for the community, namely by "expanding the local market" for fisheries, "adding value and positioning exports as fair trade products," "improving management systems," and offering employment insurance (Thompson et al., 2014: 187). The aforementioned deliverables were accomplished through an assessment of community assets, where strengths were identified and used to produce a tangible business plan in collaboration with the community for practical application. For instance, the business plan strengthened existing assets and 
enhanced food security through the available infrastructure and institutions (including the school and health centre). The project facilitated relationships between commercial fishers, the school, and the health centre to include locally caught fish in school lunches. The project also drew upon human assets including traditional knowledges and practices such as fish smoking to create more marketable value-added products.

Thompson et al. (2014) offer a good example of action-oriented, participatory research with practical applications for Indigenous communities. The authors also provide an example of a focused, development project-specific approach to the SLA itself. As the authors demonstrate by focusing solely on the fishery cooperative, the SLA does not have to apply to every aspect of a community's collective livelihood. This project replicates Thompson et al.'s (2014) approach to conducting an SLA. In this case, fish composting is the primary focus for a project-specific analysis. One key difference, however, is that the Cooperative discussed in Thompson et al. (2014) was already established and running at the time of the study, whereas the fish composting pilot project remains in its infancy. This factor must be taken into consideration in the analysis, as it likely has an impact on the data and research outcomes.

\subsection{Political ecology}

Political ecology is broadly defined as "a field that seeks to unravel the political forces at work in environmental access, management, and transformation” (Robbins, 2012: 3). Proponents of political ecology assert that concepts of "nature" and "environment" are socially constructed through various competing discourses, and they remain attentive to notions of power in analyzing these discursive constructions. Political ecology seeks to view the "environment" as a non-human actor, or a valuable agent in and of itself. It also 
provides a lens for critically analysing the weaknesses associated with dominant understandings of environmental change (i.e., climate change) and investigates alternative methods for adaptation in a way that challenges current trends of "mismanagement and exploitation" (Robbins, 2012: 20). Given this project's emphasis on investigating fish composting as a way to both adapt to climate change and care for the land, and the importance of community-driven action research, political ecology offers a complementary line of reasoning as a guiding framework.

While political ecology is a broad field, much work in political ecology shares a list of similar guiding principles with the SLA (Perrault et al., 2015). Perrault et al. (2015: 7-8) highlight the overlap. First, they identify a "theoretical commitment" to post-positivist understanding and production of knowledge about nature and environment, with close attention to the socially constructed aspects of this knowledge production. Second, they highlight a "methodological commitment" to place-based and historically contextualized, open-ended qualitative studies of the "social relations of production and exchange" and "environmental practices." Third, they flag a "political commitment" to protecting and acting upon the interests of marginalized populations, with emphasis on social justice and broader political change. The concept of place-based and historically contextualized studies is significant for this project given the geographic location and cultural atmosphere of where this project will take place. The North is a unique environment - partly due to its vulnerability to subtle ecological or environmental changes, and partly to the relationships Indigenous peoples in the North share with the land. To understand how livelihood decisions are made, and what those decisions mean to community members, I will pay close attention to socio-cultural relationships between people and the land and investigate 
how colonial history has shaped the current social, political, economic, and environmental landscapes.

Jarvenpa (2008) offers insight into how a political ecology framework can be operationalized in the context of research in northern Indigenous communities. Jarvenpa (2008) applies a political ecology framework for understanding food as "social and symbolic forms" for negotiating production, exchange, politics, and international markets. The project analyzes two northern Indigenous communities: the first, a Dene community in northern-central Canada, and the second, an Indigenous community in northern Finland. This research investigates how northern Indigenous communities are uniquely impacted by colonial phenomena including wage labour and global political economic pressures. The author explores how traditional environmental knowledge and practices are often integrated in communities' approaches to adapting to change, focusing on how this adaptation is reflected in food culture, and emphasizing how food plays a role in "(re)defining cultural identity and relationships with the environment and social others" (Jarvena, 2008: 1). While furthering these goals, Jarvenpa (2008) provides an example of how political ecology takes a place-based and historical approach to understanding knowledge production as symbolic and socially constructed. The author's emphasis on symbolism, meaning, and relationships in the context of food illustrates how political ecology might operate northern Indigenous contexts.

Escobar's (1996) post-structural political ecology also grapples with the question of local significance and social resistance to dominant structures of power - both useful for this project. Escobar views culture and local social groups as significant, since quests for sustainability involve "the creation of spaces in which to foster local alternative productive 
projects" using a participatory approach and "culturally defined" alternatives to dominant discourses of sustainability (Escobar, 1996: 339). The author's emphasis on participatory approaches and culturally defined alternatives supports the choice of political ecology as a theoretical framework in Kakisa, since this project was created in collaboration with the KTFN. While I have taken on the role of principal investigator for the fish composting project in Kakisa, this role was only delegated to me after I built strong working and personal relationships of trust with community partners facilitated through my research assistant network at Wilfrid Laurier University. The work I perform in the community has been and will continue to be carried out in partnership with community researchers (funded by the Climate Change Preparedness in the North program) to ensure community-driven research goals are identified and pursued.

\subsection{Political ecology critiques of SLA: Gaps to address for a dual framework}

Morse \& McNamara (2013) critique the SLA for often overshadowing people by quantitative, mechanical, or economic language, despite advocating for "people-centred" research. The SLA focuses on mapping or quantifying capitals, where people are viewed as a form of capital as opposed to dynamic actors forming complex relationships with other people and capitals within their communities (Morse \& McNamara, 2013; Sneddon, 2000). The complex relationships between people and the environment, or "natural capital," is often oversimplified in sustainable livelihoods frameworks (Sneddon, 2000). While people actively participate in and structure complex livelihoods, the way they are represented in an SLA study can often be rather simplistic and descriptive rather than analytical (Morse \& McNamara, 2013; Knutsson \& Ostwald, 2006). The descriptive nature of this framework 
stems from the SLA's tendency to rely on economic language, and its lack of attention to detailed analyses of culture (Morse \& McNamara, 2013; Carr, 2015). One implication of this critique is that the SLA fails to consider deeply rooted meanings embedded in the ontologies of people within communities, and the role this plays in shaping their livelihoods, as decision-making is informed by culture and negotiated within culturally and socially constructed worldviews. As a result, "some of the key aspects of human existence" may be overlooked (Morse \& McNamara, 2013: 43).

Political ecology's focus on discourse and meaning, social relations of power, and emphasis on culture offers one way to overcome this possible oversight in the SLA. The SLA's tendency to produce descriptive catalogues of community assets can still produce benefits because it allows the communities to take stock of their strengths and gain perspective on how those strengths can be used more productively to bring about practical changes. However, on a theoretical level, simply describing a community's assets does little to help us understand how communities got to where they are or how they will get to where they want to go. Application of a political ecological lens to the descriptive catalogues in question can guide further investigations of the historical contexts of the places and people in question to gain a better understanding of the meanings attached to various forms of capital and social relationships (Carr, 2015; Armitage \& Tam, 2007; Sneddon, 20000). These critiques could also be mitigated by adding cultural capital to the list of capitals the SLA will take stock of in the first place. To ensure the complexity of livelihoods is fully considered in the context of fish composting in Kakisa, questions of discourse, meaning, and social relations of power have been built into the project's research questions. 
It is also unclear how the SLA should analyse or measure capitals, and how these capitals will be assessed (Morse \& McNamara, 2013; Arce, 2003). Typically, this is where the SLA might take a more quantitative approach to measuring capital, often in financial or economic terms (Morse \& McNamara, 2013; Carr, 2015; Arce, 2003). A useful approach to overcome these challenges may be to analyze value in terms of meaning and relationality in addition to quantitative or monetary measurements. From a political ecological perspective, this can be accomplished by determining how many relationships different capitals locked into (which satisfies the need to track or quantify value) (Scoones, 1998), while simultaneously investigating what these relationships mean to people (satisfying alternative ways of valuing capitals) (Carr, 2015; Arce, 2003).

The literature also critiques SLA research projects on their application in local contexts. Despite the level of detail an SLA can produce in cataloguing assets and capitals, it is unclear how this information gets translated into action on the ground (Morse \& McNamara, 2013; Carr, 2015; Scoones, 2009). Additionally, there is often a disconnect between the people who participate in the SLA and the people who are in positions of power to bring about change (Morse \& McNamara, 2013). Researchers, communities, or the funders of a given SLA project may not necessarily be the ones who communicate the results of the project to policy makers, which can stall or impede action. This lack of a clear trajectory could occur for a number of reasons including: 1) the end goal of the SLA is not clearly articulated - there is a lack of consensus on how the information will be used; 2) the way information is communicated is inaccessible to community members or not communicated directly to policy/decision makers - researchers wish to publish the findings in academic journals with the assumption that community members or knowledge 
purveyors will read and understand them; and 3) the end users of information generated from the SLA project are not clearly identified (Morse \& McNamara, 2013).

Addressing these issues might involve clearly defining the end users of the information and communicating information in culturally/socially appropriate ways directly to community partners and participants. This knowledge translation could include plain language summaries, action plans, and practical recommendations for implementing projects or influencing policy action as clearly stated deliverables of an SLA project. However, the issue of generating action and the disconnect between participants and knowledge purveyors within the SLA also manifests other questions about the roles and responsibilities of the researchers. What happens when the researchers have generated results and completed the project? What responsibility do researchers have to ensure participants are educated and equipped to pursue action independently of the researchers? These questions are dealt with in Chapter 3: Methodology, ethics, and methods, where I delineate such ethical considerations.

One avenue for addressing these questions is to build participatory action research (PAR) methodologies into the SLA project. PAR strives to empower participants and build capacity within communities for generating action that meets community needs. For instance, working alongside community researchers to define key aspects of the project helps to educate participants throughout the entire process, while also giving them an opportunity to define the project's trajectory to ensure that community needs and goals are met (Gilmore et al., 1986; McTaggart, 1999; Baum et al., 2006; Kemmis et al., 2014). Whether the community identifies policy generation or implementation of locally based initiatives as their goals, PAR methodologies can help bridge this gap by building capacity 
and educating participants throughout the duration of the SLA project, while also holding the SLA researcher(s) accountable to the community. As such, PAR has been selected as a guiding methodology for this project.

Another significant critique for the SLA found in the literature addresses possible issues of scale, and a lack of attention towards the relationships between local and extralocal processes in shaping livelihoods (Carr, 2015; Scoones, 2009). When communities are viewed independently as isolated from extralocal contexts, they are often misrepresented as passive agents "receiving and responding to the influences and impacts of events and processes in other places, or operating at different scales," as opposed to active participants in these relationships (Carr, 2015: 336). The implication is that, since communities from a regional perspective interact and often have relationships with one another, the opportunities to investigate how different livelihoods and livelihood interventions might cascade or scale across a given region remains overlooked (Carr, 2015). From a political ecological lens, addressing these gaps in the SLA would mean building mechanisms into a project for better understanding the power dynamics and relationships between different communities and scales. To address some of these concerns with the SLA from a political ecological lens, questions regarding knowledge sharing and generating a regional impact from the fish composting project in Kakisa have been built into the project's structure.

\subsection{Framework summary and reconciling tensions}

The combined SLA and political ecology framework used in this project promotes both practical, rich description and more discursive, theoretical analysis. Both frameworks 
individually bring attention to sustainability and local empowerment, and are aligned with participatory research methodologies. However, the SLA's overly descriptive approach to community asset mapping insufficiently addresses the theoretical requirements for academic research. Conversely, political ecology's overly theoretical focus could potentially create a disconnect between research findings (especially the communication thereof) and the community's lived experience. In Chapter 6, I argue that these differences complement one another in the combined framework's application to this particular community-driven research project. Tensions over language and framing of community characteristics, particularly environmental resources, also exist between the SLA and political ecology. Reconciling these tensions likely require a re-framing of community assets to shift away from overly technical economic language to include concepts of relationality and agency. Applying a PAR methodology to the project could assist in addressing these tensions, as it prioritizes community needs, values, and goals, worldviews, and epistemologies. The next chapter covers the application of PAR for this project. 


\section{Chapter 3: Methodology, Ethics, and Methods}

This chapter discusses participatory action research (PAR) as a methodological approach. The first three sections of this chapter outline the community profile, researcher positionality, and project timeline to provide contextual information for the sections that follow. Next, this chapter outlines key principles that inform the project's use of PAR. This section also explains how PAR unfolds throughout this project and outlines initial research plans and various modifications to address COVID-19 impacts on conducting the research. The following section discusses ethical considerations for carrying out the research and expands on methods for obtaining informed consent and safely storing data. Then, the chapter covers various qualitative data collection methods, including focus groups, interviews, and participant observation, and explains how each method contributes to the project, with special attention to safe, remote data collection. The final section of this chapter covers data analysis methods used to interpret data and generate results covered in the following three chapters.

\subsection{Community profile}

Kakisa is located in the South Slave region of the NWT and is home to the KTFN. "Ka'a'gee Tu" translated means "between the willows" (Community members, personal communications, June 2019). The following information on the KTFN's traditional territory comes from a video the KTFN produced and shared with me on the history of Kakisa. As Figure 2 illustrates, the KTFN have traditionally lived in many seasonal locations where they hunted, trapped, and fished in vast areas extending from Beaver Lake to the Cameron Hills. The KTFN originally resided along the bottom shores of Tathlina 
Lake. The community was historically relocated three times due to a combination of natural and colonial phenomena. The first relocation occurred in the 1940s after a wildfire burned between the Cameron Hills and Tathlina Lake. Several Kakisa Elders grew up living their traditional lifestyle until they were forced into residential schools, where the state separated them from their families. When many youths returned, the community had been relocated to an area between First River and where the community stands today. In the early 1950s, resource development in the oil and gas sector started in and around the KTFN's traditional territory. The community was not included in negotiations for this development. In 1962, the community was relocated for the final time to the area where the KTFN reside to this day. The decision to relocate came from the federal government, likely to provide communities with increased access to services (Margaret Leishman, personal communication, April 2021). Since many Elders in the community still have memories of growing up on the land, the traditional way of life exists in the community's living collective memory, and still exists strongly in Kakisa as a result.

Currently, Kakisa rests on the eastern bank of Kakisa Lake, which is approximately $372 \mathrm{~km}$ from the NWT's capital city, Yellowknife. As Figure 3 illustrates, Kakisa is located in the South Slave region of the NWT and falls within the territory covered by Treaty No. 11. The population of Kakisa fluctuates, as many residents relocate to seek employment in larger towns and cities - however, the population of Kakisa is commonly reported as having 50 residents (Spring et al., 2017). Most full-time residents seek employment at the Band Office. The community has a school for young children that offers up to Grade 8 education. High school students are required to access further education in other communities such as Hay River or Fort Simpson, located roughly $135 \mathrm{~km}$ and $322 \mathrm{~km}$ from 
Kakisa, respectively. When students leave Kakisa for high school education, this requires them to move away for long periods of time, and some students may choose not to return as they build social networks and find careers in their new locations.

The community has at least eight years of experience conducting community research on climate change and northern agriculture projects. Previously, the KTFN have worked closely with Dr. Spring on the Food, Locally Embedded, Globally Engaged (FLEdGE) grant, and three years ago the KTFN took on a leadership role in establishing the NAF project.

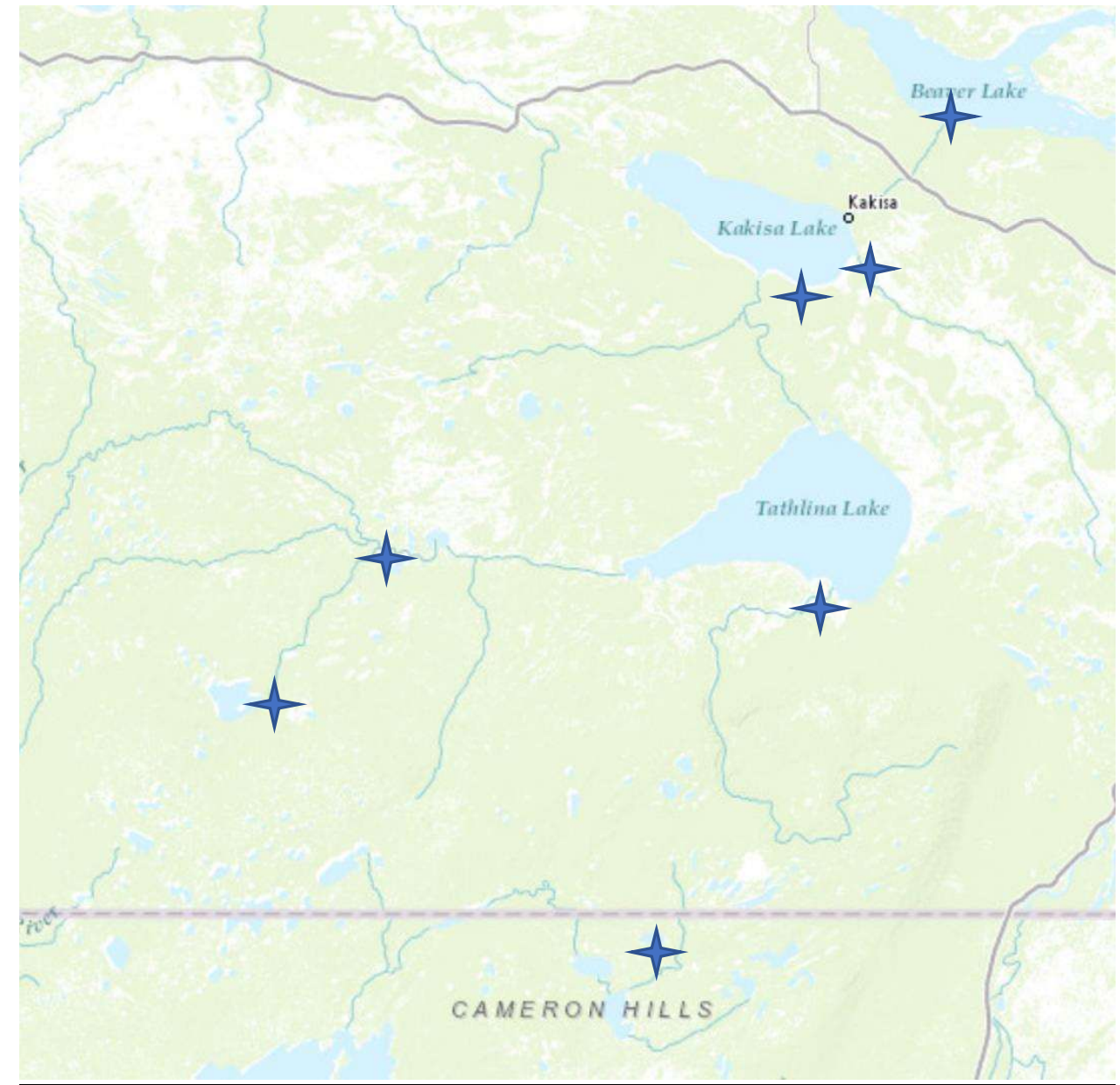

Figure 2. Map illustrating the KTFN's traditional territory. The territory from Beaver Lake extending to the Cameron hills comprises most of the area where the KTFN have historically conducted traditional livelihoods. Hunting moose \& caribou, trapping muskrats \& beavers, fishing, and berry picking include some of the traditional practices for food procurement. The stars on the map show several areas that community members identified as culturally significant throughout the History of Kakisa video. (Map obtained from: GNWT, n.d.a). 


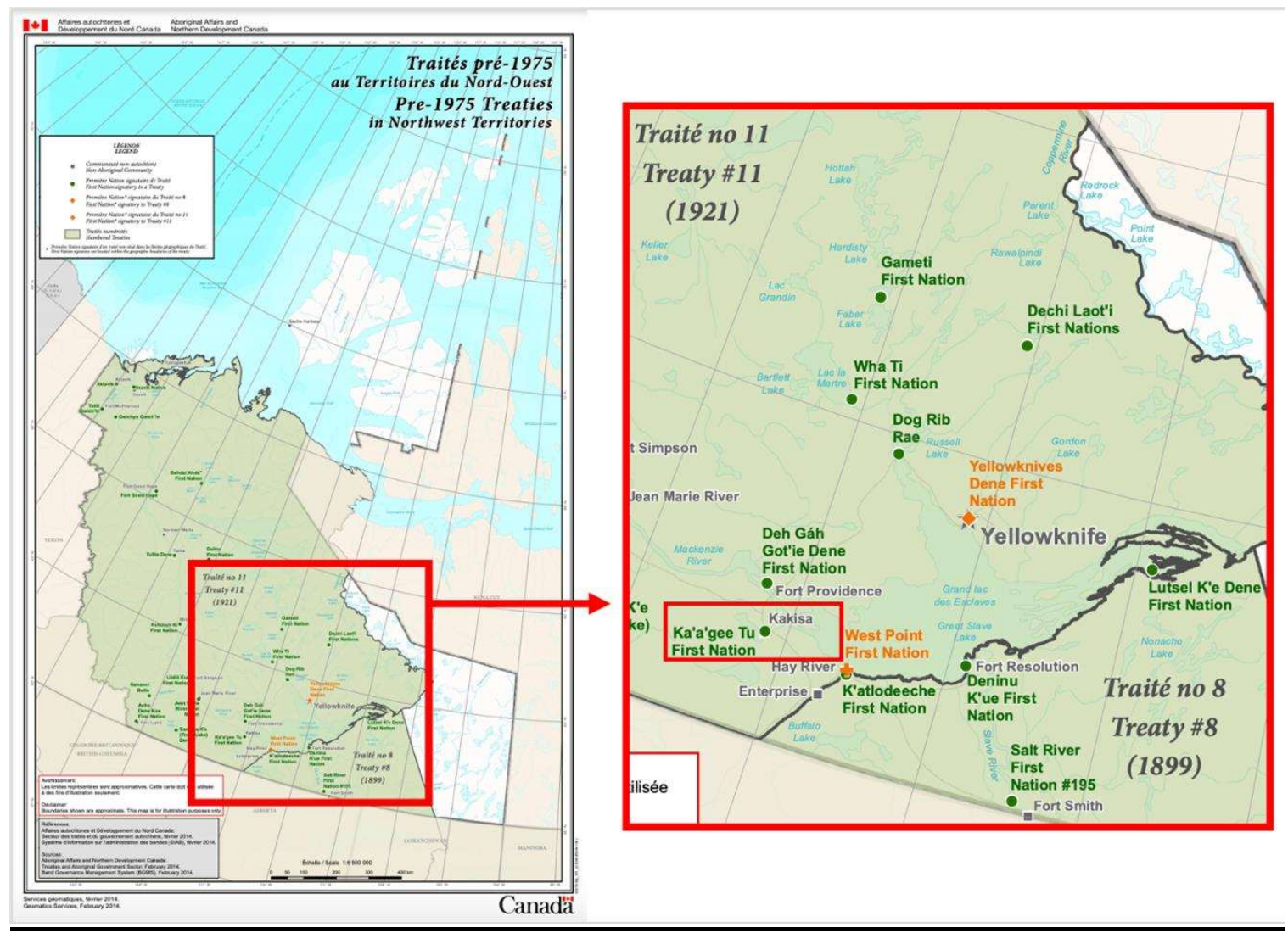

Figure 3. Pre-1975 Treaties in Northwest Territories. Map showing Kakisa in relation to 2 NWT treaties. Kakisa is included in Treaty No. 11 (signed 1921) (Government of Canada, 2014) (Boxes and arrows added).

\subsection{Researcher positionality}

It is important to situate myself in relation to the fish composting project in the North. According to Foote \& Bartell (2011: 46), researcher positionality “entails delineating one's position in relation to the study and understanding that" this positionality will "influence various aspects of a research study, including the questions asked and the conclusions drawn." As an outside researcher working in a northern Indigenous space, it will be important to acknowledge the "necessity of understanding relationality between all entities in Indigenous ways of knowing, being and doing" (Somerville \& Turner, 2020: 182) to the best of my ability. 
I identify as a White, settler Canadian from southern Canada. For most of my life, I have lived in the Ottawa region on the unceded territory of the Anishinaabe Algonquin. I attended public school from 2001 to 2013 in southern Ontario. It was not until I attended Trent University in Peterborough, Ontario in 2015 that I received an adequate education on colonialism, Indigenous history, and Indigenous struggles in Canada. As a Bachelor of Arts student in Environmental \& Resource Studies at Trent University, I became increasingly interested in climate change, food systems and Indigenous environmental studies. The institution's focus on Indigenous studies and inclusion through various disciplines also inspired my commitment to better understanding and attempting to dismantle colonial structures of knowledge and power. My experiences working and living with the KTFN in 2019 and for the duration of my Master's program at Carleton has further solidified my commitment to supporting Indigenous community-driven research.

I have learned a lot from the KTFN. I have learned how to question my pre-existing worldviews and how to better connect with the land and people around me. This experience provided insights useful to this project, however, the North is not my original home. As such, regardless of what I have learned thus far, this learning continues to be an on-going experience. There are still many things I do not know about the northern landscape, Dene culture, and their deep personal connections to the space - and much of what I do not know is still unknown. What I have learned so far will help me tailor my questions, analyses, and conclusions to fit within the KTFN's worldview and epistemologies. However, it is important to acknowledge that I have not learned all there is to know. Being aware of my incomplete knowledge will be crucial to avoid presenting my analyses as an absolute or complete body of knowledge. 
Filling in the gaps of my knowledge makes PAR a critical piece of this project. Ultimately, this project seeks to empower the KTFN to carry out the fish composting project in a way that meets their needs. However, it is also important to realize how my positionality informs this goal. As Nicholls (2009: 119) explains, outside researchers "might consider Indigenous participants as candidates for empowerment" because they have historically been denied access to power and subject to colonial forces. But whose knowledge qualifies Indigenous communities as candidates in the first place, and further, whose knowledge is best suited to empower and work toward social change? PAR provides a critical methodological framework for this project because it seeks to make space for alternative ways of knowing and learning. This process requires an acknowledgement of how I learn from the KTFN, and how the project fosters co-learning between myself and the community. Ultimately, "empowerment cannot be stimulated from outside by means of material reasoning; it must be subjective and emergent from within a 'participatory mode of consciousness" (Nicholls, 2009: 119). The next section of this chapter provides a timeline for research specific details to follow. In the following section, I expand my discussion of PAR and reflect on its implications for this research project.

\subsection{Research timeline summary}

Table 1 briefly summarizes this thesis project's key timeline. Each point is covered in more detail throughout the following sections of this chapter. The table includes information about planning related to this thesis project, and other research assistant work not covered in this thesis (though tangentially related to it) conducted in the summer of 2020. 
Table 1. Project Timeline. Table illustrating key parts of the research process discussed in more detail throughout the remaining sections of this chapter.

\begin{tabular}{|c|c|c|}
\hline Date & Item & Description \\
\hline March-April, 2019 & Research Assistant Offer & $\begin{array}{l}\text { Co-supervisors connect PI with Dr. } \\
\text { Andrew Spring's research team } \\
\text { (Wilfrid Laurier University) }\end{array}$ \\
\hline June 17, 2019 & PI Arrives in Kakisa & $\begin{array}{l}\text { - PI lives in Kakisa from June-August } \\
2019 \\
\text { - Trip purpose: } \\
\text { - Build relationships with the KTFN } \\
\circ \quad \text { Assist in conducting research on } \\
\text { community-driven projects } \\
\text { Offer support for community } \\
\text { projects }\end{array}$ \\
\hline July 2019 & $\begin{array}{l}\text { Collaborating on Fish } \\
\text { Composting Project }\end{array}$ & $\begin{array}{l}\text { PI collaborates with community } \\
\text { researcher to investigate fish } \\
\text { composting methods and locations } \\
\text { PI and community researcher } \\
\text { collaboratively organize a community } \\
\text { focus group }\end{array}$ \\
\hline July 29,2019 & Focus Group & $\begin{array}{l}\text { PI facilitates fish composting focus } \\
\text { group with community members } \\
\text { Data is collected and eventually used } \\
\text { for this thesis project }\end{array}$ \\
\hline September, 2019 & Carleton University & $\begin{array}{ll}\text { - } & \text { PI starts MA program in Political } \\
\text { Economy at Carleton University }\end{array}$ \\
\hline Winter, 2020 & Project Planning & $\begin{array}{l}\text { - PI begins working on project plan and } \\
\text { proposal }\end{array}$ \\
\hline March, 2020 & COVID-19 & $\begin{array}{l}\text { Shutdowns to prevent the spread of } \\
\text { the virus begin, travel-restrictions and } \\
\text { in-person research limitations } \\
\text { implemented }\end{array}$ \\
\hline Summer, 2020 & Remote Research & $\begin{array}{l}\text { - PI assists with community greenhouse } \\
\text { projects and works with youth } \\
\text { researchers remotely (travel prohibited } \\
\text { for safety reasons) }\end{array}$ \\
\hline $\begin{array}{l}\text { September - October, } \\
2020\end{array}$ & Thesis Proposal & $\begin{array}{l}\text { PI submits final thesis proposal to the } \\
\text { Institute of Political Economy, } \\
\text { Carleton University }\end{array}$ \\
\hline $\begin{array}{l}\text { October-December, } \\
2020\end{array}$ & $\begin{array}{l}\text { Literature Reviews \& Data } \\
\text { Collection Planning }\end{array}$ & $\begin{array}{l}\text { PI conducts literature review on } \\
\text { theoretical framework \& contextual } \\
\text { information for thesis project } \\
\text { PI makes arrangements in } \\
\text { collaboration with the community for } \\
\text { moving forward on remote data } \\
\text { collection }\end{array}$ \\
\hline February, 2021 & Interviews & $\begin{array}{l}\text { PI conducts interviews remotely over } \\
\text { the phone with community members }\end{array}$ \\
\hline February-March, 2021 & Data Analysis & $\begin{array}{l}\text { PI analyzes data \& frequently } \\
\text { validates data with participants and } \\
\text { knowledge holders in the community }\end{array}$ \\
\hline
\end{tabular}




\subsection{Participatory action research (PAR)}

This project uses participatory action research (PAR) as a guiding methodology. PAR methodologies typically follow a set of common principles and core values, rather than rigid or technical methods and requirements (Ozzane \& Saatcioglu, 2008; Kidd \& Kral, 2005; Greenwood et al., 1993; McKenzie et al., 2012; Datta et al., 2015). At its core, PAR represents a fluid, dynamic, multidisciplinary, and context-specific approach. PAR methodologies also strive to promote collaborative learning, co-production of knowledge, and local empowerment to address community-specific needs and goals for positive social change.

As Ozanne \& Saatcioglu (2008: 424), an "important goal of action research is to promote workable solutions to immediate concerns" within a community, and to "develop human capacities." Goals for addressing community concerns and fostering local empowerment align with the guiding theoretical frameworks for this project. As the authors state, action research grounds itself in practical problems faced by specific groups of people. The SLA's approach to improving sustainable livelihoods through asset mapping and strengthening reflects a mutual goal with PAR for providing practical solutions and actionable recommendations through research with tangible application for the communities involved. In addition to solving problems, PAR strives to foster academic contributions and build theory (Ozanne \& Saatcioglu, 2008). While PAR rejects the idea that research is binary in the sense that it must either focus on community practice or academic theory, it is important to foster space for epistemological differences and ensure theoretical knowledge contributes meaningfully to communities. Political ecology's emphasis on discourse and meaning throughout this project aligns with PAR as the 
former's application strives to theorize fish composting in a locally significant way. Applying a PAR methodology to guide the application of the combined framework throughout this project is intended to assist in bridging the gap between community practice and academic theory.

One key aspect of PAR involves building strong working and personal relationships of trust with communities and participants (McKenzie et al., 2012; Datta et al., 2015; Peltier, 2018). When I applied for the Master's program at Carleton University, I identified northern agriculture and climate change as primary research interests. At the time, my cosupervisors connected me with Dr. Andrew Spring at Wilfrid Laurier University for a research assistant position. Dr. Spring has worked with the KTFN for eight years on various food security projects through Food, Locally Embedded, Globally Engaged (FLEdGE) - a SSHRC-funded Partnership Grant - and through his dissertation research. Prior to conducting research on any community projects, Dr. Spring arranged for me to live in Kakisa during the summer of 2019 to start my individual relationship building process with the community.

Prior to my arrival, the KTFN had worked with several other graduate students from Dr. Spring's research team. Given these past relationships, the KTFN already had significant experience working with outside researchers on participatory projects. Past student relationships and the KTFN's research experience made my personal integration with community life and community-driven research projects relatively straightforward and accessible. The community was extremely welcoming and invited me to participate in community events within days of my arrival. For instance, on Indigenous People's Day (June 21), community members taught me how to pluck, process, and cook duck. In July, 
various community members invited me on berry picking excursions after work and on weekends. Elders invited me into their home for tea and stories, and youth of all ages frequently visited our research house to chat and play games. These interactions resulted in many important personal friendships extending far beyond simply conducting research in the community.

Building strong friendships and relationships with the community formed an integral part of this project. As Peltier (2018) explains, building personal relationships in PAR benefits research outcomes for two reasons. First, building relationships helps foster co-learning and increased community engagement, which tends to produce relevant, meaningful results for the community. Second, building relationships creates a personal connection between the researcher and the community, which fosters an overall sense of researcher responsibility for redistributing power more democratically in research relationships, and increases researcher accountability for generating beneficial research outcomes. Throughout this project, the application of PAR reflects a mutual learning opportunity. Many Elders and community members have expressed that they enjoy working with researchers from outside their communities to conduct community-driven research and mutual learning.

While building friendships with the community fostered positive research outcomes throughout this project, it also complicated my role as a researcher. Grappling with theoretical frameworks and taking on a more formal role for collecting data often felt inappropriate and uncomfortable, as it sometimes changed the dynamic of my interactions with participants and collaborators who are simultaneously my friends. Even though the KTFN has a long history of conducting community-driven research, I was still conscious 
of the colonial legacy of research in Indigenous communities (Tuhiwai-Smith, 2012; McGregor, 2004), especially given my positionality as a non-Indigenous researcher from the South. However, applying a PAR methodology offered some insights for overcoming these discomforts. As Wilson (2001) explains, conducting research in Indigenous communities involves establishing relationships - where the researcher's responsibility for gaining knowledge should actively fulfil their duties in that relationship. As I reflected on this research process as a whole, I realized my discomfort actively strengthened my sense of responsibility to the community and their needs, as I made conscious efforts to adjust the framing of my questions and interpretations of data to align with the KTFN's worldview - discussed further in Chapter 6.

\subsubsection{PAR and fish composting in Kakisa}

Reflective of PAR (Gilmore et al., 1986; McTaggart, 1999; Baum et al., 2006), and previous work in the North (Pearce et al., 2009; Spring et al., 2018), this project aims to generate community action through project recommendations and capacity building insights to inform the construction and operation of the fish composting system in Kakisa. I will generate plain language research summaries and an action plan for advancing this project on the ground. Following completion of this thesis, I will produce and present my plain language recommendations and facilitate the production of an action plan. The action plan will include specific details on budgetary needs, infrastructure development, project timelines, and proposals for accessing training programs. Plain language summaries will be shared with NAF project partners to facilitate knowledge sharing and dissemination across northern communities. 
This thesis project also promotes local empowerment by collaborating with participants from the KTFN more efficiently meet community-driven needs. In the summer of 2019, the KTFN Band Office hired George Simba from Kakisa using NAF grant funds as a community researcher for the fish composting project and other NAF initiatives. George is also employed for conducting community maintenance in Kakisa by the Band Office. The community researcher(s)' roles included the following: 1) acting as community liaison to articulate community concerns, goals, values, and knowledge as it relates to this project; 2) providing feedback on all written work prior to submission or publication to minimize any possible misrepresentations or inaccuracies; and, 3) assisting the principal investigator in following community research protocols and guidelines throughout all stages of the project.

In the summer of 2019, George participated in various planning stages for the fish composting project. First, he and I worked together to compile a list of possible composting methods (i.e. windrow, in-vessel composting) and recommendations for Kakisa. We also researched and made recommendations for possible fish composting site locations. We presented our findings in a plain language document (see Appendix A) and through inperson meetings with members of the Band Office. For the next stage of the research, the Band Office, George, and I collectively decided to host a community focus group to gain community input on the project. George and I collaboratively generated questions and research objectives for the focus group.

Unfortunately, due to the COVID-19 pandemic, data collection and data analysis for this project was not as participatory as I originally hoped. When I formalized a plan for my thesis project in winter 2020, I hoped to refine my interview questions and analyze the 
data collaboratively with community researchers. However, since I was unable to travel to the community for the summer of 2020, due to travel and research restrictions implemented between March and April 2020, this was no longer possible. Prior to the shut-down, the KTFN Band Office planned on hiring additional community researchers to work on community projects. The KTFN also hired some youth researchers during the summer of 2020 to work on greenhouse projects, however, my inability to travel to Kakisa meant that I had to mentor youth remotely which resulted in insufficient research training and support.

In a small northern community like Kakisa, being physically present is the most effective and comfortable way to work on research. Community researchers may also have other jobs and spend a significant amount of time on the land. Some community researchers do not own a cell phone or laptop, which makes constant communication difficult from a distance. From December 2020 onward, no community researchers were actively employed since travel restrictions severely stalled on-going community projects. As a result, I was unable to collaborate with community researchers to create interview questions and research objectives. I was also unable to work collectively with community researchers on data analysis. To address the lack of collaboration, I actively involved community knowledge holders who I regularly keep in contact with to validate information and my framing of results. Despite the participatory challenges encountered from COVID19, the Band Office gave me their blessing to carry out the work to the best of my ability - even though it meant interpreting the data mostly on my own accord with significantly reduced community input. 


\subsection{Ethics}

I obtained ethics approval from the Carleton University Research Ethics Board in January 2021. During the summer of 2019, while I lived in Kakisa, I facilitated a preliminary focus group in Kakisa to gather information on the KTFN's vison for a working fish composting project, which was approved by the Wilfrid Laurier University Research Ethics Board (for interview guide and recruitment letter, see Appendix B). As Dr. Spring's research assistant for this project and the NAF parent project, the appropriate research licensing from the Aurora Research Institute (ARI) was secured (see Appendix C). The ARI acts as the governing body for conducting research in the NWT, to ensure northern research applies culturally appropriate research methods and produces beneficial results for improving quality of life in northern communities (Aurora College, 2019).

Due to travel restrictions from COVID-19, four interviews conducted in 2021 took place remotely over the phone. Interviews and focus groups were audio recorded only after receiving informed verbal consent (signed consent forms have not been deemed culturally appropriate in this context). To obtain informed consent, I distributed plain language recruitment letters and a copy of the interview guide to possible participants one week in advance (see Appendix D) - written in English and verbally translated for South-Slavey speakers. I read the recruitment letter verbally to the participants at the beginning of the focus group and interviews, which was followed by a question period. Then, I verbally communicated the possible risks for participating with the participants including possibly making statements that make them feel awkward or uncomfortable when made public. Finally, the participants provided verbal consent to proceed with the focus group/interview and acknowledged they could withdraw consent to participate at any time. Throughout the 
course of this project, all information was kept confidential unless a participant stated they wished to be identified.

\subsection{Methods:}

\subsubsection{Focus groups}

Semi-structured focus groups were the primary source of data collection for addressing research questions 1 and 2 . The focus groups encouraged community members to conceptualize the practical steps necessary for, and meaning behind, implementing the fish composting project. The first focus group was held in the summer of 2019. Two weeks prior to the chosen date, I recruited possible participants with door-to-door invitations. Given the small population in Kakisa, I visited each household (about 15-20 houses) to distribute invitations and provide information on the focus group's topic. To make the invitations, I created an arts and crafts activity for the young children in the community where the kids painted fish-shape cardboard cut outs. Prior to making the invitations, I informed parents or guardians that I wished to involve the children in this stage of my research, and I arranged a date and time for the kids to meet at the Band Office for afternoon crafts. Each child was given an opportunity to choose which community member would receive the invitations they painted. Afterwards, I wrote the information for the focus group onto the invitations and distributed them door-to-door (see Figure 4). This was an excellent way to build stronger relationships and trust with community members, as well as involving young people in the research process. 


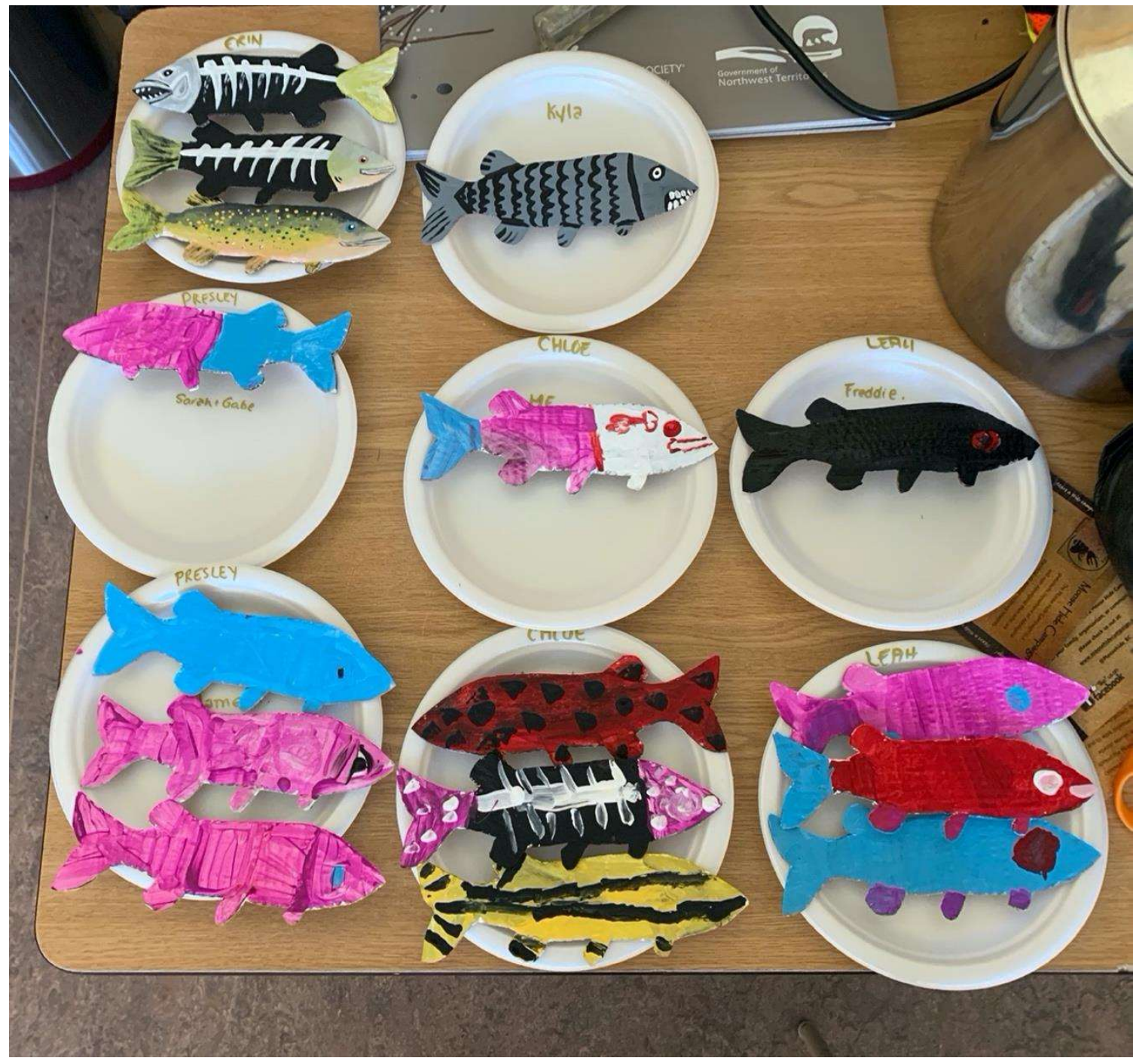

Figure 4. Photo illustrating the fish invitations painted by Kakisa Youth for the 2019 focus group. Children between the ages of 6 and 10 painted fish cut-outs on carboard and chose which community members they would like to give them to.

The 2019 focus group had a total of 11 participants and included youth, adults, and Elders. Those who did not attend included some community members who may not have been comfortable or interested in participating in the research, people who were not home or seen around the community during the recruitment phase, or other community members whose schedules conflicted with the date and time. This focus group gave community members an opportunity to voice their initial reactions and preliminary ideas for operating 
a fish composting system. The focus group also functioned as an educational opportunity for participants to learn about fish composting. I constructed educational materials for the focus group, which included a paper mâché diorama (see figure 5) and a slide show.

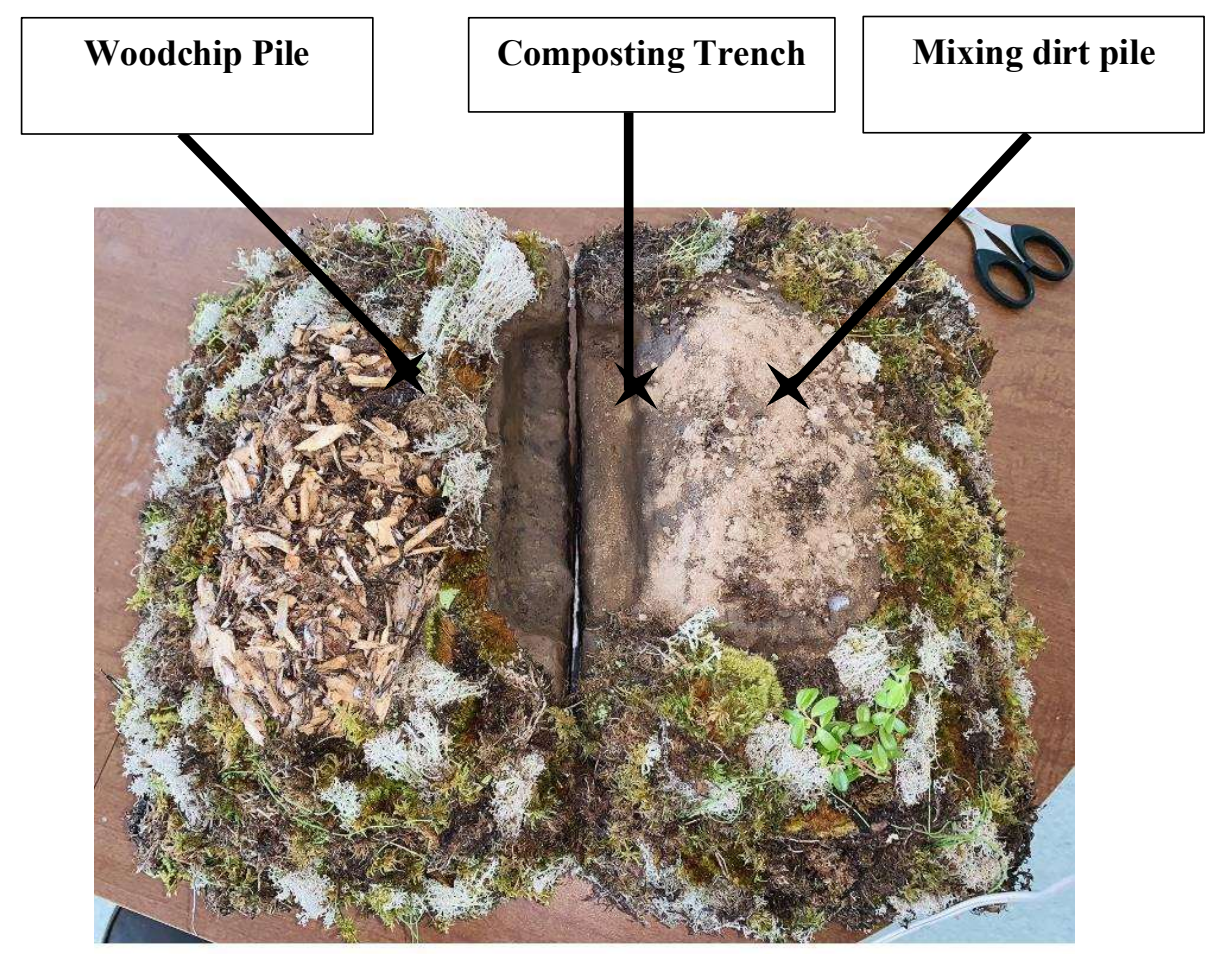

Figure 5. Paper mâché diorama illustrating how a fish composting trench would look. The diorama was used as an educational tool in the 2019 focus group.

I originally planned on facilitating a larger focus group in 2021 remotely with assistance from the community researchers using Microsoft Teams at the Band Office, since COVID-19 prevented research-related travel. However, after discussion with some community members, concerns were raised about how well this method would work. Hosting a larger group of people was perceived as unsafe, and many community members, particularly elders, might have struggled with online communication. Hiring a trained interpreter for the event was also an issue since interpreters are usually hired from outside 
the community - no longer an option due to COVID-19 guidelines. Given these challenges, the KTFN Chief, Band Manager, Dr. Spring, and I decided to modify the focus group structure to accommodate the participants. Instead of conducting one large focus group, we initially decided to conduct two smaller focus groups and increase the number of individual interviews. However, this decision changed once again, and we eventually decided to conduct interviews instead of another focus group. The 2019 focus group was open to all members of the community, as I recruited people door-to-door and displayed posters at the Band Office. The sample size for the 2019 focus group the sample size was $n=11$.

\subsubsection{Interviews}

For the 2021 interviews, I recruited participants based on their roles in the community either as knowledge holders, members of the Band Office, or as people who come into contact with fish waste on a regular basis. I conducted four semi-structured, in-depth interviews over the phone, for a sample size of $n=4$. Obtaining information from knowledge holders on fish waste proved useful for contextualizing community assets and commercial fishing and/or fish processing in Kakisa. Understanding how people conduct their livelihoods related to fishing and fish processing will be essential for mapping community assets and potential barriers when applying the SLA. As such, interviewing persons of interest with direct experience helped generate a more realistic action plan for implementing the fish composting project on the ground. Follow-up interviews with focus group participants also gave participants a chance to verify their data. Chief Lloyd attended some interview sessions to provide translations from English to South-Slavey and technical assistance. 
I framed the Winter 2021 interview questions around the following topics: 1) identifying community strengths and assets; 2) applying community strengths and assets to enhance the fish composting project; 3) identifying practical needs and necessary action for getting the project off the ground; and 4) understanding what fish composting means to the community. The SLA informed questions 1-3 for descriptively cataloguing community asset and their potential applications to the project. Political ecology's emphasis on discourse and meaning informed question 4 for applying recommendations in a culturally significant way. Political ecology also helped reveal community visions, ideas, and discourses around fish composting. Prior to COVID-19, these questions originally contributed to a workshop style focus group structure. Various workshop style activities would have allowed smaller groups of people to brainstorm community assets and their possible relevance or application to the project. However, since community representatives and I decided to conduct interviews instead of a remote focus group, I modified the questions slightly to fit within an interview context. The language of the questions also changed to emphasize storytelling and less capitals-oriented language, since some interviewees proved either unsure or uncomfortable with approaching the questions using "asset" phrasing.

\subsubsection{Participant observation}

Participant observation is an exploratory, interactive process where researchers embed themselves in particular spaces or settings (Guest et al., 2017). Throughout this project, I used personal experiences and communications to identify community assets I observed that were not identified by participants in focus groups or interviews when conducting the 
SLA. Additionally, personal experiences and communications helped validate my interpretations of what fish composting means to the community when I applied a political ecological lens to the data. As Guest et al. (2017) explains, participant observation provides an additional intuitive lens for understanding the meaning of data, since the researcher either intentionally or passively collects observations through embedded experience. Ultimately, my experience living in the community provided insight into how the community functions from day to day, which in turn allowed me to map community assets and interpret meaning.

\subsection{Data analysis}

I analyzed data from the 2019 focus group using constant-comparison analysis and inductive coding methods to answer broader political ecological research questions about meaning and discourse. Using inductive coding for political ecological analysis allowed the data to speak for itself (Srivasta \& Hopwood, 2009; Leech \& Onwuegbuzie, 2007; Boeije, 2002) - where themes including practical perceived benefits, and layers of deeper meaning and significance, emerged from the data as I reviewed it. Then, I used a keywordsin-context method of analysis to identify key connections and relationships between various themes and layers of significance. Applying a Srivasta \& Hopwood's (2009) framework for reflexive inductive analysis also helped ensure analyses produced aligned with community needs and realities. The framework suggests taking three primary steps to reach a conclusion: 1) identify what the data is saying; 2) acknowledge what questions need to be answered to fulfil the research objectives; and, 3) identify dialectic relationships between what the data says and what questions need answering. These methods of data 
analysis allowed me to address research question 1. First, I wanted to understand why the KTFN was interested in composting, and what they perceived as benefits of the project. Second, I wanted to know what fish composting means to the community. Third, using the SLA, I wanted to identify assets to generate recommendations for carrying out the project. For the first two sets of information, I did not know specifically what themes I was looking for before I started.

I used deductive coding methods to choose themes prior to analyzing (Leech \& Onwuegbuzie, 2007) the information collected from the 2021 interviews, 2019 focus group, and participant observation in order to map out assets and community capitals. First, I categorized the assets based on seven types of capital (cultural, natural, social, economic, political, physical, and human). I used this information to identify assets that were practically relevant to the fish composting pilot project. I also used this information to identify challenges and barriers to overcome. I then cross examined the assets alongside my political ecological analysis of meaning discourse to generate meaningful recommendations for strengthening assets and considering long-term success of this project. The results of this research will inform the future action-plan for implementing the fish composting project on the ground. Using deductive coding for mapping community assets allowed me to address research question 2. I discuss my reflection on my experience using these data analysis methods in more detail in Chapter 6.

\subsection{Chapter summary}

This chapter discusses the use of PAR as a guiding methodology for community-driven research projects. PAR's guiding principles for prioritizing community action, community 
epistemologies and worldviews, and for bridging the gap between community experience and theory provides a culturally appropriate approach to guiding this research project. While COVID-19 impacts the participatory nature of this project, pre-COVID research took place collaboratively with a KTFN researcher. On-going communication with community members and knowledge holders also addresses some of the challenges with the participatory nature of this project. The next chapter presents results interpreted from the focus group and interview data through the lens of political ecology to identify underlying meaning for the fish composting project to address research question 1 in this thesis. 


\section{Chapter 4: Meaning and Perceived Benefits - Why Fish Composting?}

To approach data analysis for this chapter, I applied inductive coding methods for analyzing qualitative data. To understand what fish composting means to the KTFN, imposing key ideas or themes onto the data from the onset using deductive coding would have limited the scope of this chapter's analysis. Instead, I wanted to allow the data to speak for itself, so that insights on possible perceived benefits and deeper layers of meaning or significance could emerge from the participants' own words. However, I did apply some of the more detailed questions included research question 1 to help guide this process. As a result, this chapter discusses the perceived benefits and deeper layers of significance that emerged from these more general inquiries. This chapter argues that the KTFN's goals for increasing waste management capacity and agricultural productivity relate and connect to one another, and that some of the KTFN's core cultural values on health, caring for the land, self-sufficiency, and traditional knowledge inform these goals interconnectedly.

\subsection{Main themes and meaning}

To understand what fish composting means to members of the KTFN, I first explore the perceived benefits of fish composting, including how fish composting might reflect traditional practices and/or values. The ways the KTFN perceive fish composting as beneficial or valuable to their community and broader goals helps to explain what this action-oriented project means to the community beyond simply improving waste management or converting waste into soil amendments. Exploring the connections between fish composting as a practice, and traditional practices and values, also illuminates deeply embedded cultural meanings. Together, the perceived benefits and traditional 
values work to create and define meaning in this project for the community, which, ultimately, informs and is informed by, their broader, interconnected goals of agricultural expansion and improving waste management.

Some of the perceived benefits of fish composting that emerged during the 2019 focus group and 2021 interviews include: 1) building soil to grow food; 2) increasing waste management capacity; 3) creating employment; 4) increasing self-sufficiency and taking a proactive approach to climate change; and, 5) sharing knowledge with other communities. Each theme is discussed in more detail below. Each section includes a detailed analysis of how these themes are interconnected with one another. Collectively, these themes form a holistic web of meaning, the threads of which cannot be disentangled.

The holistic web of deeper meaning intertwines with the KTFN's epistemologies (ways of knowing) and ontologies (ways of experiencing). As Goldman et al., (2015: 3) explain, full engagement with climate change knowledge and adaptation "needs to include an exploration of epistemology and ontology, and thus discourse and practice." The perceived benefits discussed throughout the chapter address the KTFN's practical understanding of the project. However, in discussions about the practical benefits, the KTFN also linked these ideas with more deeply entangled meanings, or discursive aspects, rooted in Indigenous epistemology and ontology. These discursive elements include the value of health and caring for the land, traditional teachings, and self-sufficiency - all of which participants frequently discussed within the context of practical benefits. These deeper meanings thus, emerge directly from the data itself. The sections below will illustrate how these layers of deeper significance interconnect with the perceived practical benefits of fish composting for the KTFN. The final two sections of the chapter will further 
explain the significance of these discursive elements articulated through the KTFN's worldview and ways of knowing.

\subsubsection{Building soil to grow food}

Several factors influence the relationship between soil and food as a perceived benefit. First, food from the store is expensive in Northern regions and difficult to access. The closest grocery store to Kakisa is located roughly $150 \mathrm{~km}$ away - in Hay River. This distance means, in addition to the high costs of food in and of itself, community members must also spend a significant amount of money on fuel, while incurring wear and tear on their vehicles, to acquire food. The opportunity cost of the time spent to acquire the food should also be factored in - as it takes approximately an hour-and-a-half to reach the grocery store going one way, which makes grocery shopping approximately a four- to fivehour endeavour.

Second, food purchased from the store - largely processed foods from outside of the community - are perceived as unhealthy in comparison to locally grown produce or traditionally harvested foods (Spring et al., 2020). Shifts in diet from traditional, land-based foods to highly processed, market-based foods contribute to decreased nutrition and overall health in Indigenous communities (Richmond et al., 2021; Coté, 2016; Cidro et al., 2015; Gracey \& King, 2009). The community experiences the physical and mental effects of this shift on a regular basis, making these perceptions a lived reality for many community members. As I read through the interview and focus group transcripts, health emerged as a deeper layer of significance attached to more practical conversations around building soil to grow food in Kakisa. Participants frequently discussed both of these concepts holistically 
in context with one another - the paragraphs below parse out the relationships between enhancing soil fertility and promoting health through fish composting in more detail.

Throughout the 2019 focus group and 2021 interviews, participants discussed the relationship between healthy soil and healthy food positively as a benefit of fish composting. As one participant acknowledged: "If we're going to build our own garden in the community, then we have to start doing what we need to do to build up the compost for the garden" (Anonymous Community Member, Kakisa NT). This statement directly acknowledges that soil is the foundation of any garden. Both academic literature and traditional teachings acknowledge that fish composting can provide a productive soil amendment. The process of fish composting ultimately converts organic waste materials into a low-cost soil amendment, which can provide alternatives to synthetic or chemical fertilizers for increasing soil fertility in organic agriculture (Laos et al., 1998; Illera-Vives et al., 2017). Fish waste is a nutrient-rich material to include in organic agriculture because it contains high concentrations of nitrogen, phosphorus, and calcium - all beneficial to agricultural production (Radziemuska et al., 2019). The compost generated from the fish waste composting process also improves the texture of soil and the soil's capacity for carbon sequestration (Radziemuska et al., 2019). Returning fish waste to the land to generate healthy soil is also linked to traditional teachings and does not appear to be a new idea in the community. For instance, as Kakisa Elder, Margaret Leishman, explained:

The fish waste was really disposed of in a good way-you didn't throw it all over the bush. You chose one area where the waste used to go. You could make fish broth and that was given to the dogs. That's what I think of when I think of fish bones. And I think at one point the fish bones were even used to sew your garments before the needles came. I would know how to survive just living off fish. Even the bones going back on the land, it's very nutritional for the ground. It's a fertilizer. We don't think of the things we dispose of on the land. To this day I still do that. I keep bones 
until there's enough gathered and then I take them and put them on the land again. That's the way I was brought up all my life.

As this quote highlights, the KTFN and their ancestors never wasted fish remains. The community used all parts of the fish to help with various other tasks throughout their daily lives. For instance, the people used fish liver and fish eggs to soften hides; fish bones as needles or in traditional art; fish skins as soft whips for training dog sled teams; and boiled fish bones and guts as a broth for cleansing the body. If something could not be used, the people would return the fish to a designated spot on the land to promote boreal forest health. Margaret's statement above directly acknowledges that, on an ontological level, the community understands fish waste as a healthy component for generating productive soil.

Community members strongly advocated for health throughout the focus group and the interviews. When talking about fish waste as compost, one participant explained: "That would be something healthy to have, to have our own soil out of our own composting because that's really healthy stuff that grows in our garden" (Anonymous Community Member). In Kakisa, fish waste is viewed as "healthy waste" that can be used to grow healthy food and promote the return to a healthier community livelihood. For instance, as Margaret explained, fish composting is an essential component of growing food and promoting health because:

[...] The land will be richer because of it. Putting it back into the gardens will help restore health in the community. That's what we need to do instead of buying fertilizers from the South - we know that the fish waste is good and that it's healthy for your gardens. It's healthy waste... Most importantly what I want to see is healthy living, that we have nutritional foods.... I never used to see diabetes coming into Kakisa...It's going to mean a lot for the community. 
As participants indicate, members of the community already embody this awareness and knowledge that fish waste is healthy, which is why fish composting is important to the KTFN; they would know at all times exactly what they add to their garden. Margaret also touches on the connections between diabetes and food purchased from the store. To Margaret, the fish composting project is a step in the right direction towards promoting health on various levels - building healthy soil, growing healthy plants, and promoting physical health for people in her community.

It is also important to acknowledge that health goes beyond just maintaining a healthy body for the Dene people in Kakisa. As Margaret explained, the traditional stories and teachings she learned from her Elders emphasized four components of health: physical, mental, emotional, and spiritual - all are equally important. Margaret also explained she believes the fish composting project will help maintain all of these aspects of health, because to her, when people are healthy, they are more likely to contribute to community living in a good way. This is understood through significant traditional teachings around self-sufficiency and taking care of the land. As Margaret stated:

It [fish composting] will bring back why it's so important to continue our way of life which was really healthy for us at one time... We have to contribute everything to our surroundings and to the land because it's our guiding tool for life - the land, animals, fish, everything that is on it is a guiding tool for me as a Dene. And that goes for everybody else.

Ultimately, the concept of health cannot be ignored when talking about composting fish waste or growing food. It is also important to comment on how infused the notion of health was in all aspects of these conversations, especially with Elders. While I have picked out significant quotes to exemplify specific points on healthy soil, healthy food, and healthy people - it is important to acknowledge the fluidity of these topics that cannot be captured 
fully in this written format. When people tell these stories, they are not linear in nature. These conversations around health were not prompted by any of the general questions asked in the focus groups or interviews (keeping questions general and unspecific allowed the KTFN to present their own values and ideas around meaning and importance without outside influence from my own preconceived ideas and biases) - rather, they tended to just emerge as people talked and told stories. Ideas about fish waste and health remain deeply embedded and intertwined with one another throughout traditional teachings and practices. As such, the idea of returning fish waste to the land to contribute to the health of the land and people is not new - the only novel aspect here is the execution, where fish waste is used specifically for growing food in the community gardens and greenhouses. Further, the similar principles and values between fish composting and traditional cultural practices for properly disposing of fish waste appears to positively influence the participants' perceptions of fish composting as an appropriate community-driven initiative. As Margaret explains, "All my life as an Elder, our fish waste, all of this went onto the land believing that you know, it becomes healthy again too, for the animals and everything, so, this is a good idea, and I'd like to be part of composting things."

The costs of acquiring food from the store and its real and perceived lack of nutrition for Indigenous communities highlights one reason why growing food is important for the KTFN on a practical level. The traditional teachings also explain why the community understands fish waste as a tool to accomplish as both significant and meaningful on an epistemological and ontological level. While building soil amendments for the community gardens is a perceived benefit of the project, it means so much more than just that. It means taking care of the land and restoring its health. It means taking care 
of the people by promoting physical, mental, emotional, and spiritual health. It also means connecting traditional values and teachings on using fish waste in culturally appropriate ways with new, on-going community-driven agriculture initiatives.

\subsubsection{Increasing waste management capacity}

Increasing Kakisa's waste management capacity emerged as a practical perceived benefit several times throughout the 2019 focus group and 2021 interviews. Often, the participants offered comments about waste management in the community un-prompted, which highlights how important this topic is for the community. For instance, mid-way through a conversation about fish bones and how they provide nutrients to the soil, one participant commented about how much garbage the community produces: "We're hauling a truck load we're sending every three days. But like a truck load. And we're encouraging people to recycle. Most of the houses are not recycling” (Anonymous Community Member). In another instance when the group discussed how compost can create healthy soil to grow healthy food, one participant stated:

If you go to the bigger cities, if you go to the dump, it's a big, big mess, just a big mess. And then it just gets buried. And then people here, they always talk about taking care of the land. The thing is the GNWT, they want us to do a twenty-year plan for our dump here, and they want us to bury everything. I don't think that's something that people like doing here. People take care of the land and that kind of stuff, and we can't be doing those kinds of things. It's okay for them [the GNWT], in terms of policies, but for us it's good to take care of the land and do something about it. We have a whole bunch of garbage everywhere. We would like to do something about it.

\section{- Anonymous Community Member}

As this statement demonstrates, reducing or better managing waste in the community goes hand in hand with taking care of the land. Taking care of the land is 
something the KTFN emphasize throughout all of the projects they take on (Spring et al., 2020; Spring et al., 2018). Here, the relationship between reducing and better managing waste and taking care of the land is apparent. Since the fish composting project aims to reduce fish waste being dumped in and around the community, waste reduction can be interpreted as a perceived benefit of the project. Additionally, the community hopes to scale up the infrastructure required to run a fish composting to include household organic waste in the future (Chief Lloyd, personal communication, February 2021), which would, in turn, increase overall waste management capacity within the community.

Reducing cardboard waste was also noted as a perceived benefit of the fish composting project throughout the 2019 focus group. In one conversation about reducing waste in Kakisa, one participant noted that the acquisition of a cardboard shredder would be useful. Currently, cardboard waste in Kakisa is collected in recycling bins around the community and delivered to the Northern Farm Training Institute (NFTI), located between the Hamlet of Enterprise and Hay River, NWT, approximately 117 Km from Kakisa, where it is shredded and used for compost in their gardens. As one community member noted, however: “We can't be contributing to NFTI's garden. If we're going to build our own garden in the community then we have to start doing what we need to do to build up the compost for the garden" (Anonymous Community Member). This statement acknowledges that building compost requires materials. As this community member notes, instead of contributing their cardboard resources to an external source, it would be more desirable to turn waste materials generated in the community into compost for the community. 
For a fish composting system to work, the compost recipe does not just require the nitrogen provided from decomposing fish. Compost also requires materials rich in carbon. Cardboard is an excellent source of carbon that can be added to the compost to help produce a healthy soil amendment for gardens (Nair \& Okamitsu, 2010; Cooperband, 2002). The statement above therefore highlights that reducing other types of waste is another perceived benefit of a fish composting project.

Woodchips represent another form of waste that can be used for the fish composting system. In 2014, the KTFN were threatened by a wildfire that burned right up to the community. In the wake of the fire, the community cleared a large strip of land adjacent to the community as a fire break, felling many large trees within it. These logs were then chipped and stored in piles in various clearings around the community. One participant in the 2019 focus group suggested that using these woodchips in the composting would be beneficial. Though they did not use technical terms to explain the benefits of using woodchips in composting, woodchips are in fact a good source of carbon for compost, as well as a bulking agent to ensure that compost materials decompose evenly (Laos et al., 1998; Cooperband, 2002). The connection made between fish composting and making use of the woodchips that came from building a fire break reinforces the notion that reducing other forms of waste is a perceived benefit of the project for the KTFN.

Overall, improving waste management in Kakisa through composting represents both a real and perceived practical benefit of the project. As more organic waste is diverted from landfills, this will significantly reduce the amount of methane emissions (Jenish, 1997; Government of Western Australia, 2018; Ayalon \& Shechter, 2001) and toxic leachate produced in community landfills (Environment Canada, 2013). Composting can 
also sequester carbon in the ground and offset greenhouse gas emissions and other impacts associated with the use of chemical fertilizers (Favoino \& Hogg, 2008; Bolan et al., 2012; Radziemuska et al., 2019). In addition to these more scientific benefits, however, reducing waste in Kakisa is meaningful because it helps to uphold traditional values and teachings around forest stewardship and taking care of the land, which also promotes overall community and forest health. It means striving toward self-sufficiency by doing things differently than how the government instructs them to live, and reinstating their traditional lifestyle as Kakisa Chief, Lloyd Chicot, noted:

When it comes to the municipal side of stuff, I think we've struggled with that for a while, because when we first started here, we had the dump right in the middle of the community, and that didn't sit well. You have the government telling us we need to have those things there. Some of the Elders, they sort of went with it for a while. But after a while they said this is not the way to do things. So, we've taken the way we were taught with our traditional lifestyle where you take care of stuff and we approached it that way. So, we are doing things a little bit differently than the government wanted us to do. We are doing things our own way based on our culture and the way we have been taught to take care of things.

As Chief Lloyd explains, improving waste management capacity in Kakisa is one way to revitalize the Dene identity in his community. Once again, it is important to acknowledge how various ideas come together to form a bigger picture throughout these conversations. Ultimately, "culture plays important roles in MSW [municipal solid waste] management, particularly because interactions within a culture can impact people's understanding of MSW, the value of waste, and how it is or can be managed" (Assuah, 2020: 56). Improving waste management means more than just taking care of the land in a practical sense - in connection with the KTFN's worldview and ways of knowing, it means asserting control over their land and reaffirming the importance of traditional teachings, 
despite the federal and territorial government. The fact that conversations about waste management are often heavily intertwined with conversations about growing food also highlights how important each component is to realize their overall goals. Since waste management and food production cannot be disentangled in this context, the connections between waste management and food production highlight how important composting is for achieving a more holistic and sustainable lifestyle in Kakisa rooted in self-sufficiency, health, and traditional values.

\subsubsection{Creating employment}

When I began working on the fish composting project, the KTFN first asked me to work on research and recommendations for possible composting methods, site locations, and collection systems (see Appendix A). A community researcher assisted with conducting the research and generating recommendations. As Appendix A highlights, one collection option would have involved providing education to commercial fishers and fish processors on how to transfer the fish waste to the composting trench and mixing the compost. This method would mean that each person handling fish waste in the community would be responsible for collectively maintaining the site on a voluntary basis. The other option outlined in Appendix A would create a part-time, paid position for someone else in the community to take on the full responsibility of transferring the waste to the site, mixing it, and maintaining the compost. The latter option was identified as the ideal option by the KTFN in the 2019 focus group. As one participant stated when talking about generating compost in the community: "By doing this you might be able to create at least one or two positions, that's just to create work" (Anonymous Community Member). "Creating 
employment" was also directly stated by another participant as a positive outcome of this project. However, participants did not discuss in detail how these positions would be funded outside of the NAF project grant for long-term operation - covered more in Chapter 5.

There are a few reasons why the KTFN views creating employment as an attractive to the KTFN. First, the remoteness of a small community in the North creates a lack of economic opportunities due to isolation. Isolation, coupled with the high cost of living in general, contributes to increased food insecurity in small northern communities (Spring et al., 2020; Islam \& Berkes, 2016; Leblanc-Laurendeau, 2019). One of the benefits of the broader Northern Agriculture Futures project thus far has been creating employment opportunities in the community. For instance, hiring community researchers to assist with the framing, facilitation, and execution of research projects helps to increase community engagement while also offering more economic opportunities for the community. Adding a part-time composting position would allow an additional person in the community to contribute to the projects while also receiving some of the economic benefits. This position paired with other necessary positions such as greenhouse and community garden maintenance would help diversify the opportunities Kakisa has to offer its residents.

In the interim, increasing employment opportunities in Kakisa means more to the community than just increasing economic benefits. As one participant noted, providing employment opportunities with the fish composting project might actually be a useful way to pass along traditional teachings for young people and the children of residential school survivors whose parents either forgot or were unable to learn about various traditional stories and practices as a result of the residential school system. In Kakisa, there is a story 
for everything. As previously mentioned, some participants suggested that fish composting aligns with traditional teachings of taking care of the land, returning fish waste to the earth, and maintaining overall health of the land and people. In our conversation about employment, one participant explained how teaching these principles to the young people who might take up these part-time jobs, is an important way to re-teach traditional stories, and to improve the health of the people. She noted: "It will bring back why it's so important to continue our way of life which was really healthy for us at one time" (Margaret Leishman, Kakisa Elder). For Margaret, this project might actually provide an opportunity to strengthen the relationships between youth and Elders in the community by passing on traditional stories and values. Strengthening these relationships by fusing traditional stories with employment addresses these concerns and further promotes healthy community living.

Overall, providing employment in Kakisa is meaningful in multiple different, interconnected ways. Not only does it improve the economic opportunities in the community for young people, but it might also serve to strengthen relationships between youth and Elders and promote the inter-generational transmission of traditional knowledge. Given these identified perceived practical benefits and their connections to Indigenous epistemology, ensuring space is made for prioritizing traditional teachings in education and job training will likely be important - as discussed further in Chapter 5 .

\subsubsection{Taking a proactive approach to climate change adaptation}

Another prominent theme of the 2019 focus group included promoting and increasing selfsufficiency in the context of climate change adaptation. In this context, self-sufficiency 
refers to the community meeting its own needs. Relying on the store or market-based foods in this context can be seen as the antithesis of self-sufficiency. Participants heavily interconnected self-sufficiency as a meaningful aspect of climate change adaptation. As one community member stated: "Down the road things are going to get tougher. We can't be counting on the store for everything. We've got to start growing our own stuff because it's going to get more expensive with climate change. This is serious...we've got to start growing our own food or there will be no food" (Anonymous Community Member). The idea of taking back control over food procurement is tangled with the perception that relying on market-based foods is an unreliable way to obtain sustenance, given the impacts of climate change in the North. These ideas also proved prominent during the Climate Change Adaptation Workshop held in Kakisa in February 2019 where I was a participant. On multiple occasions, during the workshops, participants identified self-sufficiency as a key aspiration for carrying out projects that respond to climate change impacts on their community.

While self-sufficiency in and of itself can be interpreted as a perceived benefit of the fish composting project and various other projects taking place in Kakisa, the connection between self-sufficiency and taking a proactive approach to climate change adaptation remains significant. By connecting the two ideas, it appears participants fundamentally believe that a proactive approach to adaptation for the community must come from the community itself. In other words, a proactive approach to climate change adaptation cannot happen unless the community is self-sufficient. This is exemplified by one comment made in the 2019 focus group: "We're going into some tough times and things are not going to be the way it is right now further down the road. So, we need to 
start doing something now" (Anonymous Community Member). As this remark highlights, being proactive with climate change adaptation is a key practical motivation for carrying out the fish composting project. It also highlights how, on a more meaningful level, selfsufficiency is often coupled with the idea that a proactive approach to adaptation is a perceived benefit of the project. By linking the two ideas, this implies the community is eager to take back or maintain control over how they obtain their food and how they plan for the future.

As other on-going projects in Kakisa indicate, the community identified growing their own food as a way to build a "more resilient food system" in the face of climate change (Spring et al., 2020: 54). As Spring et al. (2020) highlights, doing this type of research in Kakisa in and of itself advances key aspects of self-determination. The idea of self-sufficiency and self-determination also inherently links to traditional teachings and health, as previously discussed in the Soil, Waste Management, and Employment sections. The KTFN perceive climate change adaptation strategies and building a more resilient food system as a benefit, because the fish composting project aims to strengthen the soil-related foundation for these larger projects, and to address gaps in waste management capacity. Self-sufficiency, and the traditional teachings and concepts of health that come with this worldview cannot be disentangled from the community's climate change adaptation goals, which adds a complex layer of meaning that connects this discourse with various other perceived practical benefits of the project. 


\subsubsection{Sharing knowledge with other communities}

One final theme that emerged in the 2019 focus group and 2021 interviews included knowledge sharing and building and/or strengthening relationships, both within their own community and with other communities. Given this project's affiliation with the Northern Agriculture Futures project, knowledge sharing is an important component of projects led by the KTFN. As an anonymous community member explained: "This [fish composting] is a good idea to generate. We might be the first community to do that. Then we could help others to all share information." Often, participants pair the idea that the KTFN might be one of the first communities in the Northwest Territories to pursue fish composting with sharing knowledge across the region. The connections between these ideas indicates that the fish composting project provides a source of community pride, and by extension, sharing these ideas with other communities offers the community a sense of pride as well.

As previously mentioned, some participants believe that this project provides an opportunity to revitalize and reapply traditional teachings in on-going community initiatives. Sharing knowledge as a practice can also be interpreted as fulfilling that goal as knowledge sharing in and of itself is a big part of Indigenous culture. How knowledge is shared, through Elders, Indigenous women, storytelling, community gatherings, on-theland experiences, etc., is also culturally significant (Kaplan-Myrth \& Smylie, 2006; Barnhardt \& Kawagley, 2005; Berkes, 2009b). As a result, the knowledge sharing aspect of this project can be interpreted as a multifaceted benefit for the KTFN, with many layers to unpack.

Sharing knowledge with other partnered communities in the NAF project provides opportunities for the KTFN to build and strengthen mutually beneficial relationships on a 
regional level. For example, the Sambaa K'e First Nation (SKFN) in Sambaa K'e, NWT, is a partnered NAF community that participates in knowledge exchange with the KTFN. The SKFN has expressed interest in learning from the fish composting pilot project in Kakisa, so they might implement it in their own community. The SKFN has also exchanged agriculture knowledge with the KTFN. In the summer of 2020, SKFN hosted a Kakisa Youth research trip to help educate the KTFN on northern greenhouse operation and managing community gardens. Exchanging information in this way offers both communities a chance to strengthen social and human capital for meeting their community agriculture goals, thus, strengthening community self-sufficiency and Dene selfdetermination, and by extension, applying traditional knowledge and promoting community health.

\subsection{Summary of findings}

As each of these sections highlight, the five practical benefits (building soil, improving waste management, creating employment, adapting to climate change, and sharing knowledge) all interconnect with three key elements of deeper meaning articulated through the KTFN's worldviews and ways of knowing. These three concepts include health and caring for the land, upholding traditional teachings, and self-sufficiency. These layers of deeper meaning connect with and inform one another in multiple ways, and they cannot be disentangled (see Figure 6). For instance, promoting health and taking care of the land comprises many of the traditional stories and teachings passed down - many traditional teachings emphasise the importance of taking care of the land. The KTFN views taking care of the land as a responsibility, which in turn, allows the community to promote and 
attain human health in the four ways (emotional, physical, spiritual, and mental) (Margaret Leishman, personal communication, February 2021). Healthy land yields healthy people, and this notion is directly taught through traditional teachings. Likewise, Elders and other members of the community promote self-sufficiency through traditional teachings - core to the Dene identity. The Dene people have survived in such harsh environments for thousands of years as a result of self-sufficiency communicated through traditional knowledge and teachings to maintain a healthy community lifestyle. Finally, selfsufficiency and promoting health and caring for the land connect with one another, not only through traditional teachings, but through the notion of responsibility. As the above discussion highlights, the KTFN have a strong desire to take care of their own land and people in their own way. Since these goals for self-determination and taking care of the land often come together through traditional teachings, this highlights how these three discursive themes cannot be separated from one another.

The three layers of meaning - health and caring for the land, traditional teachings, and self-sufficiency - reveal levels of significance embodied by the KTFN's worldviews and cultural epistemologies that cannot be disentangled from the perceived practical benefits of the fish composting project. Understanding these perceived benefits and meanings in relationship with one another are important, because it allows us to gain a deeper understanding of the KTFN's approach to caring for the land and cultural identity associated with this project. In turn, understanding the discourse and meaning behind these perceived benefits will help to gain a better understanding of the KTFN's identified assets and their application to ensuring success in this project - covered in Chapter 5. 
Fish Composting in Kakisa: Relationships between practical benefits and layers of deeper significance

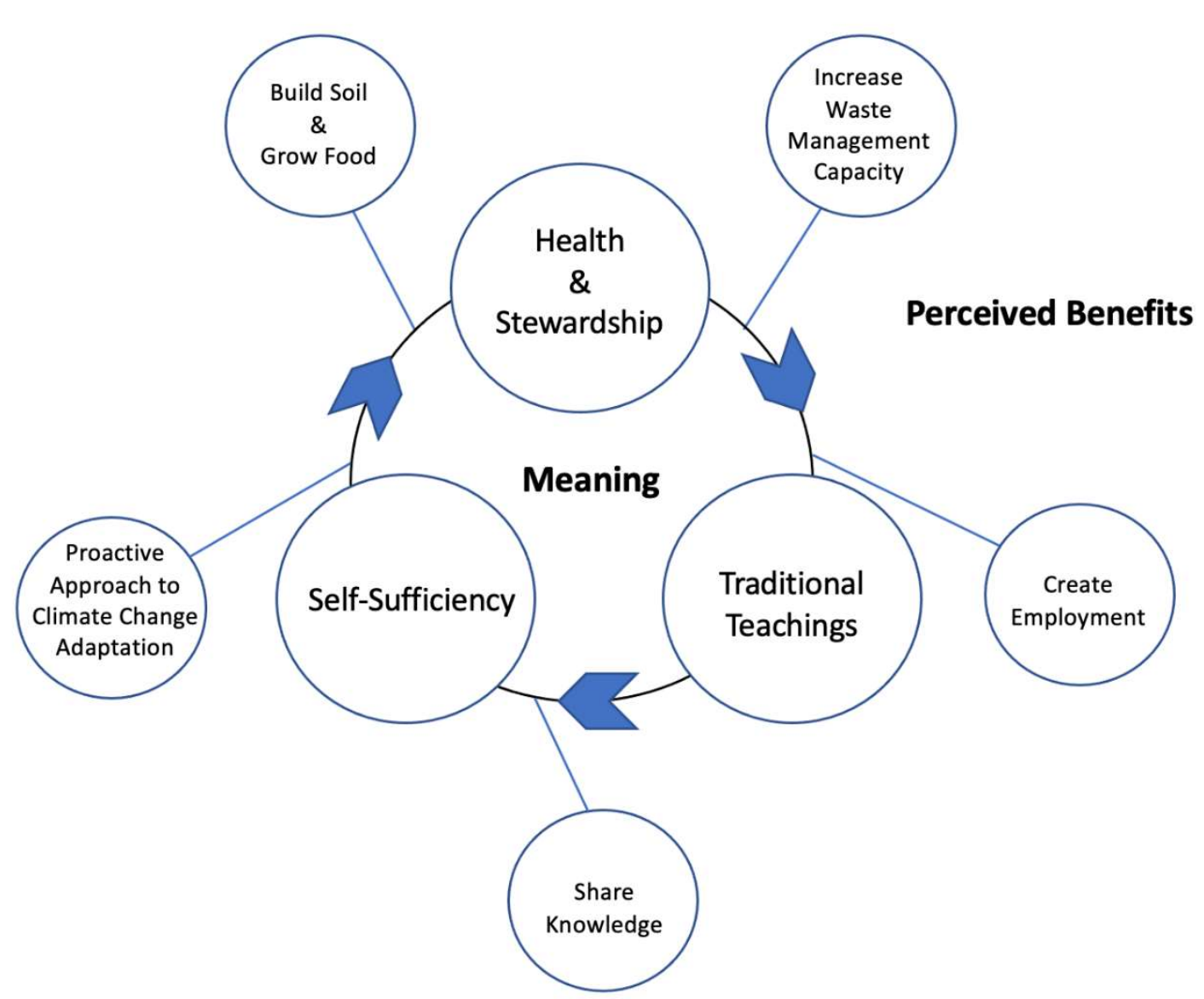

Figure 6. The outer circles on the chart demonstrate how each perceived benefit is connected to a circular and fluent web (represented by the inner circles) of deeper significance.

I would like to acknowledge that this analysis is not a comprehensive list of the possible meanings and benefits associated with fish composting - there is only so much information that can be collected in a short time. This analysis only begins to scratch the surface of the holistic worldview the KTFN may have. There may be other members of the community who did not participate in the research who have different perspectives and points of view on the matter. Additionally, reconciling cross-cultural barriers in how this 
knowledge is presented in academia may limit the ability to communicate these deeply felt concepts, meanings, and relationships. However, given the discussions we had together, these major themes were discussed the most frequently, and often in relation to one another, which is why I have emphasized the interconnected nature of these themes.

As this project moves forward, knowledge dissemination through culturally appropriate media and language will be essential for sharing knowledge with communities. Appendix E offers one example of how knowledge can be communicated through posters, artwork, cultural symbols, and traditional language in an Anishinaabe context. The 13 Moons Poster highlights traditional practices based on seasons and moon cycles presented in a circle to emphasize non-linear ways of understanding. A similar model could be adopted for knowledge dissemination for the fish composting project to tell the story of fish composting. Designing posters could also provide a creative outlet for youth collaboration. Producing knowledge sharing documents and posters outlining the results of this project also has an opportunity to be even more inclusive and collaborative in comparison to this thesis - since time tends to impose a limiting factor for completing academic work, and the remote aspects of data collection and analysis due to COVID-19 also limited collaborative opportunities.

Despite the fact that this Chapter does not provide a completely comprehensive discussion, I have done my best to piece together the various stories and fragments members of the KTFN shared with me in this short time. The ability to even begin understanding the perceived practical benefits and underlying meanings for this project will promote researcher accountability to the community, as cross-cultural understanding is a key aspect of using PAR methodology. 


\subsubsection{Political ecological analysis}

Understanding the perceived practical benefits of the project and the underlying layers of deeper meaning for the KTFN grounds the process for making connections between community stories and experiences, and the political ecological portion of this project's framework. I will elaborate on these connections by discussing relationships with the land, real and symbolic meaning, questions of power, and understanding how these meanings shape livelihoods.

First, the relationships between people and the land are a prominent factor in shaping meaning for the KTFN. In line with political ecologists' recognition of the environment's agency, the KTFN acknowledge the land's role in shaping their livelihoods - even though both the framework and the community use different language to convey a similar idea. For instance, many participants have acknowledged throughout the research process that the land provides them with everything they need to survive. In return, they view themselves as responsible for carrying out their livelihoods in a way that cares for and promotes the land's health. This relationship is mutually beneficial, and each actor (the land - water, soil, plants, and animals - and the people) each has a role to play. Understanding the land and its significance for the KTFN, and relationships between the land and people will be critical for assessing community assets and their value, which is discussed in Chapter 5. Ultimately, the land has agency in this context because it plays a critical role in maintaining health, shaping traditional worldviews, and bolstering community agency (self-sufficiency and self-determination) - which is why the three discursive layers discussed above have particular significance. 
Second, political ecology offers a lens for understanding both the real and symbolic meaning attached to this project. Looking at the community's perceived benefits of fish composting allowed me to find interconnected themes of deeper meaning that go beyond just enhancing soil fertility, expanding agriculture, or improving waste management. Analyzing the more practical, perceived benefits revealed a more symbolic statement about the land, traditional teachings, and self-determination. In line with Jarvenpa's (2008) findings that food plays a role in redefining relationships between the Dene people, the land, social others, and their overall cultural identity, fish composting, in both a real and symbolic way, aligns community-driven agriculture and waste management initiatives with traditional teachings to assert control over their land, livelihoods, governance, and health.

Third, the political ecology framework intersects with these findings through questions of power and discourse. Akin to Escobar's (1996) assertion that political ecology challenges culturally defined alternatives to dominant discourses of sustainability, the KTFN have openly challenged the federal and territorial government's role in shaping their livelihoods, especially when it comes to waste management. Many statements the participants made (included above - this information was also obtained from personal communications and participant observation) elaborated on the community's pride in "doing things differently", or the striving to live by ways they were taught. As discussed above, members of the KTFN believe the composting project is beneficial because it will: 1) allow them to improve soil fertility to expand community-driven agriculture projects;2) improve community waste management practices; 3 ) provide employment for community members; 4) help them take a proactive approach to climate change adaptation and regain self-sufficiency; and, 5) strengthen relationships between other communities through 
knowledge sharing initiatives. As highlighted by the three layers of deeper meaning connected to these perceived practical benefits, members of the KTFN have taken a holistic approach to making their livelihoods more sustainable. The connections between the practical and symbolic benefits go beyond environmental sustainability. Social, economic, and cultural sustainability - all of which are deeply linked to one another - are just as important to consider. In doing so, members of the KTFN challenge dominant discourses and approaches to sustainability by taking matters into their own hands and building on a foundation of stewardship, health, and traditional knowledge. In the next chapter, I apply what I have learned about the KTFN's worldviews and ways of knowing as they relate to fish composting in my analysis of community assets and recommendations for moving forward. 


\section{Chapter 5: Community Assets and Recommendations}

Mapping the KTFN's assets directly addresses one of this project's goals to generate recommendations on strengthening community capitals for implementing the fish composting project. Applying the SLA throughout this chapter directly addresses research question 2 for this project - how can identifying the KTFN's assets inform the generation of recommendations and overall implementation of the fish composting project in a community context? To address these questions, I use deductive coding analysis to predetermine asset categories prior to analyzing the data. Categories include seven different types of assets: natural, physical, cultural, social, economic, political, and human. The asset mapping reveals strong physical, natural, cultural, and social capital in Kakisa. Then, I explore how these assets might be applied to practical next steps for implementing this project, including generating a project budget, creating a project timeline, and accessing training for future fish composting employee(s). The asset mapping also reveals possible opportunities for strengthening community capitals including human and political capital, since Kakisa's small population limits overall capacity for addressing administrative aspects for community-driven projects. Ultimately, this chapter argues that, while practical next steps for project planning are equally as important as infrastructure development for ensuring project success, capacity related challenges must also be addressed for achieving long-term project viability.

I approach community asset mapping primarily through interviews with community members coupled with insights gleaned through participant observation and verified the data with community researchers and participants to ensure validity. I also interpret some assets from the data collected in the 2019 focus group. While some sections 
on individual assets provide quotes from focus groups and interviews, the use of quotations may be unevenly distributed due to the nature of my involvement with the project as a research assistant. Much of the insight discussed in this chapter comes from participant observation or personal communications and project planning sessions with team members, which were not recorded. The first section of this chapter describes Kakisa's assets. The second section of this chapter briefly discusses challenges and barriers to implementing the fish composting project the participants identified. The third section applies the assets to generate practical recommendations, recommendations for asset strengthening, and future considerations for addressing capacity-related challenges for long-term success with this project.

\subsection{Community assets}

Throughout the interview process, I chose to modify the language slightly from traditional SLA projects, where communities are simply asked to identify assets and capitals directly. For instance, Karki (2013) conducted an SLA project where surveys were distributed to community households that directly asked participants about their "livelihood capitals," where participants were asked to identify household assets based on five categories (financial, natural, physical, social, and human). Similarly, Jacobs \& Makaudze (2012) used a questionnaire that directly asked participants to identify "what assets exist in rural areas?" and "how do people gain access to assets?". Rather than framing the interviews as a workshop or question period for identifying assets, I inquired about the participants' favourite things about their community. I made this conscious change to the SLA's methodology to make space for different ways of understanding and relating to the world 
- a key element of PAR. As Chapter 4 revealed, the KFTN view community realities through a holistic lens informed by cultural values. To make space for this epistemological difference, I did not want to limit the participants' views of "assets" to purely instrumental or resource-oriented language. For instance, participants were asked questions like "what are some things your community does really well?" "could you tell me a story about your favourite things about Kakisa?" or "what makes Kakisa a strong community?" The changes in language for framing the questions helped bridge the gap between the research and community reality - which will be discussed further in Chapter 6 .

In hindsight, the ways I modified the questions and language tended to emphasize positive or "favourite" aspects of community life, which could have limited participants' responses - perhaps important assets exist in the community that do not qualify as a participant's favourite attribute. Important, but not favourite assets, might include more mundane community attributes that, while not the most exciting, still form an integral part of community life. Fortunately, some participants were acutely aware of my oversight, and volunteered information on challenges and more neutral assets. For instance, in a followup conversation, one participant explained that, while they are proud of how the community operates, running the community does not happen effortlessly or perfectly free from conflict or struggle (Anonymous community member, personal communication, February 2021). Other interview participants also reached out after the fact with additional information they felt it was necessary for me to know, some of which included things they wish to see more of in their community, or challenges they hope to overcome. Section 5.2 covers these challenges in more detail. 
Once I completed the interviews, I reviewed transcripts and notes to compile a categorized list of the following types of assets: physical, cultural, natural, economic, social, political, and human. Table 2 summarizes these assets. The list of assets I produced prove consistent with, but also expand on Spring et al. (2018) - a study that mapped Kakisa's assets using a community capitals framework (CCF) in relation to community food systems more broadly. One notable difference between the asset catalogue I produced, and that of Spring et al. (2018) (see Appendix F), is that I separated the positive assets or strengths for this portion of the project from outstanding needs or challenges, which aligns with the SLA's framework (Ashley \& Carney, 1998; Serrat, 2017), whereas Spring et al. (2018) integrated both positive assets and outstanding needs into one table more consistent with the CCF. My assets table also provides a more specific or itemized approach compared to Spring et al. (2018). Spring et al. (2018) also approaches community capitals with a focus on assets particularly relevant to a food systems perspective. I chose to include more detail and expand on assets relevant outside of a food systems context, since this project applies the SLA to a practical project, where additional detail is necessary for generating context-specific recommendations.

I would also like to acknowledge that this is not a comprehensive list, and that some of the assets listed in the table might be subject to disagreement depending on who you talk to in the community. As several participants acknowledged, perceptions of strengths and assets will differ depending on who you talk to. Some people might spend more time on the land, and as a result, would prioritize natural, ecological, or cultural assets, whereas a person employed at the Band Office might have a more administrative perspective to offer. 
Each type of asset is described in more detail below, with an explanation of notable or most

relevant assets and their possible application to the fish composting project.

Table 2. Kakisa's Assets. Chart summarizing the KTFN's various assets for each category. Information was interpreted from the 2019 focus group and obtained through interviews and participant observation.

\begin{tabular}{|c|c|}
\hline Asset & Description \\
\hline $\begin{array}{l}\text { Physical } \\
\text { Assets }\end{array}$ & 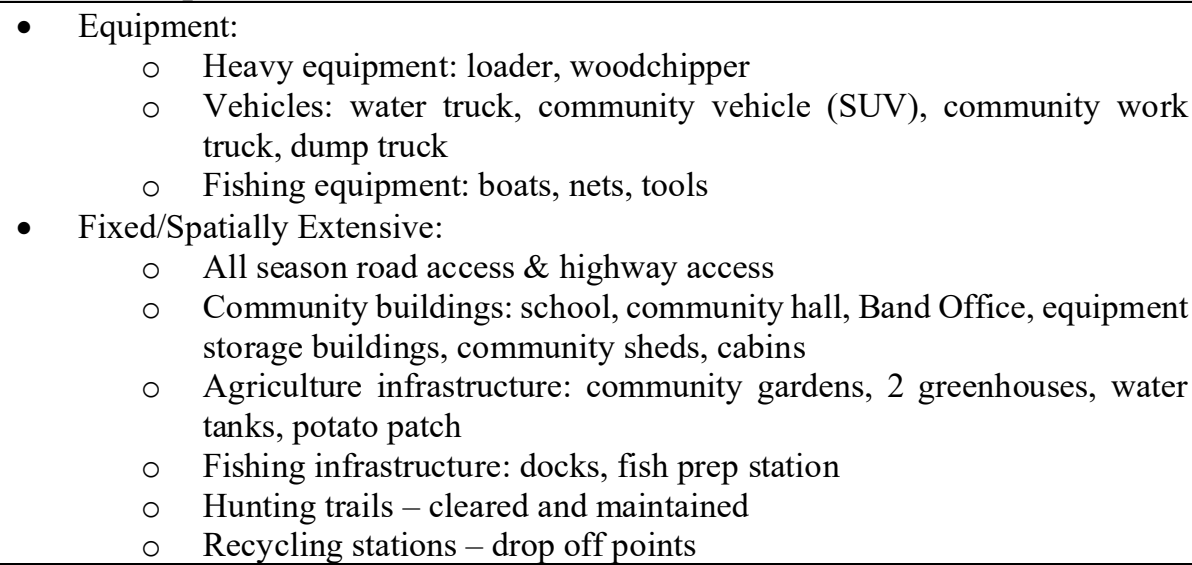 \\
\hline & $\begin{array}{l}\text { - Traditional knowledge, lifestyle, values - still maintained and practiced by } \\
\text { community members } \\
\circ \quad \text { Hunting, fishing, gathering } \\
\circ \quad \text { Dry fish making } \\
\circ \quad \text { Sewing \& crafts } \\
\circ \quad \text { Caring for \& respecting the land } \\
\circ \quad \text { Holistic worldview } \\
\text { - Community gatherings } \\
\text { - Food sharing amongst families and Elders } \\
\text { Language - South Slavey }\end{array}$ \\
\hline & $\begin{array}{l}\text { - } \text { Kakisa Lake } \\
\circ \text { Access to fresh surface water } \\
\circ \text { Access to fish (main part of traditional diet) - Pickerel and White Fish } \\
\text { - Tathlina Lake } \\
\text { - Kakisa River, various other rivers connecting the two lakes in a system (First and } \\
\text { - Second River) } \\
\text { Boreal forest surrounds the community } \\
\quad \text { Access to traditional foods: many types of berries (blue berries, } \\
\text { raspberries, saskatoon berries, cloud berries, high and low bush } \\
\text { cranberries), herbs, and wildlife (moose, beaver, wild chicken, ducks) } \\
\text { - Traditional knowledge intertwined with knowledge of the land } \\
\text { - Land facilitates social and cultural relationships, and livelihoods }\end{array}$ \\
\hline $\begin{array}{l}\text { Economic } \\
\text { Assets }\end{array}$ & $\begin{array}{l}\text { - Access to funding for various projects (Climate Change Preparedness in the } \\
\text { North \& ITI) } \\
\text { Employment opportunities with Band Office - community maintenance, Band } \\
\text { Office Administration } \\
\text { - Youth \& student employment programs } \\
\text { - Commercial fishery }\end{array}$ \\
\hline
\end{tabular}




\begin{tabular}{|c|c|}
\hline $\begin{array}{l}\text { Social } \\
\text { Assets }\end{array}$ & $\begin{array}{l}\text { - Close relationships between community members - food sharing, community } \\
\text { gatherings, often help each other out, community hunts, berry picking, caring for } \\
\text { Elders } \\
\text { - Strong research network for various projects - relationships with various } \\
\text { institutional, community, government agencies, and non-governmental } \\
\text { organizations }\end{array}$ \\
\hline $\begin{array}{l}\text { Political } \\
\text { Assets }\end{array}$ & $\begin{array}{l}\text { - } \\
\text { - } \\
\text { - Community has a Chief and Council - acts as a functioning, governing body } \\
\text { - Community is a recognized Legal Entity } \\
\text { - } \quad \text { On-going efforts to increase access to land and gain independence in land-use } \\
\text { decisions }\end{array}$ \\
\hline $\begin{array}{l}\text { Human } \\
\text { Assets }\end{array}$ & $\begin{array}{l}\text { - People who spend time on the land - embody traditional knowledge, acquire } \\
\text { traditional food } \\
\text { - People who keep the Band Office functioning in the best interest of the } \\
\text { community } \\
\text { - Student \& youth workers assisting on various projects } \\
\text { - } \text { Elders - traditional knowledge holders } \\
\text { - } \text { living, community pride } \\
\text { - People who organize community functions, activities, and projects }\end{array}$ \\
\hline
\end{tabular}

\subsubsection{Physical assets}

Physical assets in a community include infrastructure, tools, and vehicles (Emery \& Flora, 2006; Serrat, 2017). Consistent with Spring et al., (2018), I identify road access, community buildings, and the school as physical assets through participant observation and participant data. I also expand on the community's physical capital through an identification of additional equipment related assets. Many, if not all, of these assets could help play a role in operating the fish composting project. Heavy equipment can be used to transport and generate waste materials. The loader is a significant asset for transporting fish waste, woodchips, and loads of cardboard to the fish composting site. The loader could also be used to transport finished compost to the greenhouses and community gardens. This material is heavy, and it would be more efficient to transport in bulk. The woodchipper is also a significant asset because it generates woodchips to use in compost as a source of carbon and a bulking agent. Participants in the 2019 focus group and 2021 interviews 
directly mentioned the loader and woodchipper as assets for this project. For instance, in the 2019 focus group, one participant voiced concerns over the weight of fish waste collection bins, and another replied they could "bring the loader over" (Anonymous Community Member).

Community vehicles also support the fish composting project, because the composting site is located several kilometers outside the community near the landfill (see Figure 7). The community dump truck could also be used to transport waste materials to and from the composting site. As Chief Lloyd Chicot explained, "We recently got, it's called an I-37, it's a dump truck, so we could move material around. So, if we need to move more stuff in softer areas, we could use that to move [wood] chips and other things...it can go anywhere, even in the swamps and stuff." The dump truck might also be more reliable than the loader for this purpose, since the person responsible for maintaining the composting site might not be experienced enough or licensed to operate the loader. Having access to various other community vehicles (including the Ford Edge SUV) also ensures that a maintenance person has easy access to the site for non-transport related maintenance - which includes watering, turning, and monitoring the compost (Cornell Waste Management Institute, 2004; Ecology North, n.d.). 


\section{Map of Kakisa: Relevant fish composting locations}

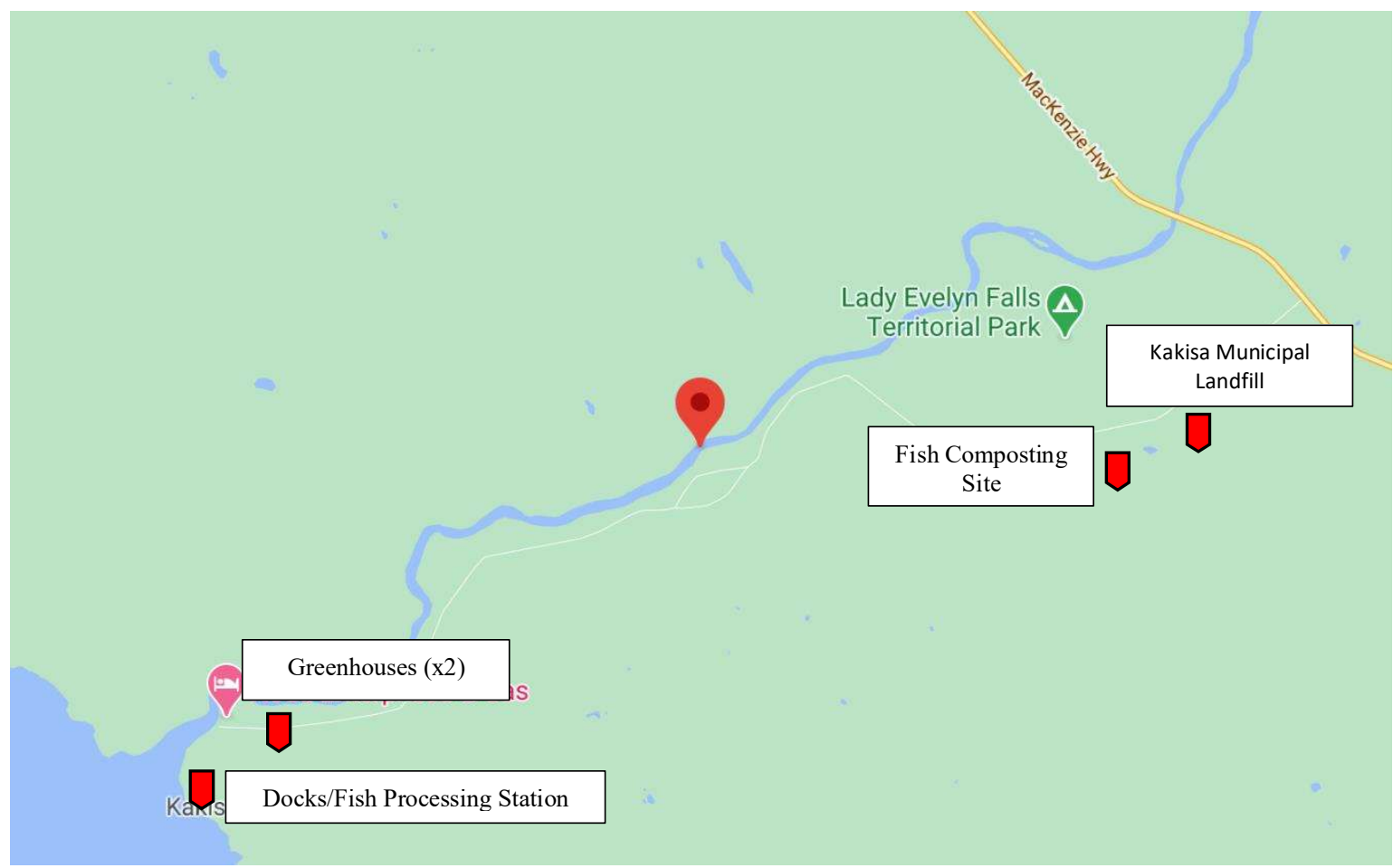

Figure 7: Map of Kakisa and relevant fish composting locations. This includes the docks and fish processing station at the mouth of Kakisa River, the greenhouses located in the north-east corner of the community, and the fish composting site located west of the Kakisa municipal solid waste landfill (Google Maps screenshot, locations added).

Some community buildings provide more relevance than others for the project most notably equipment storage buildings and sheds. One of the community sheds has already been relocated to the composting site for tool storage (Chief Lloyd, personal communication, February 2021). The other community buildings might be useful in the future for setting up compost collection bins. If the KTFN decides to expand the fish composting project to include kitchen and household waste, setting up collection bins inside the school, Band Office, and community hall would be ideal, as this would ensure the waste is stored inside to mitigate animal activity in the community. These locations 
tend to experience higher community traffic for larger gatherings of people (participant observation experience), which could significantly increase waste diversion from landfills in the future (Parrot et al., 2009). Adhikari et al. (2010) explain how Compost Collection Centres located in close proximity to larger producers of organic waste can increase waste diversion from landfills. Community cabins also provide a notable location for collecting fish waste - as they are often used for traditional hunting and fishing trips near the community. Setting up collection bins in these locations could increase the amount of fish waste being converted into compost for the gardens, as generating enough compost to expand agricultural production could be a concern in such a small community.

Agriculture infrastructure such as greenhouses provides a final destination for the compost material, making it a notable asset for a fish composting context. Chapter 4 covered community perceptions for the value of agriculture more extensively. The greenhouses were recently constructed as a result of community-driven agriculture expansion projects during the summer of 2020. Since the greenhouse construction completed towards the end of the summer, the first growing season for community greenhouses will take place from May to September 2021. The community has been working closely with NAF researcher Russel Chase, who operates his own greenhouses just outside of the Hamlet of Enterprise, NWT. Chase will also provide education and training for sowing seeds, maintaining greenhouses, and harvesting plants in Kakisa throughout the summer. As such, the agriculture infrastructure is a relatively new asset for Kakisa that is still being developed. Nonetheless, some agriculture tools could also be used to help produce the compost - most notably the water tanks. The community has several water tanks at their disposal, and it is likely that one of these could be moved to the 
composting site to make watering the compost more efficient, rather than hauling water to the site. The site's location just off the main road into Kakisa also provides easy access for water trucks to fill the tank when it runs low.

Fishing infrastructure such as the docks on Kakisa lake and the fish prepping station provide some of the most relevant physical assets to the project. The fish prepping and dock station would provide an ideal collection point for the community's fish waste, as this is where the majority of the waste is generated from the commercial fishery. If a collection point were added at the docks, it would significantly minimize the amount of driving (and thus time) commercial fishers put into dealing with waste - as fishers often have to drive the waste outside the community or dump it along the shores. For community members who dry fish in their homes, the docks could serve as a closer drop off point for fish waste, which would also minimize the amount of driving necessary for disposing of the waste. Having a main collection point in the community would increase the likelihood of community-wide participation, as it minimizes individual responsibility for dealing with the waste (Parrot et al., 2009). The community's recycling collection stations operate on a similar model and community-wide participation has improved significantly since 2019 (Anonymous Community Member, Personal Communication, February 2021). Having a similar model for fish waste pick up would require minimal education and outreach, as it operates in a similar manner to other waste collection systems in the community - as Wilson et al. (2006) highlight, working within a community's own informal or independent waste collection systems framework is more likely to improve waste management capacity than imposing a new system. 


\subsubsection{Cultural assets}

Cultural assets include traditional or ancestral knowledge, practices, values, lifestyles, artefacts, or history (Emery \& Flora, 2006). Many of the KTFN's cultural assets and their significance were discussed at length in the previous chapter, so I will keep this section brief to avoid repetition. Throughout our interviews, the participants often cited traditional knowledge and way of life as the most important asset in Kakisa - exemplified by the following statements: "The traditional way of life is so strong in the community," (Margaret Leishman, Kakisa Elder), and, "An asset I think is the traditional lifestyle and the cultural part of it... We are doing things our own way based on our culture and the way we have been taught to take care of things. So, I think that's one of the biggest ones [assets] here," (Chief Lloyd Chicot, Kakisa). Cultural assets are important to recognize throughout this project, because they provide meaning and guidance for how the KTFN conduct their livelihoods. As I explained in the previous chapter, traditional teachings of caring for the land underpin many of the perceived benefits for carrying out this project. As such, cultural assets such as traditional values and the ideology for taking care of the land, could help strengthen this project and better ensure its success by bridging the gap between the Western nature of agriculture and Dene culture.

Arcand et al. (2020) provide an example of how to approach bridging the gap between the Western nature of agriculture and Indigenous cultural knowledge. The authors' study focuses on First Nation farmers in Saskatchewan, where they facilitated a knowledge co-creation session to identify ways to restore Indigenous self-determination in First Nations agriculture. Throughout the sessions, participants emphasized the importance of "reclaiming and revitalizing traditional relationships to the land" for Indigenous 
agriculture initiatives and to "address long-standing sustainability issues with industrial agriculture" (Arcand et al., 2020: 626). The participants also emphasized traditional practices as primary solutions - specifically, more general Indigenous values of land management for guiding the process, where connections to culture and land-based relationships were most commonly stated.

As Chapter 4 explored, participants attach various layers of meaning to fish composting and agriculture- most notably when it comes to addressing the impacts of climate change and food security. Agriculture projects in Kakisa only happen because the community identifies it as a solution to climate change and food security related issues, and because they have taken a leadership role in researching and implementing these projects. However, the community also wishes to ensure agriculture develops in a way that promotes caring for the land and upholding cultural values, which informs the guiding principles of the NAF project. Thus, while gardening or agriculture do not reflect historically traditional food procurement practices, the community strives to transform agriculture as a solution to climate change and food insecurity into a practice that actively applies their traditional values on caring for and protecting the land.

In the context of waste management, Assuah (2020) provides an example of bridging cultural knowledge gaps with new waste management programs in Heiltsuk and Peguis First Nations. Peguis and Heiltsuk First Nations are two communities who have recently made efforts to improve waste management programs and community waste education. As the author found, participants in this study emphasized that communities need to "consciously teach and apply" cultural factors, "which are important to them and their existence, to help in positively changing attitudes and behaviours in relation to MSW 
[municipal solid waste]" (Assuah, 2020: 100). Many of the author's participants identified that the impacts of residential schools and the 60's Scoop interrupted their traditional learning, which in turn, impacted their perspectives on waste. With the introduction of new waste diversion and management practices such as recycling programs and composting pilot projects, participants identified a need to reconnect cultural teachings to these new systems to improve participation, motivation, and a stronger understanding of why these projects and systems were necessary. Similar to the KTFN (as explained in Chapter 4), participants in Assuah's (2020) research identified taking care of the land and dealing with waste in culturally appropriate ways as core values that bridge the gap between traditional knowledge and new waste management practices.

Bridging this gap between Western practices and Indigenous communities through cultural significance in the context of fish composting should be approached through education, training, and project planning. This could involve strengthening engagement between Elders and the rest of the community, and building core cultural values into the project's design. For example, incorporating the KTFN's cultural knowledge around traditional practices for dealing with fish waste would emphasize similar core values from a traditional perspective, the KTFN's ancestors taught the importance of returning fish waste to the land for nutrients, while composting applies this existing knowledge in a new way for expanding agriculture and improving waste management. Ultimately, bridging this gap and making the project more culturally relevant may increase the likelihood of achieving on-going community participation and approval (Sillitoe, 2004; Bebbington, 1993; Williams \& Muchena, 1991). 


\subsubsection{Natural assets}

Natural assets include ecological systems, landmarks, traditional knowledge, and access to resources (Emery \& Flora, 2006; Serrat, 2017). Some notable natural assets in Kakisa include various bodies of surface water including Kakisa Lake, Kakisa River, Tathlina Lake, and "First River" (that connects Kakisa and Tathlina Lake). In addition to cultural assets like traditional knowledge, participants emphasized the importance of natural assets including the two lakes, fish, and the forest - more broadly summarised as "the land" (Anonymous community members, personal communications, February 2021). The community's location, which is surrounded by boreal forest and situated right beside Kakisa Lake, was identified as a rich resource in and of itself, as one participant noted: "You don't have to go very far to enjoy life” (Anonymous Community Member).

Throughout the conversations, the participants often emphasized the significance of fish as part of their diet, and more specifically, pickerel and white fish. The participants often described the significance of traditional foods while simultaneously explaining how the experience of being on the land is an asset - "It makes us rich" (Anonymous Community Member). Based on these findings, the land is clearly intertwined with culture and livelihoods. In Indigenous communities, the land facilitates social structure, cultural and spiritual practices, knowledge and values (Receveur \& Kuhnlein, 1998; Greenwood \& Leeuw, 2007; Greenwood \& Lindsay, 2019; McGregor et al., 2010; McGregor, 2004). The fact that the land is intertwined in various relationships with other capitals reveals that natural assets have a tremendous amount of value for the community - value that goes far beyond monetary value. As such, natural assets and their specific value or relevance to this 
project cannot be disentangled from their relationships with other assets, and deeper meanings they have for the community.

Natural assets, including the water, fish, and forest all have a significant role to play in ensuring the success of this project. On a material level, the fish provide the nutrients for the compost. Peat soils and sand that are abundant in the area (Day, 1968) are also useful for mixing with the compost to generate productive soil for the gardens and greenhouse (Ecology North, n.d.). The lake shore will provide a physical space for waste collection bins.

Beyond the material level, the land can provide motivation for contributing to this project, and the project can provide opportunities for community members to spend more time on the land. As many participants noted, people are spending less time on the land "People don't go out as much anymore," (Anonymous Community Member). The community's reduced time spent on the land could be attributed to several factors including increasing emphasis on wage labour (Lambden et al., 2007; Kuhnlein \& Chan, 2000; Natcher, 2009), which significantly reduces the amount of free time people have to partake in traditional food and resource procurement (Spring et al., 2018; Johnston \& Spring, 2021). In Kakisa, community members either seek employment at the Band Office - which tends to be administrative - or they seek employment elsewhere, either commuting or relocating to Hay River or Yellowknife. As discussed in the previous chapter, the fact that the fish composting project aims to increase the KTFN's capacity for taking care of the land and apply traditional values to agriculture and waste management could serve as motivation for community members to actively participate. Further, ensuring that the project remains culturally relevant means directly including the land as an agent in future 
work, since the land itself is entangled in various relationships with cultural, social, economic, and human assets. In extension, the project will also offer community members a chance to work on and with the land, albeit, in a slightly different way than what they are used to. Many community members have commented in personal conversations that they highly prefer working outside with their hands, as opposed to behind a desk or in an institutional setting. The project thus, offers community members a chance to make a living while also transforming waste from traditional foods into productive soil resources that can grow fresh food locally. As such, the land is an important asset for this project, and efforts to ensure the composting system functions successfully should strive to incorporate onthe-land experience into the framework as much as possible.

\subsubsection{Economic assets}

Economic assets include access to financial or monetary resources, income, employment opportunities, and businesses (Emery \& Flora, 2006; Serrat, 2017). There are various economic assets in Kakisa, where one of the primary assets includes access to funding for community projects. Currently, the community has access to government funding through ITI, the GNWT, and with academic partnerships. The Northern Agriculture Futures (NAF) project is funded through the Climate Change Preparedness in the North program, which includes funding allocations for community researcher and project employment. The KTFN has also received funding from ITI to offset the costs of greenhouse and agriculture supplies. Details on how the KTFN obtains funding will be discussed further in the section covering social assets. 
Access to funding opportunities is a significant asset for the fish composting project, because it provides funds for employment, training, and education, which, in addition to expanding economic opportunities in the community, also bolsters human capital simultaneously. There are some challenges or barriers with this funding - as funds only last for a certain number of years before a grant runs out or expires - which leaves some level of long-term vulnerability to job positions. Solutions to this problem are beyond the scope of this research project, however, I suggest that future work in the community should focus on finding solutions to the unpredictability of funding for employment related to these projects if the pilot project operates successfully. The reason behind this conclusion stems from the novel approach to generating employment for a NAF project that the fish composting project presents. Currently, gardening work either happens voluntarily or through youth workers employed through summer work programs, with limited success. Since the fish composting project will be one of the first NAF projects striving for its own paid position, implementing the position and determining what works well and what does not will determine whether or not this model functions effectively for the community, which will take place outside the scope of this thesis.

Youth employment opportunities and subsidies for student wages is another economic asset in the community. Each year the Band Office receives funds from the GNWT to subsidise youth wages for student work programs, which offers some stability for community employment, at least in the summer months. Youth employment opportunities present an asset for this project because they ensure there are enough workers and funds for their wages to perform the work necessary for maintaining the compost site. 
The strategic opportunities for involving youth workers will be discussed further in the Recommendations section of this chapter.

\subsubsection{Social assets}

Social assets include relationships between individuals and members of the community, and the community's external relationships and networks with institutions, government, and other community partners (Emery \& Flora, 2006; Serrat, 2017). In Kakisa, participants identified strong relationships between community members as an asset, with particular emphasis on the sharing economy (of food, resources, labour, knowledge, etc.). As one participant noted, the KTFN excels when it comes to hosting community gatherings, celebrations, and feasts (Anonymous Community Member, personal communication, 2021). During my time in Kakisa, I also observed how the community takes care of their Elders. Often, student employees would make baked goods for the Elders. For social gatherings, younger community members would ensure Elders were escorted to the community hall on the community bus, and young people got plates and tea for the Elders. The community also invited me to take part in this sharing and caring economy when we went on berry picking trips. I shared the Saskatoon berry harvest with the Elders, since these berries grow on the banks of the river and are difficult for some Elders to access. These strong social ties in the community are an asset; however, some community members feel as though they could be even stronger, specifically between Elders and youth (Spring et al., 2018; Hadlari, 2019; Anonymous Community Members, personal communication, $2019 \& 2021)$. 
Participants also identified strong research partnerships and relationships with universities and other communities as social assets. For the past eight years, the KTFN has been working closely with Dr. Andrew Spring and the Wilfrid Laurier University research team on food systems and climate change research. Each summer (except for 2020 due to COVID-19), several graduate students have been given the opportunity to work in Kakisa on community-driven projects. These relationships with academics not only lead to progress and research on community projects, but they also help to gain funding for the KTFN. For example, as part of my research assistant position, I wrote a grant to ITI for obtaining greenhouse subsidies. Another student just recently finished writing a grant for the KTFN's trail maintenance and on-the-land safety projects. These relationships have also been instrumental in gaining recognition for the KTFN's projects on a regional scale, which spreads awareness and increases regional interest in food security and climate change related projects. "One of the biggest assets we have here is getting the students to come work with us. And a lot of them have connections up in Yellowknife and stuff, so we can get the word out" (Chief Lloyd Chicot, Kakisa).

These social assets are significant to this project because they strengthen the KTFN's ability to share knowledge and generate a regional impact, which was one of the identified benefits of this project. Chief Lloyd Chicot reflects: "Other communities are building on some of the things we're doing here. Which is good, that's what the whole purpose of this is about" (Chief Lloyd Chicot, Kakisa). While the KTFN's social relationships with researchers are important for making progress on projects in the community, these relationships also help to strengthen ties with other communities and generate regional impacts for food security and climate change related projects. The social 
assets that participants identified are relevant to this project because they help address the knowledge sharing piece of the project. Social assets also strengthen human capital by offering new training and learning opportunities (such as the Trout Lake youth trip in the summer of 2020, or the climate change adaptation workshop in Kakisa during winter 2020).

\subsubsection{Political assets}

Political assets include access to power and decision-making (Emery \& Flora, 2006). The KTFN identified several political assets throughout the interviews. For instance, the KTFN has been recognized as a Legal Entity for over 30 years. The community also has a Chief and Council that acts as a functioning, governing body. The KTFN is also part of the Dehcho First Nation - a governing body comprised of seven smaller communities, with an Executive Committee that oversees primary concerns and issues for the region (Dehcho First Nations, 2021; Margaret Leishman, personal communication, March 2021). The KTFN's Chief sits on the Executive Committee, which gives the community a voice for regional governance.

There are some challenges with the KTFN's political context. One issue is that the KTFN currently does not have formal tenure over their traditional territory (Johnston \& Spring, 2021). The Dehcho First Nation has been negotiating land claims with the federal government since 1999, which have stalled many times over disagreements on land use and resource management (Johnston \& Spring, 2021; Dehcho First Nations, 2021b). The KTFN also made efforts to classify $9600 \mathrm{~km}^{2}$ of land as a Candidate area for future protection, which has also stalled since the GNWT withdrew from the process in 2012, with no recent headway made on negotiations (see Figure 8). Candidate areas include pre- 
determined areas mapped out for future conservation planning in the NWT (GNWT, n.d.a). This significantly limits the KTFN's jurisdiction for land use, as regional and territorial permits are needed for expanding agricultural projects (Johnston \& Spring, 2021).

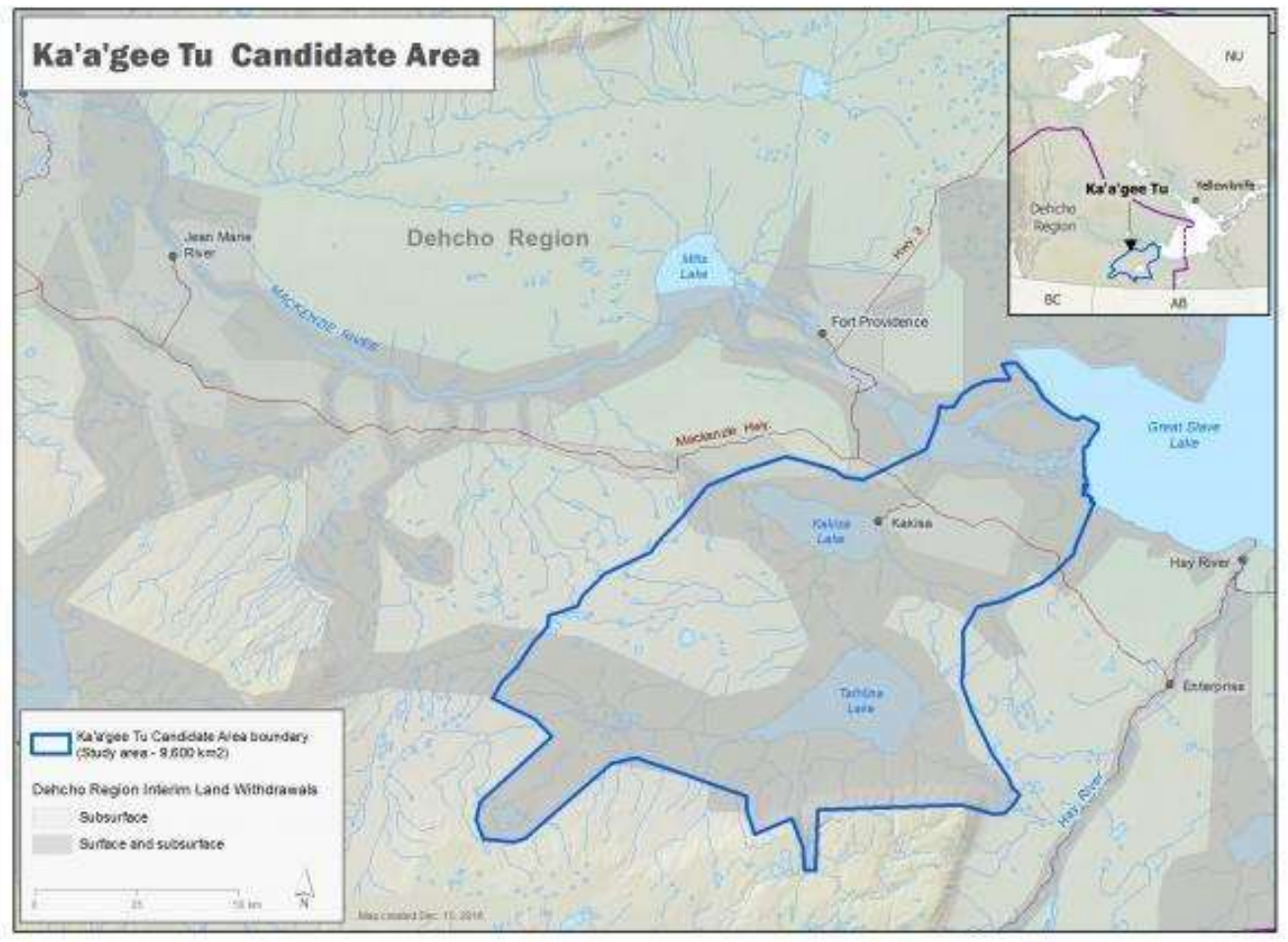

Figure 8. Map illustrating the Ka'a'gee Tu Candidate Area (contained within the blue line). The area includes the community of Kakisa, Kakisa Lake, Kakisa River, Tathlina Lake, and a vast amount of surrounding Boreal Forest area for a total of $9600 \mathrm{Km}^{2}$ (GNWT, n.d.a).

The KTFN currently strive to increase political capital through global governance strategies. For instance, international network connections including community partners from Brazil, Mexico, and Kenya help to build "international solidarity movements that can aid in local actions" (Johnston \& Spring, 2021: 12). Additionally, many of Kakisa's agriculture and waste management projects have gained recognition on the regional level, and other communities increasingly express interest for implementing and supporting these 
types of initiatives. As Chief Lloyd Chicot explains, "All of the ideas we come up with here, we talk about it at meetings, so people are picking up on that...I had a chance over the last two years to talk at the municipal meetings...Now they're starting to include the Chiefs from the communities into the meetings." The projects' collaborative nature and increasing recognition highlights that, despite challenges and barriers, the KTFN have actively sought to increase their political assets through knowledge sharing on the international stage and by gaining local and regional recognition in the NWT.

Strengthening these political assets would have a few implications - either directly or indirectly - for the fish composting project. First, securing land ownership and tenure over the KTFN's traditional territory would ease the community's ability to expand composting and agriculture initiatives by minimizing the bureaucratic processes for project approval and permits. Second, increasing awareness and promoting regional and international initiatives and knowledge sharing might increase the community's chances for accessing funding to support these projects and potential wages for employment opportunities. The latter point would work to strengthen the KTFN's economic, social, and human assets through network building, wage subsidies, and knowledge dissemination.

\subsubsection{Human assets}

Human assets include individuals and their labour, knowledge, health, and skills (Emery $\&$ Flora, 2006; Serrat, 2017). Of the various types of assets outlined, human assets are the most interconnected with other capitals. For instance, there are several people in Kakisa who spend significant amounts of time on the land where they gather resources and have an intimate understanding of local ecological systems, and who participates in social 
gatherings and food sharing - which utilizes natural capital and enhances social, cultural, and economic assets (i.e. economies of sharing, commercial fishing). There are Elders and knowledge holders who teach cultural practices and tell stories - which are deeply intertwined with natural, cultural, and social assets. Many Kakisa residents also work at the Band Office, which helps keep the community operating - meeting needs and enhancing economic, political, and social assets.

Human assets will be one of the most crucial for ensuring the fish composting project runs successfully - yet human assets, or general capacity, are probably one of the most lacking capitals in the community (Spring et al., 2018; Johnston \& Spring, 2021). Many people of working age are already employed, either for the Band Office or in other communities. Despite these challenges, youth are likely the most promising for filling these gaps. As previously discussed, summer work programs, and even project grants help employ youth to carry out community researcher positions and other jobs the Band Office delegates to them. There are several youths who have recently graduated high school, or will be graduating soon, who have not left the community. In the summer of 2020, I worked with several students to make progress on the greenhouse construction. This was challenging because the mentoring took place remotely due to COVID-19. Nonetheless, the students proved to be extremely valuable in advancing these projects and keeping momentum going, despite limitations from the pandemic. In the future, if proper mentorship and guidance were available, youth workers could be instrumental in ensuring the fish composting collection, maintenance, monitoring, and transportation runs smoothly. 


\subsection{Challenges and barriers}

As many participants noted throughout our interviews, there are a number of challenges intertwined with the community's strengths. While the SLA may call for researchers to focus on the positives, the negatives are also a part of the KTFN's story and must be acknowledged. Some challenges have been discussed in the preceding section. In this section, I briefly summarize various challenges associated with each type of asset (see Table 3). Recommendations for strengthening assets, and practical recommendations for action are addressed in the following section. Some of the challenges illustrated in Table 2 include material challenges, such as the lack of animal protection for the composting site and lack of materials. While these assets could easily be acquired, the main challenge is securing funding. The NAF project grant is likely a viable source of funding for these supplies and generating a budget should be a priority going forward.

As previously stated, many of the challenges and barriers to implementing this project relate to lack of human capacity. While the youth offer a promising solution to some of these challenges, ensuring they receive adequate training and mentorship needs to be considered moving forward. The short-term nature of youth employment could also be a concern, as many students might choose to leave the community for higher education or other forms of employment - which means the turn-over rate for this position that requires training and education on composting could be high. In the long-term, it would be ideal to have one full-time employee to manage and oversee compost and other agriculture related operations. Additionally, the administrative aspects of organizing workers and tasks has fallen heavily on the university students from outside the community, which conflicts with the community's goals for self-sufficiency. 
Table 3. Kakisa's Identified Outstanding Needs \& Challenges. Chart illustrating various challenges associated with each type of community asset.

\begin{tabular}{|c|c|}
\hline Challenges & Description \\
\hline Infrastructure & $\begin{array}{l}\text { - } \quad \text { Lack of protection from animal activity } \\
\text { - } \quad \text { Lack of animal-safe collection bins }\end{array}$ \\
\hline Cultural & $\begin{array}{l}\text { - Limited time for some people to take part in traditional activities (Spring } \\
\text { et al., 2018); limited time to participate in on-going community } \\
\text { agriculture initiatives (participant observation \& personal } \\
\text { communications, 2019-2021). } \\
\text { - Loss of traditional language for knowledge transfer (Spring et al., 2018; } \\
\text { personal communication, 2021) } \\
\text { - Generational disconnect between youth and Elders - youth engagement } \\
\text { could be strengthened (Spring et al., 2018; personal communications, } \\
\text { 2021). }\end{array}$ \\
\hline Natural & $\begin{array}{l}\text { - Ecological changes \& impacts of climate change - unpredictable } \\
\text { flooding, temperature fluctuation \& precipitation } \\
\text { - Concerns over external land use \& development (Spring et al., 2018) }\end{array}$ \\
\hline Economic & $\begin{array}{ll}\text { - } & \text { Lack of employment opportunities } \\
\text { - } & \text { Higher costs of supplies and/or limited access to locally sourced supplies }\end{array}$ \\
\hline Social & $\begin{array}{l}\text { - } \text { People tend to leave for education \& employment (Spring et al., 2018) } \\
\text { - Generational disconnect between youth and Elders }\end{array}$ \\
\hline Political & $\begin{array}{l}\text { - Limited decision making for land use and resource management (Spring } \\
\text { et al., 2018; Johnston \& Spring, 2021) } \\
\text { - Stalled protected area initiative (Johnston \& Spring, 2021) }\end{array}$ \\
\hline Human & $\begin{array}{l}\text { - Small population (up to } 50 \text { people) } \\
\text { - } \quad \text { Lack of experienced people to perform jobs required } \\
\text { - } \quad \text { Band Office staff have a heavy workload - limited time to engage with } \\
\text { projects } \\
\text { - Human health issues \& harvester safety risks - } 3 \text { Elders were lost between } \\
\text { November } 2019 \text { and October } 2020 \text { (non-COVID-19 related) }\end{array}$ \\
\hline
\end{tabular}

Ultimately, these barriers stem from an overall lack of human capacity due to small population size. While I can recommend practical solutions for strengthening assets and proceeding with project design, addressing capacity-related issues in greater detail is beyond the scope of this thesis. It is imperative that future research seeks to address capacity-related challenges in Kakisa to ensure long-term viability of composting, waste management, or agricultural related projects in the community. 


\subsection{Recommendations}

I have organized my recommendations with three categories to help guide project advancement. First, I have generated a list of practical recommendations, which include steps that can feasibly be taken in the near future to develop infrastructure, collection programs, and training (see Table 4). The recommendations outlined below are my own, based on my experience working with the community and based on the information they provided through the interviews, focus group, and personal conversations. Due to COVID19, and various other pressing community engagements, it was not feasible to collaborate in the production of recommendations. Community members will be given an opportunity to review the recommendations. The KTFN is not obligated to follow the recommendations outlined below, and steps will be taken moving forward with project planning to ensure increased collaboration.

Generating a project budget for fish composting costs for both the composting site and collection points should be the first step taken for moving forward with this project. The budget would include costs for designing and making signage to indicate collection points, as well as bear-safe collection bins for the fish waste. It will also be important to purchase a solar-powered electric bear fence to mitigate animal activity at the composting site to ensure worker safety. For construction and compost collection, we should also estimate the amount of labour costs necessary to complete the tasks and estimate fuel costs for either bi-weekly or tri-weekly collection. The budget should differentiate between onetime costs and on-going costs for the project. After a budget is created, necessary steps should be taken to purchase the supplies and implement them in the community. 
Determining where funding will come from (there are various grants and funding pools to choose from) should also be a part of this process.

Table 4. Results: Recommendations. Chart illustrating recommendations for practically moving forward with fish composting, strengthening assets, and building long-term capacity for agriculture and waste management projects.

\begin{tabular}{|c|c|}
\hline Recommendations: & Description: \\
\hline Practical & $\begin{array}{l}\text { - Generate a project budget - costs for: } \\
\circ \text { Signage } \\
\circ \text { Collection bins } \\
\circ \text { Electric bear fences } \\
\circ \text { Labour } \\
\circ \text { Estimated fuel costs for bi- or tri-weekly collection } \\
\text { - Create a project timeline: } \\
\quad \text { Scheduling for outstanding construction/infrastructure } \\
\quad \text { development } \\
\quad \text { Create a collection schedule (recommended bi- or tri- } \\
\quad \text { weekly collection to mitigate odour) } \\
\text { - Create a job description for composting collection \& } \\
\text { maintenance person } \\
\text { Arrange for training \& education opportunities (Either with } \\
\text { NFTI, or a university student could work with NAF partners } \\
\text { like Ecology North to design a training program } \\
\quad \text { Work with Elders to ensure training applies cultural } \\
\text { knowledge } \\
\text { Determine how and where funding will be obtained for } \\
\text { materials \& wages }\end{array}$ \\
\hline Asset Strengthening & $\begin{array}{l}\text { - Engage with Sambaa K'e youth to strengthen social assets and } \\
\text { human capacity } \\
\text { - Continue raising regional and global awareness of local } \\
\text { agriculture and waste management initiatives - create a } \\
\text { communications plan } \\
\text { - Facilitate community engagement strategies to improve } \\
\text { community wide participation and involvement }\end{array}$ \\
\hline $\begin{array}{l}\text { Future } \\
\text { Considerations }\end{array}$ & $\begin{array}{l}\text { - Improve organizational development and NAF project } \\
\text { oversight - clearly define leadership roles } \\
\text { - Establish a clearly defined local governance model for } \\
\text { managing community projects and defining research } \\
\text { trajectories }\end{array}$ \\
\hline
\end{tabular}

The next practical step will be creating a project timeline. A timeline will be necessary for scheduling outstanding construction and infrastructure development. The project timeline can also include on-going collection, maintenance, monitoring, and reporting for the employee overseeing fish composting in Kakisa. Since this project is a 
pilot project, determining a necessary trial period (perhaps 2-3 years) and identifying goals for that timeframe will be important for reflecting on what works well and possible changes that need to be made.

Creating a job description for the fish composting position will also be necessary for hiring and determining responsibilities. Once a job description is created, we will have a better understanding of the training and education necessary for doing the jobs required. Arrangements for training should be made before someone is hired for the position. Depending on how the community chooses to access training (i.e. through NFTI or create their own training with collaboration from NAF partners like Ecology North), will determine the amount of work necessary for generating training programs. If the community opts to pay for training through NFTI, this would reduce the amount of time necessary for designing training programs. Accessing training through NFTI would also ensure the fish composting employee receives a tested and well-structured curriculum. However, NFTI does not provide training in community settings - community members must travel there to receive training, and the training opportunities are more standardized. This might be a barrier if the community would rather gear compost training specifically to their community context. Thus, determining how the KTFN wishes to approach compost training is an important practical step to consider.

The second recommendations category includes asset strengthening - these recommendations still have practical elements to them; however, they are geared specifically to strengthening overall capacity as opposed to taking practical steps for advancing the project. One practical way to strengthen social and human capital in Kakisa is to engage with Sambaa K'e youth through programs like Youth-Swaps. A Youth-Swap 
program would allow Sambaa K'e youth to work in Kakisa on various projects - sharing knowledge on things like greenhouse maintenance that they already know how to do and gaining new knowledge to take back to their own communities on things like fish composting. The same would go for Kakisa youth visiting Sambaa K'e. Implementing a Youth-Swap program would be beneficial for strengthening community relationships, engaging youth, knowledge sharing, experiential learning, and increasing human capacity. Since Kakisa is a small town of roughly 40 to 50 people, it is likely they will need to outsource labour in the future if they continue to expand their projects.

I also recommend that the KTFN create a communications plan for raising regional awareness about local management and waste management initiatives. This could be done in collaboration with some of the NAF institutional partners. By raising awareness, the KTFN will increase their chances of making a long-term impact on regional policy (Johnston \& Spring, 2021), which could lead to more funding opportunities, partnerships, and support in the long-term. It is also important to consider local community engagement in the communications plan. Strategies for involving community members, Elders, and youth is important for increasing and maintaining local momentum and pride on the projects. Some approaches might include creating volunteer positions - where local high school students could obtain their necessary volunteer hours. Involving elementary school students in some of the work might also increase parental interest in the projects.

The final recommendations category includes future considerations. Future considerations address ways to strengthen the fish composting project, and other agriculture or waste management projects in Kakisa, in the long-term. Ultimately, a lack of human capacity is among one of the most significant barriers to project development in 
Kakisa. Ensuring the success of these projects will mean strengthening capacity in the community. Capacity refers to the community's ability to determine courses of action for identified goals and initiatives, or the community's ability to put plans into practice (Chaskin, 2001). Some ways to build capacity in Kakisa includes improving organizational development for NAF project oversight, creating clearly defined leadership roles, and establishing a local governance model for managing community projects and defining research trajectories.

As Chaskin (2001) explains, focusing on organizational development such as leadership and project oversight can help improve a community's access to job training, funding, and resources. Similarly, Schmidt et al. (2012) advocates for building up organization and governance to increase capacity through the use of established leadership and collaboration with other agencies or communities. Strengthening capacity through leadership and organization will help ensure long-term sustainability for these projects (Schmidt et al., 2012). There are a number of ways the KTFN could approach this idea of increasing project leadership, organization, and oversight. First, they could use some of the project's funding to hire someone with the specific skills to design a program (Schmidt et al., 2012). The KTFN's partnership with universities could also be beneficial, as the task of structuring a governance or leadership model for the projects could be delegated to a graduate research assistant. However, the small population in Kakisa still leaves uncertainty with who might be responsible for filling these leadership roles and taking on these administrative/organizational responsibilities. It might be worthwhile for the KTFN to outsource this position to people in other communities who might have the appropriate experience and skill set required for these roles. 


\subsection{Conclusion}

The KTFN has a wide range of assets that could be applied to the fish composting project. Physical assets can be applied to collection and infrastructure development for the project. Cultural assets are significant because they establish values and culturally appropriate guidelines for undertaking this project, which is a key motivating factor. The KTFN also has significant access to funding opportunities for these projects, and well-established social networks with a wide range of community, institutional, and governmental partners. In the short-term, these assets will be important to put the practical recommendations discussed in the previous section into practice. However, political assets could be strengthened to ensure better access to funding, and human assets could be strengthened through outsourcing labour and by implementing student Youth-Swap programs, to ensure long-term stability for the project. Future considerations for long-term success should target capacity building strategies such as increasing leadership for project organization and oversight. The next chapter reflects on the application of the SLA and political ecology throughout this project. 


\section{Chapter 6: Learning from Experience - SLA and Political Ecology Reflections}

In this chapter, I take a reflexive approach on my experience with using the SLA and political ecology as a combined framework. I reflect on the positive aspects of the framework - what worked well generally, specific strengths of each framework individually, and how the frameworks complemented one another when applied together. I also reflect on the challenges I encountered with each individual framework, and the resulting tensions these generated throughout my analyses. I then reflect on different approaches I might have taken and offer recommendations for future work using the SLA and political ecology. Ultimately, I argue for two major benefits of using the combined frameworks of SLA and political ecology together. First, the SLA's emphasis on practice and political ecology's theoretical emphasis on meaning, effectively bridges the gap between community-driven action and academic research, because it allows the researcher to generate both practical and meaningful recommendations for achieving sustainable livelihoods projects. Second, the combined framework creates a mutually beneficial relationship between the SLA and political ecology, as their differences help to overcome stand-alone critiques of their individual application and theoretical abilities. Future application of the combined framework must attend to Indigenous methods and decolonizing methodologies (Tuhiwai-Smith, 2012; Louis, 2007) to further strengthen both practical and theoretical application in northern Indigenous contexts. 


\subsection{Framework strengths and limitations}

In this section, I reflect on the strengths and weaknesses of conducting the SLA and political ecological analysis individually and on their overall impact as a combined framework. I explain what worked well about each framework as well as the challenges I encountered. I also reflect on tensions between the two frameworks including language and framing and their substantial differences to approaching theory and practice.

\subsubsection{SLA: Strengths and limitations}

The SLA's descriptive framework for cataloguing assets instrumentally identified the KTFN's overall strengths and helped determine how these strengths could be applied to the fish composting project. Organizing assets in this way allowed for visualization of the resources available in the community, which informed the practical recommendations. Despite the utility of this framework, I commonly encountered challenges with both the language and framing - specifically with using assets and capitals to categorize community strengths - throughout the research process. The language of "capital" tends to reduce assets to mere "production factors" (Knutsson \& Ostwald, 2006: 1577). However, as my experience revealed, this view of assets does not fit within the KTFN's epistemological framework. Additionally, SLA projects typically ask participants to identify assets directly through interview questions or surveys (Karki, 2013; Jacobs \& Makaudze, 2012), and this type of language was relatively ineffective for generating community response in Kakisa.

For some participants, when prompted with questions about assets, they either felt uncomfortable responding or did not understand what information I needed and why. This challenge was easily overcome by using flexibility and reflexivity in the interviews, where 
I modified the language and framing for my questions. As Prowse (2010: 225) explains, "reflexive livelihoods research is able to refine the questions under study and deploy the most appropriate research tools to further investigate the questions in hand." Instead of asking participants about strengths and assets, I quickly learned that asking participants to tell a story about what they liked about Kakisa prompted more rich and meaningful discussions. Afterwards, I could check in with participants and validate my interpretation of their story, by pin-pointing various strengths they discussed and asking if they agree that those examples were assets. In hindsight, I would have framed assets differently from the beginning. While I changed my framing part way through to include questions like "what are your favourite things about Kakisa" or "what makes Kakisa a strong community," I realized afterwards that the questions could have been even more specific, and more neutral (or less biased towards positivity). I could have included questions like "what helps the community function?" or "tell me a story about daily life in Kakisa." If I had asked these questions, I might have gotten a better first-hand account on how community members conduct themselves from day to day, which would have allowed me to interpret various assets they employ on a regular basis.

Taking a reflexive approach and making space for storytelling proved an important part of conducting an SLA research project in a northern Indigenous context - since storytelling generally is a large part of Indigenous epistemologies (Wilson, 2001; Datta, 2018a; Datta, 2018b). According to Datta (2018b: 36), "traditional storytelling privileges holistic interconnectedness, collaboration, reciprocity, and humanity; more importantly, it impacts positively on practice." Ultimately, in order for a researcher to "engage competently with social actors," a researcher must be able to "display an adequate 
understanding of their lifeworld and the discourses they use" (Prowse, 2010: 227). Conveying holistic interconnectedness was a notable aspect of the storytelling I encountered throughout this process. As Chapter 4 highlights, the KTFN's practical perceived benefits, or actionable motivations for fish composting were often articulated within a wider worldview and ways of knowing that revealed various layers of deeper significance, summarized by concepts of health, traditional teachings, and self-sufficiency. These layers of significance were interpreted by analyzing the story as a whole, rather than focusing exclusively on each individual part. Taking the stories at face value in this way allowed me to reconstruct a web of interconnected goals, benefits, underlying motivations, and epistemologies - rather than simply extracting individual pieces to compose a list.

Ultimately, adding storytelling as a method added tremendous value to this project and the analyses I produced. As my experience, and others (Christiensen, 2012; Spring et al., 2018) highlight, storytelling fits well with participatory northern research in Indigenous communities. More general asset mapping literature also covers storytelling as a valid method for data collection. For instance, Fuller et al. (2002: 19) suggest that "asset storytelling reveals the positive activities of a time and place in which one or more assets are used to form a positive outcome" in community asset mapping projects. Applying storytelling as an asset mapping strategy allows the researchers to draw key elements and resources used from these stories (Fuller et al., 2002).

In line with this project, Pstross et al. (2014) also provides one example on how storytelling can emerge from community asset mapping initiatives. As the authors explain, their efforts to map assets for improving health and human services programs for strengthening education for elementary school students did not effectively capture 
community diversity with their limited resources. Applying reflexivity in their initial stages for data analysis, the team designed a catalytic storytelling methodology to address gaps in their data. Catalytic storytelling means "that for a certain amount of time, the community development researcher partakes in the story-making within a given community by asking essential questions, collecting stories about the community, and then retelling those stories and asking vision-oriented questions" (Pstross et al., 2014: 533). This methodology thus allows researchers to gain more nuanced and diverse understandings of community assets as they reflect community lived experience. The methodology also takes a more participatory approach by positioning the researcher(s) as “co-teller[s] of the community's stories" (Pstross et al., 2014: 534), which more evenly distributes relationships of power between researchers and participants. While the authors did not initially build storytelling methodologies into their project framework, taking a reflexive approach allowed the researchers to modify their approach to facilitate richer discussions on community experience, which allowed them to draw out key elements or assets based on the stories, as Fuller et al. (2002) advocates.

Jeannotte (2016) also provides an example for pairing storytelling methods with asset mapping research. The author's study focuses on cultural asset mapping initiatives in Wawa, Georgina, and Windsor, Ontario, Canada. Jeannotte (2016) states that, while cultural asset mapping frameworks can successfully map tangible cultural assets (i.e. theatres, museums, galleries, etc.), it tends to lack the necessary tools for mapping intangible cultural assets (i.e. spiritual values, cultural identity, etc.). The author argues that storytelling methods helps to address the shortcomings with cultural asset mapping tools to increase community understanding and representation of intangible cultural assets in 
sustainable development projects. Ultimately, storytelling provides one avenue for increasing participatory community engagement to more accurately map cultural assets that are felt or embodied by a particular community, rather than merely focusing on spatially fixed or physical cultural assets.

While asset mapping and storytelling often connect throughout community development literature, as exemplified above, my review of the SLA literature specifically did not reveal notable in-depth discussions on the use of storytelling as a way to enhance interviews and focus groups as methods for data collection. Based on my experience with using the SLA framework for asset mapping, I think the literature would benefit from more explicitly grappling with non-Westernized forms of knowledge transfer and collective learning. Storytelling not only offers a more culturally appropriate method for data collection in Indigenous contexts (Wilson, 2001; Datta, 2018a; Datta, 2018b), it also offers a more general approach for understanding the complexity and nuance of community lived experience (Jeannotte, 2016; Pstross et al., 2014).

The SLA's focus on the positive assets offered another strength for this framework. I found it encouraging to try and work with what the community had, rather than focusing heavily on what they did not have. While negative attributes and challenges are part of the KTFN's story, focusing on the positive assets allowed me to generate more attainable and practical recommendations. Focusing on positive assets that were categorized allowed me to break the project recommendations into more manageable goals and actionable items which translates into clearly established deliverables for future work on this project. This approach also helped to mitigate power imbalances and the imposing nature of research Indigenous communities have historically experienced. (Tuhiwai-Smith, 2012; McGregor, 
2004). Using a participatory approach to conduct the SLA can guide the action portion of the project in a way that fits within the community's means (Laeis \& Lemke, 2016), and their own ontological and epistemological frameworks. For example, gaining a better understanding of the KTFN's social assets and taking into account their leadership and participation in agriculture, climate change, and food security projects allowed me to make one of the recommendations for collaborating with NAF researchers and partners to build training programs for composting. This recommendation not only fits within the community's means by applying assets they already have access to; it also takes into consideration the KTFN's epistemological frameworks by incorporating partners who assist with community projects led by the KTFN. Since the KTFN takes on a leadership role in defining the research agendas, goals, and values for the project, NAF partners have a clear understanding of how to work within and apply these knowledge frameworks.

One challenge I experienced throughout this process was grappling with how to address community challenges or limitations. Many community members explained in our interviews that the negatives still have a place in their story - as such, it felt necessary to acknowledge and address these challenges to maintain truth and fullness in telling their story. One way I overcame this struggle, was to revisit the positive assets. This included asking questions such as "how can these strengths be applied to overcome some of these challenges?" This approach is exemplified in the "Future Considerations" heading in the Recommendations section of Chapter 5 - where the KTFN's strong social assets were applied to capacity-building considerations.

Unfortunately, SLA literature sparsely acknowledges these framework-related challenges and rarely provides practical guidance for addressing them. I do not intend for 
this observation to undermine the benefits of shifting asset mapping from needs-based approaches to positivity-focused initiatives. As Fuller et al. (2002: 6) explains, "needs approaches tend to divide people and communities" since articulating needs can become a "competitive process in many cases and often pits communities and organizations against each other." Asset mapping thus provides more inclusive spaces for communities to learn about their communities, since communities already on some level have an understanding on mobilizing or using assets based on experience (Fuller et al., 2002). However, applying participatory methodologies also requires researchers to foster inclusive spaces for knowledge production and alternative ways of knowing. As Chapter 4 explained, members of the KTFN apply holistic lenses emphasizing interconnectedness. Thus, the KTFN's challenges and needs cannot be disentangled from the positives, as some participants have clearly articulated during interviews and follow-up conversations. While some of the SLA literature advocates for reflexivity, flexibility, and a positive approach to overcoming barriers (Scoones, 1998) SLA literature frequently underrepresents methodological discussions for how researchers should approach this in application. When advocating for participatory methodologies, SLA literature could benefit from providing a more transparent reflection of how these processes play out in the field. Advocating for positivefocused asset mapping while also advocating for participatory methodologies could be contradictory if the negatives and challenges are thereby overlooked, despite a community's blatant and often intentional efforts to grapple with these subjects. 


\subsubsection{Political ecology: Strengths and limitations}

Political ecology proved a useful framework for interpreting the KTFN's underlying motivations for the fish composting project - both in a practical and discursive or intangible sense. Understanding the KTFN's motivations for the project, and the connections between perceived benefits and their worldview helped to strengthen my relationships with members of the KTFN and hold me accountable to their research agenda. Since I chose to apply a political ecological lens for my analytical frame for this project relatively early on, I was prepared to listen closely for indicators of deeper significance when the participants told their stories throughout our interviews. Applying a PAR methodology with this research project also helped to build strong relationships of trust - which relieved some of my concerns over my responsibilities for relaying the KTFN's story in a truthful, accurate manner. As Zanotti et al. (2020: 48) explain, building long-term relationships are "critical for ensuring research findings are relevant and responsive to participating communities," and on-going relationships provide increased access to feedback and collaboration as necessary. In conducting participatory, political ecological research, researchers are participants in relationships with the community - where we all strive toward mutually beneficial knowledge production (Sundberg, 2015).

Questions about a researcher's role as producers of knowledge are vaguely addressed throughout political ecological literature (Sundberg, 2015). Throughout this process, I often asked myself: "how is my understanding of the KTFN's motivations for this project useful for them?" Having to use a theoretical framework at all felt initially inappropriate as narrowly defined intellectual spaces could potentially "pigeonhole research and force it to conform to existing paradigms" (Zanotti et al., 2020: 50). Turning 
to Indigenous research methodologies, Wilson (2001: 177) suggests an alternate question: "[am I] gaining knowledge in order to fulfil my end of the research relationship?" Upon reflection, I realized that generating an understanding of the KTFN's motivations and learning how these motivations are articulated through their wider worldview and ways of knowing, was necessary for creating space for alternative forms of knowledge throughout this project. Ultimately, while political ecology advocates for emphasizing discourse, ontology, and alternative ways of knowing, my experience suggests that the connections between political ecology as a framework and participatory research as a methodology could be strengthened throughout the literature.

One challenge I encountered throughout this experience was a considerable gap in the literature on conducting political ecological analyses, especially in an Indigenous context. Much of the political ecology literature covers the framework's main principles it tells us what political ecology generally strives to accomplish or avoid, and extensively outlines political ecology’s core values (Bryant, 1998; Zimmerer \& Bassett, 2003; Biersack \& Greenberg, 2006; Perreault et al., 2015). There are also sources explaining what a more Indigenous-centred political ecology might look like. For instance, Middleton (2015) presents four guiding approaches for an Indigenous political ecology including attention to colonialism, culturally specific approaches, recognition of self-determination, and attention to decolonizing processes. However, the sources I reviewed tend to lack an explanation of how political ecology is performed in a practical sense, or how these frameworks can be applied to data and observations to uncover meaning. For instance, despite pairing various search terms like "methods for data analysis," "methods for data collection," "methodology," "methods," "analysis," etc., the sources I found rarely 
provided insight or transparency on researcher's experiences with using the frameworks to guide data collection or data analysis. The framework's main principles clearly outline what researchers should strive to accomplish (as outlined in Chapter 2), however, I did not encounter a roadmap with practical guidelines for accomplishing those goals in practice within political ecology literature. Ultimately, moving outside political ecology literature to gain insight from PAR literature or qualitative data analysis more broadly supplemented information to overcome the lack of transparency I encountered.

Turning to literature on methods for qualitative data analysis can be useful for overcoming some of transparency challenges in political ecology. When I reviewed all my notes, interview transcripts, and focus group transcripts, I knew I was looking for three sets of information based on my research questions. With the SLA, it was clear from the onset that deductive coding was the necessary approach - since asset or capital categories are provided in the SLA literature as necessary pieces of information to acquire. With political ecology, while it was clear that inductive coding was necessary to identify themes in the data, I was unsure how to decipher meaning from these themes once I identified them. Ultimately, I overcame this challenge by applying a similar approach to the "keywords-incontext" tool after I identified various themes. The keywords-in-context approach is useful for identifying connections or relationships, because it allows the researcher to identify key ideas or layers of significance connected to the theme in question (Leech \& Onwuegbuzie, 2007). For example, looking at the statements made after discussions around agriculture and building soil throughout my transcripts helped me realize that several individual participants often talked about agriculture and waste management sequentially in the same dialogues. Additionally, looking at the dialogue and statements surrounding participants' 
statements on climate change helped me link the concept of self-sufficiency with climate change adaptation. Using these tools for qualitative data analysis, ultimately, helped uncover the themes discussed in Chapter 4 .

When a researcher uses tools for qualitative data analysis in political ecology, it is also important to be reflexive when developing or interpreting meaning from the information. As introduced in Chapter 3 Srivastava \& Hopwood (2009) provide practical insight for how to accomplish reflexivity in data analysis through an iterative framework. They provide three primary questions that structure the framework to reflect on: 1) "What is the data telling me?"; 2) "What is it I want to know?"; and, 3) "What is the dialectical relationship between what the data are telling me and what I want to know?" (Srivastava \& Hopwood, 2009: 78). The third question helps to identify gaps in understanding while also linking emergent themes or ideas back to the research question. For instance, using a similar reflecting process allowed me to identify health as a major research finding that linked back to my research question on what fish composting means to the KTFN. I did not anticipate finding significance in the KTFN's perceptions of health when I started reviewing my transcripts. In the beginning, I knew I wanted to know more about traditional values and their perceived benefits, and upon revisiting the data multiple times, I noticed that health was often linked to both concepts.

I also want to acknowledge how important the PAR methodology proved for validating these meanings I uncovered. Since I built strong relationships with the community, I felt comfortable reaching out to various participants to validate my findings and gain additional insight into how to frame and articulate these ideas almost instantly in follow-up calls or texts. Some participants would even text me after our interviews with 
additional information they thought of after the fact, which helped to enrich my understanding and pinpoint themes or ideas the participants thought of as important to include in my analysis and writing.

Ultimately, these reflections on the practical process of analyzing data and working with participants help to shed light on how to identify meaning when applying a political ecological lens. Qualitative research studies tend to be vague when it comes to explaining how they carry out their analyses (Boeiji, 2002) - and political ecology is no exception. Future work in political ecology needs to be more transparent about data analysis tools and how to approach participatory research, to hold researchers more accountable to how they interpret meaning and produce knowledge - especially in Indigenous contexts where researcher accountability and prioritizing community needs and knowledge within research has not been the case historically (Tuhiwai-Smith, 2012; Larsen \& Johnson, 2012; Castleden et al., 2012).

\subsubsection{Combined framework: Strengths}

Integrating the SLA within a wider lens of political ecology offered a strategic framework for addressing practical community needs while simultaneously satisfying more academic theoretical requirements. The SLA by itself is descriptive, rather than fully analytical, as it "lacks the means to analyze process" (Knutsson \& Ostwald, 2006: 1576) because it is not linked to any particular theory (Small, 2011). As Small (2011) explains, the SLA should be integrated with other more conceptual approaches for academic research - while the SLA is good at defining actions and changes that need to occur in each context, it is not well equipped for understanding underlying motivations, agency, and choices related to 
livelihood conduct. Political ecology's emphasis on discourse and meaning provided a strong framework for addressing these shortcomings with the SLA.

Understanding the meaning and significance behind the KTFN's motivations for the fish composting project allowed me to gain a fuller picture of the identified assets and how they might be applied. At the onset, some assets were difficult to place in a fish composting context. However, reflecting on the multiple, interconnected layers of practical benefits and deeper significance offered a framework for visualizing assets and the KTFN's worldview and ways of knowing in relation to one another. For example, strictly from a capitals standpoint, cultural assets including traditional teachings and traditional foods seemed practically disconnected from fish composting. However, when I revisited the KTFN's stories, they revealed that the significance of fish as a traditional food meant that the KTFN already had well-established values for how to properly dispose of fish waste which involved disposing of the waste in a specific spot to provide nutrients for the land. While fish composting itself is not a traditional practice, these stories shared by participants revealed that similar principles - primarily returning fish waste to a designated spot and understanding fish waste's nutritional value for soil - already exist within the KTFN's worldview and knowledge framework. This enriched perspective of cultural assets in the context of fish waste helped expand my understanding of how these assets might be applied in practice.

\subsubsection{Reconciling tensions}

Two clear tensions between the SLA and political ecology emerged throughout this process. First, the SLA's "capitals" or "asset" based framing of resources, relationships, 
the land, and people conflicts with political ecology's framing of the environment as an active agent. The SLA's tendency to reduce aspects of community life to capitals is problematic from a political ecological perspective, because the complexities and nuance of both human and environmental agency play a critical role in establishing community approaches to climate change adaptation and sustainability (Goldman et al., 2018). However, just because the language between the two frameworks are initially at odds, it does not mean this language has to be used or framed in this way. For instance, the SLA could expand its definition of assets or capitals to emphasize the complexity of livelihoods as Spring et al., (2018) demonstrates. Assets could be framed more broadly as characteristics or attributes of a community (rather than just resources) that interact with one another (Fuller et al., 2002).

Second, both the SLA and political ecology represent two opposing sides of the spectrum when it comes to practice and theory. On the one hand, some scholars critique the SLA for being instrumental and overly descriptive (Morse \& McNamara, 2013; Knutsson \& Ostwald, 2006). On the other hand, others critique political ecology for being too theoretical or overly confined to academic spaces, where questions about application and practice lack transparency and practicality (Sundberg, 2015; Walker, 2006; Walker, 2007). As a result, SLA analyses can leave a researcher with questions like "we have this information, but what does it mean?" whereas political ecological analysis can leave questions like "we know what this information means, but how is it useful?" My experience using these frameworks and asking these types of questions is why I argue that the SLA and political ecology are complementary, despite these differences. Each framework offers something the other one lacks. 
For a community-driven, participatory project, combining the SLA and political ecology can work towards bridging the gaps between academia and community practice. Often, tensions arise in community-based research because communities want to see research translated into action on-the-ground, while researchers often feel institutional pressures to fulfil more theoretical academic requirements. I was frequently conscious, and even anxious about this tension between community practice and academia, especially in the beginning stages of conducting my research. It was difficult to reconcile theory with the KTFN's lived experience. Taking these tensions into consideration helped me arrive at the combined framework I used for this project. While the SLA by itself may not provide a framework for theorizing community livelihoods, it offers a useful framework for identifying practical, actionable paths forward in community development. On the other side, political ecology by itself is not well-equipped to satisfy community-identified needs, because it takes a theory-focused approach and lacks a framework for translating theory into practice. When I applied these two frameworks together, it helped me bridge the gap between community practice and theory. Given these experiences, the combined political ecology and SLA framework provides a strong foundation for addressing tensions between academia and community-driven research.

However, from a northern Indigenous perspective, I think the framework would benefit from additional insight from Indigenous methodologies - especially when it comes to naming concepts and understanding fundamental differences in epistemology, which I struggled with in my analysis. For instance, Louis (2007: 133) explains how Indigenous methodologies advocate for "alternative ways of thinking about the research process," where holistic thinking forms the basis for inquiry by emphasizing "circular and cyclical 
perspectives." Indigenous methodologies also advocate for participatory research design, co-learning, and relationship building. While this project applied the latter points through the application of PAR, holistic thinking could have been applied more consistently and prominently throughout my research design - especially with my interview and focus group questions, which tended to restrict discussion towards what I thought I needed to know. Things I did not know I needed to know might not have been considered or discussed during interviews and focus groups as a result, which may have limited the scope of the data. In other words, thinking holistically in research design can prevent reducing data to the limiting factor of what researchers think they need to know.

Tuhiwai-Smith (2012) also provides insight on Indigenous research methodologies through her detailed discussion of the Indigenous research agenda. Throughout Decolonizing Methodologies, Tuhiwai-Smith explains how community-driven research projects led by Indigenous peoples themselves offer one avenue for realizing an Indigenous research agenda. From this perspective, research must be driven by Indigenous communities' needs; their worldviews, ways of knowing, and rights to self-determination must be prioritized. Since the fish composting project directly responds to the KTFN's identified research priorities, and applies a participatory approach, this project at its core fits within Tuhiwai-Smith's definition of an Indigenous research agenda. However, the framework used to collect and analyze the data should be further refined to better align with this agenda.

Figure 9 shows Tuhiwai-Smith's visual representation of an Indigenous research agenda. It represents four directions and four tides, which are symbolic to pacific Indigenous peoples (Tuhiwai-Smith, 2012). As Tuhiwai-Smith (2012: 120) explains, the 
four directions (healing, decolonization, transformation, and mobilization) "represent process." She explains that the four directions as processes means they are not "goals or ends in themselves," rather, they are interconnected processes that reveal and influence tensions between various scales (regional, local, global). The four tides (survival, recovery, development, and self-determination) are dynamic and complex "states of being" or lived experiences of Indigenous peoples (Tuhiwai-Smith, 2012: 121).

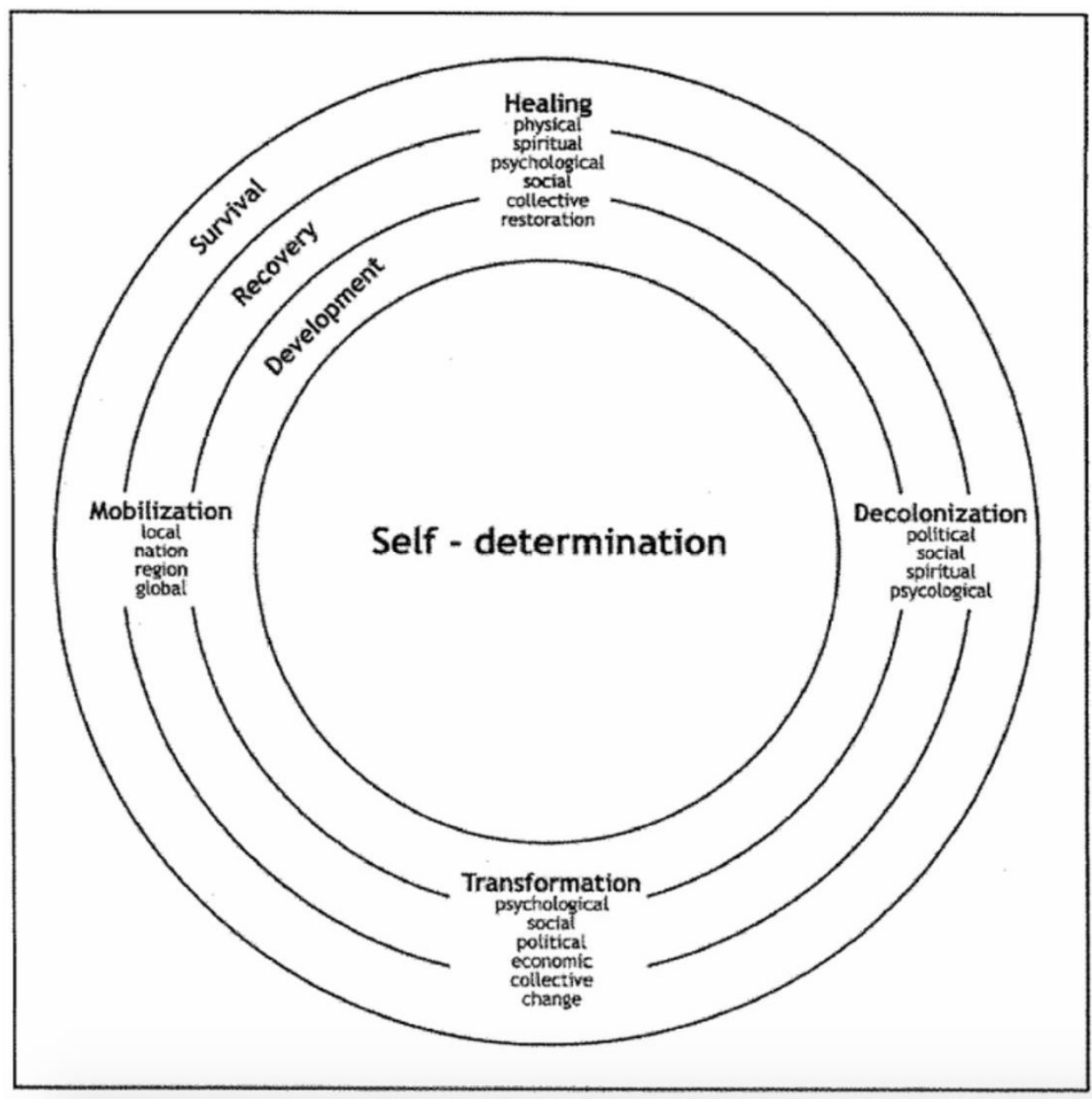

Figure 9. Linda Tuhiwai-Smith's Representation of an Indigenous Research Agenda. The four directions represent "process", while the four "tides" represent "states of being." The visual highlights the dynamic relationships between the four tides and the four directions. (Originally Figure 6.1, Chapter 6: Indigenous Peoples Project in Decolonizing Methodologies (Second Edition). (Tuhiwai-Smith, 2012: 121). 
Despite this project's alignment with Indigenous led research, the combined framework would benefit from making space for understanding various research trajectories as processes rather than merely as goals. Goal-oriented language was very prevalent throughout this thesis, especially throughout my research questions. While I think the goals-oriented approach was beneficial to the extent that it informed the action piece of the project, making space for understanding various processes that impact livelihoods may have further aligned this project with an Indigenous research agenda. Exploring the relationships between processes and states of being would have promoted a more fluid, dynamic, and holistic representation of the KTFN's story.

\subsection{Summary: SLA and political ecology in a northern Indigenous context}

Overall, the combined framework of the SLA and political ecology paired with a PAR methodology allowed me to adequately address the research questions and objectives outlined in this project. Applying qualitative data analysis with a political ecological lens was useful for identifying the KTFN's perceived benefits of fish composting, and for determining what fish composting means for the community (research question 1). Cataloguing the KTFN's assets coupled with my political ecological analysis allowed me to generate practical recommendations for future action on the fish composting pilot project in Kakisa (research question 2). Reflecting on my experience using this combined framework also helped me generate the theoretical contributions outlined in this Chapter (research question 3). A breakdown of my approach for utilizing the combined framework is summarized in Table 5 . 
Table 5. Summary of SLA and political ecological applications at each stage of the research process in a combined framework.

\begin{tabular}{|c|c|}
\hline Aspect of Research: & Description: \\
\hline Methodology: & $\begin{aligned} \text { - } & \text { PAR or other participatory approaches } \\
\circ & \text { Build strong relationships } \\
\circ & \text { Ensure knowledge production is mutually beneficial }\end{aligned}$ \\
\hline Methods: & $\begin{array}{l}\text { - Strive to include methods that fit within an Indigenous worldview } \\
\circ \text { Storytelling } \\
\circ \text { Informal data validation sessions } \\
\text { - Interview questions: } \\
\circ \text { SLA/Asset related - reframe language to be more neutral } \\
\text { and less resource-focused (i.e. "what is daily life like?" } \\
\text { "what helps the community function?) } \\
\circ \quad \text { Political Ecology - create space for alternative ways of } \\
\text { knowing - allow participants to speak in their own terms }\end{array}$ \\
\hline Data Analysis: & $\begin{array}{l}\text { - SLA } \\
\circ \text { Deductive coding - asset categories } \\
\circ \text { Make space for investigating outstanding needs - use } \\
\text { positive assets to generate recommendations for } \\
\text { strengthening negatives } \\
\text { - Political ecology } \\
\circ \quad \begin{array}{l}\text { Inductive coding - use reflexive, iterative framework for } \\
\text { interpreting meaning }\end{array} \\
\end{array}$ \\
\hline $\begin{array}{l}\text { Communicating } \\
\text { Findings }\end{array}$ & $\begin{array}{l}\text { - SLA } \\
\circ \text { Acknowledge relationships between assets } \\
\circ \text { Acknowledge agency, complexity, choice } \\
\circ \text { Uncover deeper meanings from political ecological } \\
\text { analysis to generate practical recommendations } \\
\text { - Political ecology } \\
\circ \quad \text { Explain how data was interpreted - be transparent about } \\
\text { analysis process } \\
\circ \quad \text { Ensure knowledge production is applicable and useful } \\
\text { for the community } \\
\circ \text { Use meaning to inform practical recommendations }\end{array}$ \\
\hline
\end{tabular}

Using a PAR methodology built strong relationships and ensured that knowledge production was mutually beneficial - which helped me overcome some of the tensions between community-identified needs and academic requirements. Future research using a combined SLA and political ecology framework should strive to incorporate methods that fit within an Indigenous worldview such as storytelling. Interview questions should strive for more neutral language framing (or less positive/negative biases to minimize binary 
thinking) and avoid the use of resource-based or instrumental language - especially for asset mapping. Data analysis for a combined framework will require both inductive and deductive coding tools to successfully identify community assets and interpret layers of deeper meaning and significance. Finally, to communicate findings for the SLA portion of the framework, researchers should be attentive to relationships between assets and apply the deeper meanings uncovered from political ecological analysis to generate meaningful recommendations for improving sustainable livelihoods. For the political ecology portion of the framework, researchers should be transparent about the analytical process and ensure that meaning making is useful for community partners by applying it to asset analyses.

Ultimately, as this project illustrates, using elements from the SLA and political ecology for a combined theoretical framework can address gaps between academic research and community practice. The SLA can also help address critiques of political ecology as an abstract, overly theoretical concept with unclear application, while political ecology helps to strengthen the theoretical application of the SLA. In other words, the combined framework creates a mutually beneficial relationship between the SLA and political ecology, as their differences help to overcome some of their individual shortcomings. In the future, practitioners of this combined framework must attend to Indigenous methods and decolonizing methodologies to increase applicability in a northern Indigenous context. 


\section{Chapter 7: Conclusion}

This thesis investigated the KTFN's community-driven approach to addressing the disproportionate impacts of climate change, food insecurity, and inadequate waste management practices in the NWT. Using a PAR methodology, I combined the SLA and political ecology frameworks to gain insight into community assets and the deeper layers of meaning that inform the fish composting project in the community. As this project demonstrates, integrating composting with agricultural expansion in Kakisa can simultaneously improve waste management and agricultural productivity in the NWT. Throughout this thesis, I supported three primary arguments.

First, Chapter 4 took a political ecological approach to understanding what the fish composting project means to the community - both in a practical and symbolic/discursive sense. I argued that the KFTN's core cultural values (including taking care of the land, promoting human and ecological health, affirming self-sufficiency and self-determination, and applying traditional teachings to their livelihoods) inform their goals to expand local agriculture and improve waste management practices. The analysis reveals that the KTFN recognizes various practical benefits for the fish composting project including strengthening soil to grow food, improving waste management capacity, creating employment, taking a proactive approach to climate change adaptation, and sharing knowledge with other communities. However, the analysis also indicates that various inseparable layers of deeper significance - including health and caring for the land, selfsufficiency, and traditional knowledge - form holistic relationships with the practical perceived benefits. The KTFN articulates these layers of significance through their worldviews and ways of knowing. Understanding these layers of significance informed 
this project's application of the SLA and recommendations for implementing fish composting in Kakisa.

Chapter 5 employed the SLA to catalogue community assets in Kakisa. The chapter described the KTFN's identified assets and challenges, then, applied the assets and the deeper meanings uncovered in Chapter 4 to generate three sets of recommendations (practical, asset strengthening, and future considerations). Practical recommendations included generating a project budget, creating a project timeline, creating a job description for the fish composting position, creating training programs, and securing funding. Recommendations for strengthening assets included engaging with youth in other communities, creating a communications plan for raising regional and global awareness, and facilitating community engagement strategies - all of which primarily focused on strengthening social and human capital. Recommendations for future considerations included improving organization and NAF project oversight and establishing clearly defined local governance models for managing community projects - which emphasized capacity building strategies and long-term management goals. I argued that while practical steps need to be taken to implement this project, addressing capacity-related issues is also necessary for ensuring the long-term sustainability of the fish composting project, and other agriculture/waste management projects more generally.

Finally, Chapter 6 presented my reflections on applying the SLA and political ecology as a combined framework in a northern Indigenous context. Throughout the chapter, I explained various strengths and weaknesses associated with each framework. Then, I reflected on existing tensions between the two frameworks. First, the SLA's language of "assets" or "capitals" clashed with political ecology's framing of the 
environment as active agents, and with the KTFN's holistic understanding of relationships between land, people, and health. I suggested that this tension could be overcome by framing assets more broadly as community characteristics and attributes that interact and exist in relationships with one another, as opposed to merely framing assets as resources. Second, the SLA produces overly descriptive results, while political ecology tends to produce overly theoretical analyses. However, these differences benefitted the combined framework, helping to bridge the gap between community practice and academic theory. In other words, these differences worked to strengthen the two frameworks in application. Ultimately, I argued that while the SLA and political ecology have complementary characteristics when applied as a combined framework, future application needs to be more attentive to Indigenous methodologies to fit more appropriately in a northern Indigenous context.

The arguments supported in this thesis make varied contributions for the KTFN's community-driven research, other northern communities, and SLA and political ecology literature. First, this project contributes to the NAF project's goal for generating bestpractice guidelines for conducting agriculture in the NWT. While fish composting does not directly address practices for growing food, it does provide insight on generating healthy, productive soil using materials already found within the community. Composting also offers opportunities for sequestering carbon, and reducing greenhouse gas emissions from landfills, which addresses climate change mitigation goals in the NAF project. Implementing a composting project simultaneously addresses other community concerns with waste management capacity, and helps the community strive towards a more sustainable waste management model by using waste for production. The knowledge 
sharing aspect of the NAF means that other communities in the North will be given opportunities to learn from Kakisa's fish composting pilot project and implement similar composting projects. Understanding community needs, goals, and values can also guide scientific research on northern agriculture to be more attentive of the cultural context research is conducted in, which can allow scientific research to more directly address community and environmental wellbeing.

This project made various practical recommendations for the KTFN that can have wider-ranging contributions for the community. Some of these contributions are not only applicable to a fish composting context, as many could also be applied to strengthen other on-going projects such as community greenhouse operation, fire-break farming, and the Ka'a'gee $\mathrm{Tu}$ Food Forest. As this project highlights, attentiveness toward the administrative aspects of community-driven projects compares in importance and necessity to infrastructure development. Addressing capacity-related challenges in the future will mean strengthening human and social assets for expanding networks and administrative capabilities. Project oversight and leadership will be necessary for the fish composting project to succeed, and the model used to structure this leadership could easily be applied to other projects. Additionally, many of the perceived practical benefits outlined in Chapter 4 also influence practical contributions in the community. If the project continues this trajectory, the KTFN will increase soil productivity, reduce agriculture-related impacts on climate change, and divert organic waste from landfills if composting is scaled up to include kitchen waste. The community will also create jobs for fish composting maintenance and project administration. 
Finally, this project adds to the small body of literature on using a combined SLA and political ecology framework in participatory action research and community-based research. This project advocates for the use of this combined framework to overcome disconnects between community action and academic research. This project also provides insight into how to strengthen the framework in a northern Indigenous context. More specifically, I outline various ways to modify language and methods in the SLA framework to be more inclusive of non-western ontologies and epistemologies. I also provide specific insight into how to conduct data analysis for the two frameworks, which is notably lacking in political ecology and SLA literature.

While Indigenous communities in the NWT are disproportionately impacted by climate change, inadequate waste management capacity, and food insecurity, the KTFN serves as an example of how communities can take a leading role in overcoming these challenges. The KTFN's goals for improving agricultural capacity while simultaneously addressing waste management concerns through composting could have wide-ranging regional impacts for improving community wellbeing by increasing access to fresh, locally produced food and by decreasing organic waste in landfills as knowledge is shared with NAF partners. The KTFN's leadership in northern agriculture and climate change research exemplifies strength, determination, and resilience for overcoming challenges and striving to foster a stable and healthy environment for future generations. 


\section{References}

Adhikari, B., Trémier, A., Martinez, J., \& Barrington, S. (2010). Home and community composting for on-site treatment of urban organic waste: perspectives for Europe and Canada. Waste Management \& Research, 28(11), 1039-1053.

Andrachuk, M., \& Smit, B. (2012). Community-based vulnerability assessment of Tuktoyaktuk, NWT, Canada to environmental and socio-economic changes. Regional Environmental Change, 12, 867-885.

Anisimov, O., Vaughan, D., Callaghan, T., Furgal, C., Marchant, H., Prowse, T., Vilhjálmsson, H., \& Walsh, J. (2007). Polar Regions (Arctic and Antarctic). In Parry, M., Canziani, O., Palutikof, J., van der Linden, P., \& Hanson, C. (Eds.), Climate Change 2007: Impacts, Adaptation and Vulnerability. Contribution of Working Group II to the Fourth Assessment Report of the Intergovernmental Panel on Climate Change (pp. 653-685). Cambridge: Cambridge University Press.

Arcand, M., Bradford, L., Worme, D., Strickert, G., Bear, K., Johnston, A., Wuttunee, S., Gamble, A., \& Shewfelt, D. (2020). Sowing a way towards revitalizing Indigenous agriculture: creating meaning from a forum discussion in Saskatchewan, Canada. FACETS, 5(1), 619-641.

Arce, A. (2003). Value contestations in development interventions: Community development and sustainable livelihoods approaches. Community Development Journal, 38(3), 199-212.

Armitage, D., \& Tam., C. (2007). A Political ecology of sustainable livelihoods in coastal Sulawesi, Indonesia. Canadian Journal of Development Studies, 28(1), 39-57.

Ashley, C., \& Carney, D. (1998). Sustainable Livelihoods: Lessons from Early Experiences. London: Department for International Development.

Assuah, A. (2020). Examining the Role of and Potential for Indigenous and Social Learning through Community-Based Solid Waste Management in Canadian First Nation Communities. Doctoral Dissertation, University of Manitoba. Retrieved from: https://mspace.lib.umanitoba.ca/handle/1993/35210

Aurora College. (2019). About Us. Aurora Research Institute. Retrieved from: https://nwtresearch.com/about-us

Ayalon, O., \& Shechter, M. (2001). Solid Waste Treatment as a High-Priority and LowCost Alternative for Greenhouse Gas Mitigation. Environmental Management, 27(5), 697-704.

Barnhardt, R., \& Kawagley, A. (2005). Indigenous Knowledge Systems and Alaska Native Ways of Knowing. Anthropology and Education Quarterly, 36(1), 8-23.

Baum, F., MacDougall, C., \& Smith, D. (2006). Participatory action research. $J$ Epidemiol Community Health, 60, 854-857.

Bebbington, A. (1993). Modernization from below: An alternative to indigenous development? Economic Geography, 69(3), 274-292.

Berkes, F. (2009a). Evolution of co-management: Role of knowledge generation, bridging organizations, and social learning. Journal of Environmental Management, 90, 1692-1702.

Berkes, F. (2009b). Indigenous ways of knowing and the study of environmental change. Journal of the Royal Society of New Zealand, 39(4), 151-156. 
Biersack, A., \& Greenberg, J. (2006). Reimagining Political Ecology. London: Duke University Press.

Boeije, H. (2002). A purposeful approach to the constant comparative method in the analysis of qualitative data. Quality \& Quantity, 36, 391-409.

Bogner, J., Ahmed, M., Diaz, C., Faaji, A., Gao, Q., Hashimoto, S., Mareckova, K., Pipatti, R., \& Zhang, T. (2007). Waste Management. In B. Metz, O. Davidson, P. Bosche, R. Dave, \& L. Meyer (Eds.), Climate Change 2007: Mitigation. Contribution of Working Group III to the Fourth Assessment Report of the Intergovernmental Panel on Climate Change. Cambridge \& New York: Cambridge University Press.

Bogner, J., \& Matthews, E. (2003). Global methane emissions from landfills: New methodology and annual estimates 1980-1996. Global Biochemical Cycles, 17(2), $1-18$.

Bolan, N., Kunhikrishnan, A., Chopalla, G., Thangarajan, R., \& Chung, J. (2012). Stabilization of carbon in composts and biochars in relation to carbon sequestration and soil fertility. Science of the total environment, 424, 264-270.

Bryant, R. (1998). Power, knowledge, and political ecology in the third world: a review. Progress in Physical Geography, 22(1), 79-94.

Bush, E., Gillett, N., Watson, E., Fyfe, J., Vogel, F., \& Stwart, N. (2019). Understanding Observed Global Climate Change. In Bush, E., \& Lemmen, D. (Ed), Canada's Changing Climate Report (24-72). Ottawa: Government of Canada

Castleden, H., Morgan, V., \& Lamb, C. (2012). "I spent the first year drinking tea": Exploring Canadian university researchers' perceptions on commmunity-based participatory research involving Indigenous peoples. The Canadian Geographer, 56(2), 160-179.

Chambers, R., \& Conway, G. (1992). Sustainable rural livelihoods:practical concepts for the $21^{\text {st }}$ century. Discussion paper, 296. Brighton: Institute for Development Studies.

Chaskin, R. (2001). Building Community Capacity: A Definitional Framework and Case Studies from a Comprehensive Community Initiative. Urban Affairs Review, 36(3), 291-323.

Christiensen, J. (2012). Telling stories: Exploring research storytelling as a meaningful approach to knowledge mobilization within Indigenous research collaborations and diverse audiences in community-based research. The Canadian Geographer, $\underline{56(2), 231-242 .}$

Cidro, J., Adekunle, B., Peters, E., \& Martens, T. (2015). Beyond food security: Understanding access to cultural food for urban Indigenous people in Winnipeg as Indigenous food sovereignty. Canadian Journal of Urban Research, 24(1), 24-43.

Cochrane, P. (2006). Exploring cultural capital and its importance in sustainable development. Ecological Economics, 57(2), 318-330.

Collings, P. (2011). Economic Strategies, Community, and Food Networks in Ulukhaktok, Northwest Territories, Canada. Arctic, 64(2), 207-219.

Cook, D. (2017). Building your soil: A guide to building sustainable garden soil in the Northwest Territories. Yellowknife: Ecology North.

Cooperband, L. (2002). The Art and Science of Composting: a resource for farmers and compost producers. University of Wisconsin-Madison. Retrieved from: 
https://static1.squarespace.com/static/55848984e4b0caf8e32b24b7/t/55a9ba2de4b 048cfac18595d/1437186605227/ArtScienceofComposting.pdf

Cornell Waste Management Institute. (2004). Composting Fact Sheet \#3: Improving and Maintaining Compost Quality. Cornell University. Retrieved from: https://ecommons.cornell.edu/bitstream/handle/1813/2312/compostfs3.pdf;sequen $\mathrm{ce}=4$

Coté, C. (2016). “Indigenizing” food security. Revitalizing Indigenous food practices and ecological knowledges in Canada and the United States. Humanities, 5(3), 57-71.

Council of Canadian Academies. (2014). Aboriginal Food Security in Northern Canada: An Assessment of the State of Knowledge. Ottawa: Council of Canadian Academies.

Daskon, C., \& McGreggor, A. (2012). Cultural capital and sustainable livelihoods in Sri Lanka's rural villages: Towards culturally aware development. Journal of Development Studies, 48(4), 549-563.

Datta, R., Khyang, N., Khyang, H., Kheyang, H., Khyang, M., \& Chapola, J. (2015). Participatory action research and researcher's responsibilities: an experience with an Indigenous community. International Journal of Social Research Methodology, 8(6), 581-599.

Datta, R. (2018a). Rethinking environmental science education from indigenous knowledge perspectives: an experience with a Dene First Nation community. Environmental Education Research, 24(1), 50-66.

Datta, R. (2018b). Traditional storytelling: an effective indigenous research methodology and its implications for environmental research. AlterNative, 14(1), 35-44.

Day, J. (1968). Soils of the Upper Mackenzie River Area, Northwest Territories. Ottawa: Canada Department of Agriculture.

Dehcho First Nations. (2021a). Dehcho First Nations. Retrieved from: https://dehcho.org/

Dehcho First Nations. (2021b). Negotiations. Retrieved from: https://dehcho.org/negotiations/

Derkson, C., Burgess, D., Howell, S., Murdryk, L., Smith, S., Thackeray, C., \& Kirchmeier-Young, M. (2019). Changes in Snow, Ice, and Permafrost Across Canada. In Brush, E., \& Lemmen, D. (Eds.), Canada's Changing Climate Report (pp. 194-260). Retrieved from: http://nrcan.gc.ca/sites/www.nrcan.gc.ca/files/energy/Climatechange/pdf/CCCR_FULLREPORT-EN-FINAL.pdf

Ecology North. (N.D.). Composting North of 60: A Guide to Home Composting in the Northwest Territories. Ecology North. Retrieved from: https://www.iti.gov.nt.ca/sites/iti/files/composting\%2520booklet.pdf

Emery, M., \& Flora, C. (2006). Spiraling-Up: Mapping Community Transformation with Community Capitals Framework. Journal of the Community Development Society, 37(1), 19-35.

Environment Canada. (2013). Technical Document on Municipal Solid Waste Organics Processing. Retrieved from: https://www.ec.gc.ca/gdd-mw/3E8CF6C7-F2144BA2-A1A3-163978EE9D6E/13-047-ID-458-PDF_accessible_ANG_R2reduced\%20size.pdf 
Escobar, A. (1996). Construction Nature: Elements for a post-structuralist political ecology. Futures, 28(4), 325-343.

Favoino, E., \& Hogg, D. (2008). The potential role of composting in reducing greenhouse gases. Waste Management \& Research, 26, 61-69.

Ferguson, J., \& Weaselboy, M. (2020). Indigenous sustainable relations: Considering land in language and language in land. Current Opinion in Environmental Sustainability, 43, 1-7.

Fiddler, T., Socha, T., Zahaf, M., Chambers, L., \& Abraham, R. (2012). Food security in a northern First Nations community: An exploratory study on food availability and accessibility. International Journal of Indigenous Health, 8(2), 5-14.

Fieldhouse, P., \& Thompson, S. (2012). Tackling food security issues in indigenous communities in Canada: The Manitoba experience. Nutrition \& Dietetics, 69(3), 217-221.

Flato, G., Gillett, N., Arora, V., Cannon, A., \& Anstey, J. (2019). Modelling Future Climate Change. In Bush, E., \& Lemmen, D. (Ed), Canada's Changing Climate Report (74-111). Ottawa: Government of Canada.

Flora, C., Emery, M., Fey, S., \& Bregendahl, C. (2005). Community Capitals: A tool for Evaluating Strategic Interventions and Projects. Iowa State University. Retrieved from: krse.k-state.edu/community/civic-engagement/youth-communityperceptions/documents/Community-Capials.pdf

Foote, M., \& Bartell, T. (2011). Pathways to equity in mathematics education: how life experiences impact researcher positionality. Educational Studies in Mathematics, $78(1), 45-68$

Frugal, C., \& Prouse, T. (2008). Northern Canada. In, D. Lemmen, F. Warren, J. Lacroix, \& E. Bush (Eds.), From Impacts to Adaptation: Canada in a Changing Climate, (pp. 57-118). Government of Canada.

Fuller, T., Guy, D., \& Pletsch, C. (2002). Asset Mapping Handbook. The Canadian CED Network. Retrieved from: https://ccednet-rcdec.ca/en/toolbox/asset-mappinghandbook

Gilmour, T., Krantz, J., \& Ramirez, R. (1986). Action based modes of inquiry and the host-researcher relationship. Consultation, 5, 160-176.

GNWT. (n.d.a). Atlas. Government of Northwest Territories. Retrieved from: https://www.maps.geomatics.gov.nt.ca/HTML5Viewer_Prod/index.html?viewer= ATLAS

GNWT. (n.d.). Ka'a'gee Tu. Conservation Network Planning. Retrieved from: https:/www.enr.gov.nt.ca/en/services/conservation-network-planning/kaagee-tu

GNWT. (2008). NWT climate change impacts and adaptations report. Retrieved from: https://www.enr.gov.nt.ca/sites/enr/files/reports/nwt_climate_change_impacts_an d_adaptation_report.pdf

GNWT. (2014). Growing Forward 2: Local foods production in the NWT Inuvik/Delta Region 2013-2014. Retrieved from: https://www.iti.gov.nt.ca/sites/iti/files/growingforward2_inuvik_delta_region_rep ort_2013-2014.pdf

GNWT. (2017). Knowledge Agenda: Northern Research for Northern Priorities. Retrieved from: 
https://www.nwtgeoscience.ca/sites/ntgs/files/resources/gnwt_knowledge_age nda_2jun2017.pdf

GNWT. (2019). Northwest Territories Waste Resource Management Strategy and Implementation Plan. Retrieved from: https://www.enr.gov.nt.ca/sites/enr/files/resources/waste_strategy_plan.pdf

Golder. (2018). Waste Management in the Northwest Territories: 2018 Swana Northern Lights Conference, Edmonton, Alberta. GNWT. Retrieved from: https://swananorthernlights.org/wp-content/uploads/2017/05/Paul-DewaeleNWT-Presentation-SWANA-Edmonton-2018-Draft-LPH-002-1.pdf

Golder Associates Ltd. (2016). Study of Waste Management Systems: Landfill Site Risk Factors, Waste Generation \& Management Costs in the NWT. Department of Environment and Natural Resources, GNWT. Retrieved from: https://www.enr.gov.nt.ca/sites/enr/files/resources/golder_report_volume_2_nwt_ waste_study_final_with_disclaimer_dec2016.pdf

Goldman, M., Turner, M., \& Daly, M. (2018). A critical political ecology of human dimensions of climate change: Epistemology, ontology, and ethics. Wiley Interdisciplinary Reviews, 9(4), 1-15.

Goldsmith, C., Chanton, J., Abichou, T., Swan, N., Green, R., \& Hater, G. (2012). Methane emissions from 20 landfills across the United States using vertical radial plume mapping. Journal of the Air and Waste Management Association, 62(2), 183-197.

Government of Canada. (2014). Pre-1975 Treaties Map in Northwest Territories. Indigenous and Northern Affairs Canada. Retrieved from: https://www.aadncaandc.gc.ca/DAM/DAM-INTER-HQ-AI/STAGING/texte-text/mprm_treaties_thht_nwt_1371839567617_eng.pdf

Government of Western Australia. (2018). Composting to Avoid Methane Production. Department of Primary Industries and Regional Development. Retrieved from: https://www.agric.wa.gov.au/climate-change/composting-avoid-methaneproduction

Gracey, M., \& King, M. (2009). Indigenous health part 1: determinants and disease patterns. The Lancet, 374(9683), 65-75.

Greenwood, D., Whyte, W., \& Harkavy, I. (1993). Participatory action research as a process and as a goal. Human Relations, 46(2), 175-192.

Greenwood, M. \& Leeuw, S. (2007). Teachings from the Land: Indigenous People, Our Health. Canadian Journal of Native Education, 30(1), 48-189.

Greenwood, M., \& Lindsay, N. (2019). A commentary on land, health, and Indigenous knowledge(s). Global Health Promotion, 26(3), 82-86.

Guyot, M., Dickson, C., Paci, C., Furgal, C., \& Chan, H. (2006). Local observations of climate change and impacts on traditional food security in two northern Aboriginal communities. International Journal of Circumpolar Health, 65(5), 403-514.

Hadlari, M. (2019). Why this N.W.T. woman sees being an elder as the 'highest honour.' CBC News. Retrieved from: https://www.cbc.ca/news/canada/north/eldermeaning-margaret-leishman-1.5318133 
Illera-Vives, M., Labandeira, S., Louriero, L., \& Lópes-Mosquera, M. (2017). Agronomic assessment of a compost consisting of seaweed and fish waste as an organic fertilizer for organic potato crops. J Appl Phycol, 29, 1663-1671.

Indigenous Food Circle. (2020). 13 Moons Poster. Understanding Our Food Systems. Retrieved from: https://uploadsssl.webflow.com/5da2993f20ae1b3485335ef4/5fc035b187e53784b1a4a7fb_13MOONS-30x40.pdf

IPCC. (2014). Climate Change 2014: Impacts, Adaptation, and Vulnerability. Part B: Regional Aspects. Contribution of Working Group II to the Fifth Assessment Report of the Intergovernmental Panel on Climate Change. Cambridge University Press.

IPCC. (2018). Global Warming of $1.5^{\circ}$ C. IPCC. Retreived from: https://www.ipcc.ch/sr15/

Islam, D., \& Berkes, F. (2016). Indigenous people's fisheries and food security: a case from northern Canada. Food Security, 8, 815-826.

ITI. (2015). Towards an: Northwest Territories Agriculture Strategy. Retrieved from: https://www.iti.gov.nt.ca/sites/iti/files/agriculture_strategy_what_we_learned_report_2015.pdf

Jacobs, $\bar{O}$., \& Makaudze, $\bar{E} .(201 \overline{2})$. Understanding rural livelihoods in the West Coast District, South Africa. Development Southern Africa, 29(4), 574-587.

Jarvenpa, R. (2008). Diets of Experience: Food Culture and Political Ecology in Northern Canada and Northern Finland. Food and Foodways, 16(1), 1-31.

Jeannotte, M. (2016). Story-telling about place: Engaging citizens in cultural mapping. City, Culture, and Society, 7(1), 35-41.

Jenish, G. (1997). Methane, Climate Change, and Waste Management: a review of efforts by Toronto, Ontario, Canada, to reduce waste related emissions of methane. Canadian Institute of Environmental Law and Policy. Retrieved from: http://www.cielap.org/pdf/Methane.pdf

Johnston, C., \& Spring, A. (2021). Grassroots and Global Governance: Can Global-Local Linkages Foster Food System Resilience for Small Northern Canadian Communities? Sustainability, 13(4), 1-17.

Kaplan, N., \& Smylie, J. (2006). Sharing What We Know About Living a Good Life. Regina: First Nations University of Canada.

Karki, S. (2013). Do protected areas and conservation initiatives contribute to sustainable livelihoods? A case study of Bardia National Park, Nepal. Journal of Environmental Management, 128, 988-999.

Kemmis, S., McTaggart, R., \& Nixon, R. (2014). The Action Research Planner. Singapore: Springer.

Kidd, S., \& Kral, M. (2005). Participatory action research. Journal of Counselling Psychology, 52(2), 187-195.

Knutsson, P., \& Ostwald, M. (2006). A process oriented sustainable livelihoods approach - a tool for increased understanding of vulnerability, adaptation, and resilience. Mitigation and Adaptation Strategies for Global Change, 2006, 1573-1596. 
Kuhnlein, H., \& Chan, H. (2000). Environment and Contaminants in Traditional Food Systems of Northern Indigenous Peoples. Annual Review Nutrition, 20, 595-626.

Laeis, G., \& Lemke, S. (2016). Social entrepreneurship in tourism: applying sustainable livelihoods approaches. International Journal of Contemporary Hospitality Management, 28(6), 1076-1093.

Lambden, J., Receveur, O., \& Kuhnlein, H. (2007). Traditional Food Attributes Must Be Included in Studies of Food Security in the Canadian Arctic. International Journal of Circumpolar Health, 66(4), 308-319.

Laos, F., Mazzarino, M., Walter, I., \& Roselli, L. (1998). Composting of Fish Waste with Wood By-Products and Testing Compost Quality as a Soil Amendment: Experiences in the Patagonia Region of Argentina. Compost Science \& Utilization, 6(1), 59-66.

Larson, S., \& Johnson, J. (2012). In between worlds: place, experience, and research in Indigenous geography. Journal of Cultural Geography, 29(1), 1-13.

Leblanc-Laurendeau, O. (2019). Food insecurity in northern Canada: An overview. Library of Parliament, Publication No. 2019-18-E. Retrieved from: https://lop.parl.ca/staticfiles/PublicWebsite/Home/ResearchPublications/InBriefs/ PDF/2019-18-e.pdf

Leech, N., \& Onwuegbuzie, A. (2007). An array of qualitative data analysis tools: A call for data analysis triangulation. School of Psychology Quarterly, 22(4), 557-584.

Lenton, T., Rockström, J., Gaffney, O., Rahmstorf, S., Richardson, K., Steffen, W., \& Schellnhuber, H. (2019). Climate tipping points - too risky to be against. Nature, 575, 592-595.

Loring, P., \& Gerlach, C. (2010). Outpost Gardening in Interior Alaska: Food System Innovation and the Alaskan Native Gardens of the 1930s through the 1970s. Ethnohistory, 57(2), 183-199.

Louis, R. (2007). Can you hear us now? Voices from the margin: Using Indigenous methodologies in geographic research. Geographical Research, 45(2), 130-139.

McGregor, D. (2004). Coming Full Circle: Indigenous Knowledge, Environment, and Our Future. American Indian Quarterly, 28(3), 385-410.

McGregor, D., Bayha, W., \& Simmons, D. (2010). "Our Responsibility to Keep the Land Alive": Voices of Northern Indigenous Researchers. Pimatisiwin: A Journal of Aboriginal and Indigenous Community Health, 8(1), 101-123.

McKenzie, J., Tan, P., Hoverman, S., \& Baldwin, C. (2012). The value and limitations of participatory action research methodology. Journal of Hydrology, 474, 11-21.

McTaggart, R. (1999). Reflection on the purposes of research, action, and scholarship: A case of cross-cultural participatory action research. Systemic Practice and Action Research, 12(5),493-511.

Middleton, B. (2015). Jahát Jatítotòdom: Toward an indigenous political ecology. In R. Bryant (Eds.), The International Handbook of Political Ecology, (pp. 561-576). London: Edward Elgar Publishing.

Morse, S., \& McNamara, N. (2013). Sustainable Livelihood Approach: A Critique of Theory and Practice. New York \& London: Springer Dordrecht Heidelberg.

Nair, J., \& Okamitsu, K. (2010). Microbial inoculants for small scale composting of putrescible kitchen wastes. Waste Management, 30, 877-982. 
Natcher, D. (2009). Subsistence and the social economy of Canada's Aboriginal North. The Northern Review, 30, 83-98.

Natcher, D. (2015). Social Capital and the Vulnerability of Aboriginal Food Systems in Canada. Human Organization, 74(3), 230-242.

Nicholls, R. (2009). Research and indigenous participation: Critical reflexive methods. International Journal of Social Research Methodology, 12(2), 117-126.

Oyengunle, A. (2016). Solid waste management policies in two northern Manitoba First Nations communities: Community perspectives on issues and solutions. Master's Thesis, University of Manitoba. Retrieved from: https://mspace.lib.umanitoba.ca/bitstream/handle/1993/31088/Oyegunle_Ahmed. pdf? sequence $=5 \&$ isAllowed $=y$

Ozanne, J., \& Saatcioglu, B. (2008). Participatory action research. Journal of Consumer Research, 35(3), 423-439.

Pan, J., \& Voulvoulis, N. (2007). The role of mechanical and biological treatment in reducing methane emissions from landfill disposal of municipal solid waste in the United Kingdom. Journal of the Air and Waste Management Association, 57(2), 155-163.

Parlee, B., O’Neil, J., \& Lutsel K'e Dene First Nation. (2007). “The Dene Way of Life": Perspectives on Health from Canada's North. Journal of Canadian Studies/Revue d'études canadiennes, 41(3), 112-133.

Parrot, L., Sotamenou, J., \& Dia, B. (2009). Municipal solid waste management in Africa: Strategies and livelihoods in Yaoundé, Cameroon. Waste Management, 29, 986-995.

Pearce, T., Ford, J., Laidler, G., Smit, B., Duerden, F., Allarut, M., Andrachuk, M., ... \& Wandel, J. (2009). Community collaboration and climate change research in the Canadian Arctic. Polar Research, 28, 10-27.

Pearce, T., Duerden, F., Ford, J., Goose, A., \& Kataoyak, F. (2010). Inuit Vulnerability and Adaptive Capacity to Climate Change in Ulukhaktok, Northwest Territories, Canada. Polar Record, 46(237), 157-177.

Peltier, C. (2018). An Application of Two-Eyed Seeing: Indigenous Research Methods with Participatory Action Research. International Journal of Qualitative Methods, 17(1), 1-12.

Perreault, T., Bridge, G., \& McCarthy, J. (2015). The Routledge Handbook of Political Ecology. London: Routledge.

Power, E. (2008). Conceptualizing Food Security for Aboriginal People in Canada. Canadian Journal of Public Health, 99(2), 95-97.

Prowse, M. (2010). Integrating reflexivity into livelihoods research. Progress in Development Studies, 10(3), 211-231.

Pstross, M., Talmage, C., \& Knopf, R. (2014). A story about storytelling: Enhancement of community participation through catalytic storytelling. Community Development, 45(5), 525-538.

Radziemuska, M., Vaverková, M., Adamcová, D., Brtnicky, M., \& Mazur, Z. (2019). Valorization of fish waste compost as a fertilizer for agricultural use. Waste and Biomass Valorization, 10, 2537-2545. 
Receveur, O., \& Kuhnlein, H. (1998). Decreasing Traditional Food Use Affects Diet Quality for Adult Dene/Métis in 16 Communities of the Canadian Northwest Territories. American Society for Nutritional Sciences, 2179-2186.

Richmond, C., Kerr, R., Neufeld, H., Steckley, M., Wilson, K., \& Dokis, B. (2021). Supporting food security for Indigenous families through the restoration of Indigenous foodways. The Canadian Geographer, 65(1), 197-109.

Robbins, P. (2012). Political Ecology: A Critical Introduction (Second Edition). Oxford: John Wiley \& Sons Ltd.

Rudolph, K., \& McLachlan, S. (2013). Seeking Indigenous food sovereignty: Origins of and responses to the food crisis in northern Manitoba, Canada. Local Environment, 18(9), 1079-1098.

Schmidt, G., Hemingway, D., \& Bellefeuille, G. (2012). Building healthy northern communities through strengthening capacity. Journal of Comparative Social Work, 7(1), 1-14.

Scoones, I. (1998). Sustainable rural livelihoods: A framework for analysis. Working paper, 72. Brighton: Institute for Development Studies.

Scoones, I. (2009). Livelihoods perspectives and rural development. Journal of Peasant Studies, 36(1), 171-196.

Serrat, O. (2017). Knowledge Solutions: Tools, Methods, and Approaches to Drive Organisational Performance. Asian Development Bank \& Springer Open.

Sillitoe, P. (2004). Interdisciplinary Experiences: Working with Indigenous Knowledge in Development. Interdisciplinary Science Reviews, 29(1), 6-23.

Sneddon, C. (2000). 'Sustainability' in ecological economics, ecology, and livelihoods: a review. Progress in Human Geography, 24(4), 521-549.

Somerville, W., \& Turner, B. (2020). Engaging with Indigenous Research Methodologies: The Centrality of Country, Positionality, and Community Need. Journal of Australian Studies, 44(2), 182-184.

Spring, A., Carter, B., \& Bay-Palmer, A. (2018). Climate change, community capitals, and food security: building a more sustainable food system in a northern Canadian boreal community. Canadian Food Studies/La Revue Canadienne des études sur l'alimentation, 5(2), 111-141.

Spring, A., Skinner, K., Simba, M., Nelson, E., Baltzer, J., Swanson, H., \& Turetsky. M. (2020). Taking care of the land: an interdisciplinary approach to communitybased food systems assessment in Kakisa, Northwest Territories, Canada. In A. Blay-Palmer, D. Conaré, K. Meter, A. Di Battista, \& C. Johnston (Eds.), Sustainable Food System Assessment: Lessons from Global Practice (pp. 42-65). Routledge.

Srivastava, P., \& Hopwood, N. (2009). A practical iterative framework for qualitative data analysis. International Journal of Qualitative Methods, 8(1), 76-84.

Sundberg, J. (2015). Ethics, entanglement, and political ecology. In T. Perrault, G. Bridge, \& J. McCarthy (Eds.), The Routledge Handbook of Political Ecology, (pp. 117-126). Routledge.

Thompson, S., Rony, M., \& Temmer, J. (2014). Pulling in the indigenous cooperative net: Fishing for sustainable livelihoods and food security in Garden Hill First Nation, Manitoba, Canada. Journal of Agriculture, Food Systems, and Community Development, 4(3), 177-192. 
Trapani, D., Bella., G., \& Viviani, G. (2013). Uncontrolled methane emissions from a MSW landfill surface: Influence of landfill features and side slopes. Waste Management, 33(10), 2108-2115.

Tuck, E., McKenzie, M., \& McCoy, K. (2014). Land education: Indigenous, postcolonial and decolonizing perspectives on place and environmental education research. Environmental Education Research, 20(1), 1-23.

Tuhiwai-Smith, L. (2012). Decolonizing Methodologies: Research and Indigenous Peoples - Second Edition. London: Zed Books.

Turetsky, M., Baltzer, J., Johnstone, J., Mack, M., McCann, K., \& Schur, E. (2017). Losing Legacies, Ecological Release, and Transient Responses: Key Challenges for Northern Ecosystem Science. Ecosystems, 20(1), 1-8.

Turetksy, M., Abbott, B., Jones, M., Anthony, K., Olefeldt, D., Schur, E., Koven, C., McGuire, D., Grosse, G., Kuhry, P., Hugelius, G., Lawrence, D., Gibson, C., \& Sannel, B. (2019). Permafrost collapse is accelerating carbon release. Nature, 569(7754), 32-32.

Walker, P. (2006). Political ecology: where is the policy? Progress in Human Geography, 30(3), 382-395.

Walker P. (2007). Political ecology: where is the politics? Progress in Human Geography, 31(3), 363-369.

Wesche, S., \& Chan, H. (2010). Adapting to the Impacts of Climate Change on Food Security among Inuit in the Western Canadian Arctic. EcoHealth, 7(3), 361-373.

Williams, D., \& Muchena, O. (1991). Utilizing Indigenous Knowledge Systems in Agricultural Education to Promote Sustainable Agriculture. Journal of Agricultural Education, 32(4), 52-57.

Wilson, D., Velis, C., Cheeseman, C. (2006). Role of informal sector recycling in waste management in developing countries. Habitat International, 30, 797-808.

Wilson, S. (2001). What is an indigenous research methodology? Canadian Journal of Native Education, 25(2), 175-179.

Zable, F., Putzenlechner, B., \& Mauser, W. (2014). Global Agricultural Land Resources - A High Resolution Stability Evaluation and Its Perspectives until 2100 under Climate Change Conditions. PLOS One, 9(9), 1-12.

Zagozewski, R., Judd-Henery, I., Nelson, S., \& Bhasradwaj, L. (2011). Perspectives on Past and Present Waste Disposal Practices: A Community-Based Participatory Research Project in Three Saskatchewan First Nation Communities. Environmental Health Insights, 5, 9-20.

Zanotti, L., Carothers, C., Apok, C., Huang, S., Coleman, J., \& Ambrozek, C. (2020). Political Ecology and decolonial research: Co-production with the Iñupiat in Utqiagvik. Journal of Political Ecology, 27(1), 43-66).

Zhang, X., Flato, G., Kirchmeier-Young, M., Vincent, L., Wan, H., Wang, X., Rong, R. ... \& Kharin, V. (2019). Changes in Temperature and Precipitation Across Canada. In Bush, E., \& Lemmen, D. (Ed), Canada 's Changing Climate Report (112-193). Ottawa: Government of Canada

Zimmerer, K., \& Bassett, T. (2003). Political Ecology: An Integrative Approach to Geography and Environment-Development Studies. New York \& London: The Guilford Press. 


\section{Appendices}

Appendix A: Plain Language Document: Fish Composting Methods \& Locations

Recommendations (2019)

Date: Tuesday, June 25, 2019

To: Chief Lloyd \& Andrew Spring

From: Erin Snider

Subject: Options for Fish Composting RE: Conversation with Craig (Ecology North)

\section{Summary:}

- 3 Options for fish composting:

- Windrow at the Dump

○ Windrow on the firebreak

- Building new IVC

- 2 Recommendations:

$\circ$ Build windrow at the dump (short-term recommendation)

○ Build windrow on firebreak (long-term recommendation)

- Next steps:

○ Community focus group to determine preferential methods for composting and collection systems - community input, ideas, and concerns all welcome

- Create a plan based on community input for moving forward

\section{Introduction:}

I spoke with Craig on the phone about options for fish composting. Since we are using the In-Vessel Composter (IVC) for kitchen waste, we will either have to use windrow composting or make a second IVC for fish if we intend on producing both types of compost simultaneously. The method for wind-row composting is outlined below, followed by two options pertaining to location. There is also a description of how the IVC functions and some materials we might need to build one. The document concludes with a list of recommendations for how to proceed with fish composting in KTFN.

\section{Windrow Composting Methodology:}

Craig suggested we modify the methodology for windrow composting to include a trench. The trench will help to prevent bear presence in the composting site. Here is a stepby-step description of how to build the wind-row trench:

- Dig a trench that is $10 \mathrm{~m}$ in length and $1 \mathrm{ft}$. deep in a moist area. Width was not specified (will follow-up on width)

- Make a pile of extracted soil along one side of the newly formed trench 
- Make a second pile of woodchips and other brown organic material along the other side of the trench

Once the trench is complete, fish waste can be added. This should be done by adding fish to one side first. As fish is added, use the soil and woodchips to ensure that fish waste is well covered. The fish waste will act as a source of nitrogen while the woodchips will act as a source of carbon. The ratio of fish waste to brown organic material and soil should be $1 \mathrm{~N}: 3 \mathrm{C}$. This should help keep bears away. This process is to be repeated as new fish waste is accumulated, moving methodically in a straight line until the entire trench is filled. If bears are sighted frequently, or there are signs of bear activity, we may need to build an enclosure around the trench. The fish waste does not need to be turned or touched once it is covered. This is a slower process for creating soil, as it will take 1-2 years for soil to be ready for garden use.

There are some additional resources we will need in order to build a wind-row composting trench. These include:

- Machinery or lots of people with shovels to dig the trench and pile soil alongside it

- People and vehicles for transporting woodchips to the trench

- A collection system for fish-waste in the community:

- We will need animal-proof containers stationed at the docks, and in locations where people process and/or dry fish, since waste is also produced in these areas

- We will need to create awareness for this project and find ways to encourage people to save fish waste in the containers provided - education and training will also be necessary to differentiate between efforts for composting kitchen waste versus fish waste

- Someone will need to be in charge of actually collecting fish waste within the community and transporting it to the composting site, as well as maintaining the compost pile and covering it effectively - we would likely need to hire someone to fulfil these duties and have this as a paid position for the community

\section{Location Options for Windrow Trench:}

There are two options for where we could dig the initial trench for fish composting: the dump, or the firebreak itself. A description of each is listed below with pros and cons.

\section{Dump:}


Andrew mentioned that he thinks this might be the community's preferred location. We would have to scout out an area in the dump where soil retains the most moisture. This location is beneficial because:

- It will limit bear activity in and directly around the community

- It might be a more frequently visited area, making transportation of fish waste more frequent and convenient

- Since the firebreak is not yet cleared, and since the soil building process is slow (1-2 years), we can get a head start on creating nutrient-rich soil while the firebreak is being cleared - in other words, we can coordinate the timing between clearing the firebreak and the soil building processes

Some disadvantages for this location include:

- It is further away from the community

- Ready soil will need to be transported from the dump to the firebreak site for soil building and planting

- We need to position it strategically so that runoff or contaminants from the dump do not penetrate the compost

\section{Firebreak:}

Another option is to wait until the firebreak is cleared and ready to go, then dig the trench there, directly where berries and/or fruit trees will be planted. Some benefits include:

- No need to transport soil - simply plant berry bushes and fruit trees over top once the soil is ready

- It is closer to the community and might be easier to access and maintain

Some challenges include:

- It might attract bears closer to the community if fish is not well-covered

- The firebreak is not yet cleared, and we cannot build the trench until it is, therefore prolonging the soil building process, and by extension, the planting/growing/harvesting of berries on the location

\section{Building a Second IVC:}

Another option for fish composting in Kakisa is to build a second IVC that would be stationed in a location where the majority of fish waste is produced within in the community. Currently, the IVC prototype from Ecology North is stationed at the school and being used for composting kitchen waste. The IVC is a horizontally positioned drum with rotating interior blades for mixing compost. A description of IVC function is as follows:

- There is a hatch at the top of the IVC on one side for inserting fish waste 
- Woodchips and brown organic waste should be added each time fish waste is added in a ratio of 3 to 1 ( 3 times the amount of brown organic material than fish waste)

- There is a rotating rod with 24 blades inside the barrel. The handle should be turned once or twice each time waste is added

- Moisture levels should be monitored - if there is not enough moisture then the waste will not decompose - the compost should have the same moisture as a wrungout sponge, so if it is too dry, water should be added to the mixture. The IVC should be monitored for heat generation - if the IVC is hot to the touch then it is doing its job

- There is a square-shaped spout at the bottom of the IVC, opposite end to the hatch. This hole should be left open with a collection container positioned underneath. As new compost is added, and as the handle is turned, older, decomposing compost should spill out the bottom into the container

- Material that spills out of the IVC into the collection container should be left alone - untouched - to cure. If the IVC has done its job, then this material should be relatively odorless and somewhat broken down

- Once this container is filled it should be removed and replaced with an empty container, while the full one is set aside and monitored for curing. Ideally, we will have several containers on rotation with compost at different stages of decay

Here is a working list of materials and resources we will need to build and maintain a new IVC (will follow up with Craig and see if he will share the design/blueprints/materials list):

- A welder

- Two barrels that can be welded together

- Rods to use for rotating handles and internal blades

- A stand to rest the IVC on

- Small 5-gallon collection buckets (for underneath to collect compost)

- Larger bins to hold compost for curing, and for keeping woodchips/brown organic material readily available

- A scoop for woodchips/brown organic material

- Tarps and other insulators for winter

- Education and training programs for fishermen - since the IVC will be sited near fish waste, those producing the fish waste will be more involved in the composting process

- We may also need to have someone designated for compost maintenance (i.e. checking and monitoring moisture levels, swapping collection containers, and transferring compost to larger bins for curing). 
- Means of transportation for moving finished compost to the firebreak

\section{Assessment:}

Ultimately, there are two pathways we could pursue for fish composting: IVC or windrow trenches. Each method has its own benefits and challenges. The pros and cons for each are listed below:

\section{Windrow:}

Advantages:

- The composting site will be further away, reducing the chances of attracting bears to the community

- If we choose to build the wind-row site at the dump, we can begin the soil building process significantly sooner than if we pursued the firebreak location or IVC pathway

- The collection system can be extended to include fish processors, and not just commercial fishermen stationed at the docks (IVC could theoretically also extend to fish processors, however, the IVC is a smaller operation and collecting/storing fish waste for compost might be more challenging)

- The compost pile itself requires less human interaction (turning, moving collection buckets, and curing: fish is buried and left in place until it is decomposed and deemed ready to use as soil)

Disadvantages:

- Fish waste will likely decompose at a slower rate than IVC

- Large piles of soil and woodchips would freeze in the winter and get coated with ice and snow, making it more difficult to cover the fish waste

- Transportation is a labour-intensive job - barrels of fish waste will be heavy and difficult to maneuver

- Requires more diligent monitoring and involvement with collecting and depositing waste, since it is further away from the community

IVC:

Advantages:

- Vessel can be placed on-site where fish waste is generated so it will require less transportation and heavy lifting - fish waste can be deposited directly into the compost side making collection significantly easier

- Is a bear-proof container, and, if it functions properly will reduce odor and likely not pose a threat to attracting bears to the community 
- Is easier to insulate and maintain in the winter, increasing overall composting productivity

- Ready-to-use soil will already be in buckets and will be easier to transport to the firebreak (as opposed to wind-row composting at the dump, where ready-to-use soil will have to be dug up and transported a further distance - this point does not apply if we opt for wind-row composting at the firebreak)

Disadvantages:

- We have to build and weld an IVC, which requires more specialized skills than digging a trench

- Will take longer to start the soil building process than wind-row composting at the dump, since it will take more time to plan and build the container

- The IVC we currently have in the community is just a prototype, and the flaws have not been entirely worked out yet (we do not know if there are any amendments or adjustments that need to be made to improve

With these options in mind, it is important to think through the community's goals for composting fish waste. The primary objective is to start building soil for growing berry bushes and food on the land where the trees were cleared, which will also double as a firebreak to protect the community from wildfires. In thinking through these options, we need to consider project timelines and long-term goals. Different composting methods will help us meet our long-term and short-term objectives in different ways. For instance, windrow composting at the dump will help to ensure we have ready-to-use soil once the firebreak area has been cleared. However, this is not the ideal long-term composting method to use, since it will require significantly more transportation. IVC composting would serve a similar purpose if not for the time-consuming nature of building and perfecting the system. A wind-row composting site on the firebreak would be ideal, since we would be building soil in the same spot we intend to grow food, thus, significantly reducing transportation of waste and soil. However, given that the soil building process is significantly slower, relying solely on this method would set back our project timeline by at least 1 to 2 years.

\section{Recommendations:}

Ultimately, one long-term goal should be to build a wind-row composting site on the firebreak where we intend to grow food. A windrow would allow us to cover more surface area than IVC, and it would reduce the amount of transportation, spreading, and labour-intensive activity in the long run. However, since the firebreak is not cleared or ready for us to begin soil building presently, it would be beneficial for us to get a head start on building soil in the short-run, especially since it will take 1 to 2 years to generate ready- 
to-use soil from the fish waste. This leaves us with the two options of either building a second IVC or creating a wind-row trench at the dump.

The existing IVC in the community is a prototype. It has been used for kitchen waste, however, the composting recipe of $1 \mathrm{~N}: 3 \mathrm{C}$ has not been followed up until this point, and it is not fully functioning. This means that we still have a lot of work to do (independently of our fish waste project) to figure out appropriate moisture levels and to bring it up to its full composting potential. Since it is not currently working as it is intended, we have not gained valuable experience to work out any flaws and possible adjustments. If we choose to build a second IVC, we should wait until we have the existing one fully functioning, and until we have worked out improvements for the vessel. Thus, choosing the IVC pathway is not the most strategic short-term solution for building compost, especially since it will require significantly more effort, material, and skill to replicate the existing IVC.

Given the status of our existing IVC, we recommend proceeding with the shortterm alternative of building soil in a windrow at the dump. While it does require more transportation and effort, it will be easier to build. It will also address concerns of attracting wildlife closer to the community. Once the firebreak is cleared and ready to go, it is relatively easy to fill in the trench at the dump or continue both wind-row operations if necessary. This option is preferable because it requires the least amount of effort in the short run. If we spent time and resources building an IVC, there is a chance that the IVC would become obsolete when the wind-row composting site is established at the firebreak, which would make a lot of the effort put into building the IVC redundant in the long-run. It would be best to conserve time and resources for a long-term composting site at the firebreak. Therefore, creating a temporary wind-row trench at the dump seems like the best short-term option.

\section{Next Steps:}

The next steps for bringing this composting project to fruition is to bring these options and recommendations to the community. Since community members, especially fishermen and fish processors, will be the foundation of a functioning fish waste composting program, it is imperative to listen to their ideas, values, and concerns going forward. This will help us create a fish composting program that they are willing to participate in and are proud to be a part of. It would be beneficial to host a focus group and invite commercial fishermen and fish processors, and all interested members within the community. A focus group would be an excellent opportunity to communicate the importance and functions of a fish composting program to the wider community. It would also be a great way to start building a strategic fish composting plan for implementing this project, so that the same people who will use the composting program also get a fair say in how we build it. 
Once community input is gathered and considered we can draft up a strategic plan for implementing the composting project. After a plan is drafted, we could host a followup focus group outlining the plan to keep the community in the loop as we progress.

\section{Additional Notes:}

In Sambaa K'e, they mentioned that they had tried to bury fish compost in the past and that bear activity was still an issue (with digging up and stealing the composting material). It might be beneficial to add some sort of enclosure to the trench if we proceed with that composting pathway. The ideal enclosure would keep bears out but be easily accessible for people to open and maintain the pile.

We also need to put some thought into elevation, and leachate control for the dump site: there is a river running behind the dump. We do not want heavy metals or chemicals, micro plastics, etc., infiltrating our composting site, either. Additional research on landfill leachate and composting piles is in progress. 
Appendix B: Wilfrid Laurier University Approved Ethics: Recruitment Letter \&

Interview Guide (2019)

\title{
Recruitment Letter:
}

\author{
Food Security in the Northwest Territories \\ Principal Investigator: Dr. Andrew Spring Wilfrid Laurier University \\ Researcher: Erin Snider
}

We are seeking your voluntary participation in a research project exploring community insights into sustainability, food security, and waste management. Kakisa has been a leader in waste management in the region through implementing its own municipal recycling and composting programs. Now, fish composting is something the community is eager to implement as it generates a great deal of wastes that not suitable for the community's composting program. It is hoped that through constructive dialog and participatory research, community members will be instrumental in planning a fish waste composting program for Kakisa.

We are hoping to conduct a focus group with community members who deal with or generate fish waste on a regular basis, and all other community members who are interested in fish composting. The goal of conducting this focus group is to gain community insight on a preliminary plan for creating a fish composting pilot project in Kakisa, with the hopes of building healthy soil to successfully scale-up community food production. The focus group will take place at the Community's Band Office. It will take approximately one hour and will include questions about integrating fish composting within the community's already existing recycling program and identifying opportunities and needs to make this program successful. Dialogue from the focus group will be audio recorded, and notes will be used to create the fish composting plan based on community input. A summary report will be presented to the community at a follow-up meeting in August 2019.

It is possible that as a participant, by answering the questions in the interviews, you could make statements that could be awkward for you when made public (e.g., through academic publications or plain language reports to the community). We consider these risks to be very low, and in line with the risks encountered in the participants' everyday lives; however, we will mitigate these risks by preserving your anonymity in reports, and only use your name after your consent is given and allow you to review and edit relevant field notes and transcribed interview texts prior to their being made public.

The researchers will keep the collected data in locked facilities or password-protected on 
computers. The only people that will have access to the files will be the supervisor and researchers. All data collected from this research will be destroyed by December 31, 2023 or when the report is completed, whichever comes first. Your participation is voluntary, and you are free to withdraw at any time. If you decide to withdraw from the research at any time, all data collected will be destroyed or returned to you. You are not obliged to answer any questions that you find objectionable or which make you feel uncomfortable.

This project has been reviewed and approved by the Wilfrid Laurier University Research Ethics Board. If you feel you have not been treated according to the descriptions in this form, or your rights as a participant in research have been violated during the course of this project, you may contact Dr. Andrew Spring, adjunct Professor, Department of Geography and Environmental Studies, Wilfrid Laurier University, (226) 772-3127, aspring@wlu.ca or Dr. Jayne Kalmar, Chair, University Research Ethics Board, Wilfrid Laurier University, (519) 884-0710, extension 3131, REBChair@wlu.ca.

I understand the information described on the previous page and consent to participate in this research:

Name: Date:

Signature:

\section{FOCUS GROUP}

By initialing the statements below:

I agree to participate in this focus group/interview.

I grant permission for the researcher to use an audio recorder.

I grant permission for the researcher to use direct quotations from our focus group (to preserve anonymity, no names will be used with the quotations) 


\section{Interview Guide:}

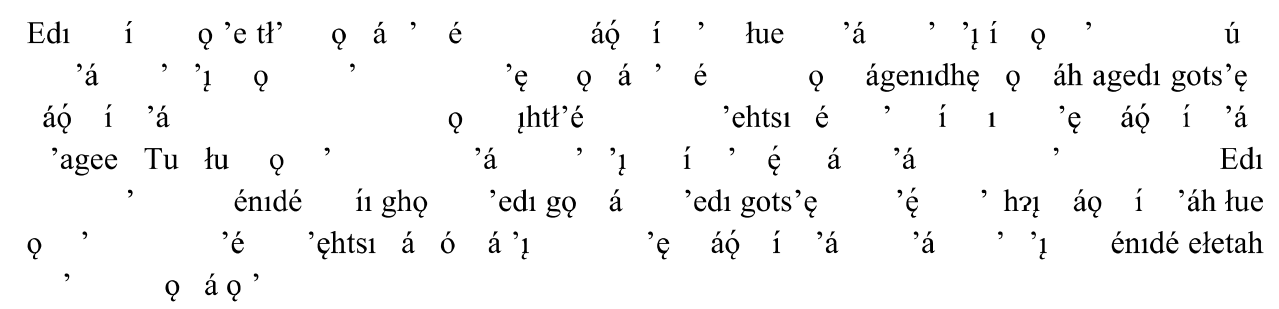

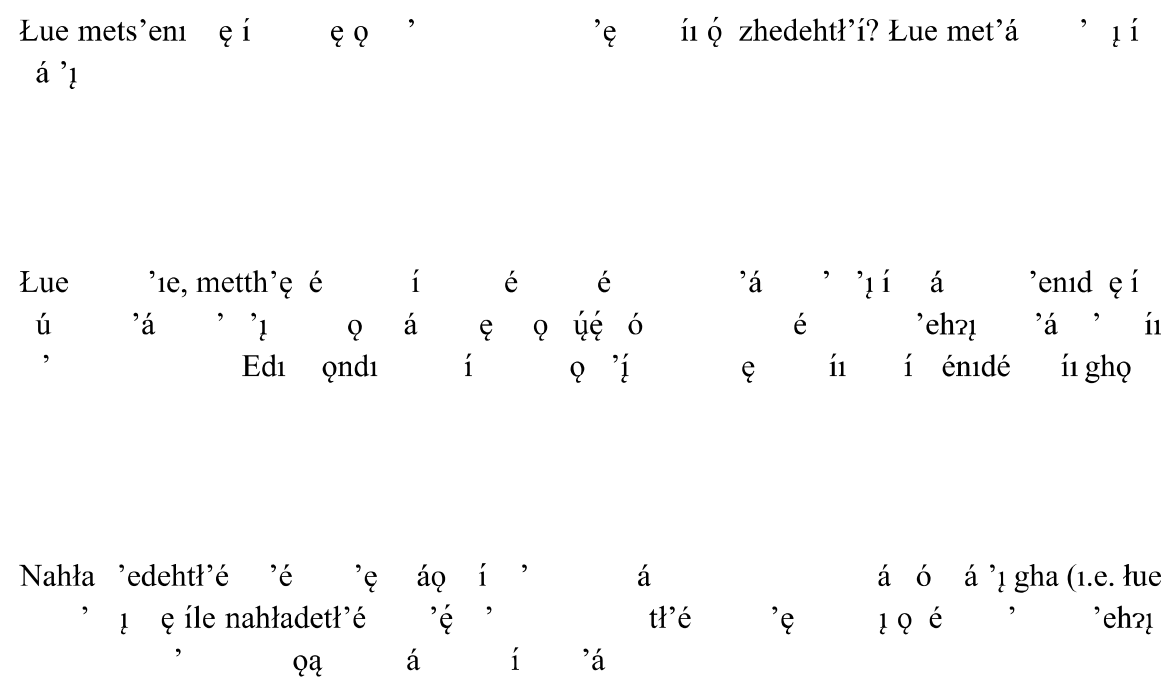


Appendix C: Aurora Research Institute License

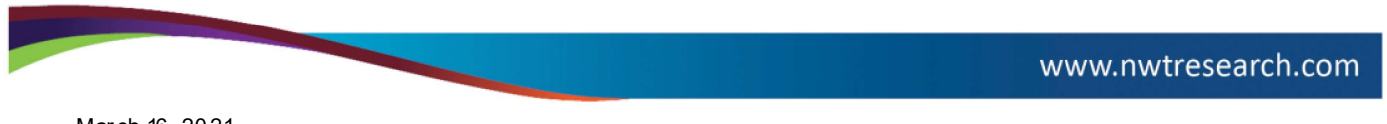

March 16, 2021

\section{Notification of Research}

I would like to inform you that Northwest Territories Scientific Research Licence No. 16795 has been issued to:

Dr. Andrew Spring

Wilfrid Laurier University

Department of Geography

75 Univer sity Ave W

Phone: (226) 772-3127

Email: aspring@vlu.ca

to conduct the following study:

Food Systems Research in Kakisa (4948)

Please contact the researcher if you would like more infor mation about this research project. Summary of Research

1. Foster training and knowledge sharing to ensure that traditional foods continue to provide an important

component of affordable, sustainable healthy food system for Ka'a'gee Tu First Nation.

2. Conduct a detailed needs assessment for a food secur ity and climate change action plan

3. Increase knowledge and capacity to grow and produce food products while exploring opportunities for food sharing, distribution and selling of locally produced goods

4. Continue documenting and monitoring impacts of climate change and development on the land and waters through community-based monitoring

5 . Incr ease youth under standing of climate change, food security and health

Sincerely,

Jonathon Michel

Manager, Scientific Services

Distribution

- Akaitcho Territory Government 
Appendix D. Carleton University Approved Ethics: Recruitment Letter \& Interview Guide (2021)

\section{Recruitment Letter}

\section{Overcoming barriers to agricultural expansion through fish waste composting in Kakisa, NT}

Principal Investigators: Erin Snider, MA Student, Institute of Political Economy, Carleton University

We are seeking your voluntary participation in a research project about moving forward with the fish composting pilot project in Kakisa. This project will contribute to the Northern Agriculture Futures project led by your community (The Ka'a'gee Tu First Nation). This research is a collaborative project between Erin Snider from Carleton University (Master's student in Political Economy), the KTFN, and Dr. Andrew Spring (Wilfrid Laurier University). This part of the study seeks to understand the community's identified assets or strengths, and challenges or barriers for organizing this project. This is important because the community has identified agriculture as a way to expand local food production as a way to cope with threats of food insecurity and climate change. Since compost can be used as a tool for increasing soil health and productivity, this project will help the community become more self-sufficient as food production in Kakisa expands.

For this phase of the study, we are hoping to conduct interviews with community members in Kakisa, in order to get a better understanding of how a fish composting system can, and should, operate in the community. The interview will take approximately half an hour to 1 hour, and it will be audio recorded. The interview will include questions about the community's strengths and assets that can be applied to make fish composting a reality in Kakisa. The interviews will take place via phone call at a mutually agreed upon time, in January 2021. Chief Lloyd Chicot will be present for interviews (unless otherwise requested by you) to offer assistance and/or translate conversations in South Slavey. It may be possible that a follow up call or interview is required, and we will reach out to you to schedule a call, if needed. Results of the interview will be presented as part of a plainlanguage report in the Spring of 2021 and will be shared with other partners of the Northern Agriculture Futures project. After the interview is conducted you will be given an opportunity to review the transcripts to request changes and validate the researcher's interpretations of your statements.

It is possible that as a participant, by answering the questions in the interviews, you could 
make statements that could be awkward for you when made public (e.g., through academic publications or plain language reports to the community) either by providing information or answers that you feel are not current, or are taken out of context by researchers. We consider these risks to be very low, and in line with the risks encountered in your daily activities. We will mitigate these risks by preserving your anonymity in reports, and only use your name after your consent is given, and by meeting with you individually after the interview to allow you to review and edit relevant field notes and transcribed interview texts prior to their being made public.

The researchers will keep the collected data in locked facilities or password-protected on computers. The only people that will have access to the files will be the researchers. All data collected from this research will be returned to you and the researcher will destroy any data in their possession after 10 years. Your participation is voluntary, and you are free to withdraw at any time. If you decide to withdraw from the research at any time, all data collected will be destroyed or returned to you. You are not obliged to answer any questions that you find objectionable or which make you feel uncomfortable.

This project has been reviewed and approved by the Carleton University Research Ethics Board (CUREB). If you have questions at any time about the study or the procedures or you experience adverse effects as a result of participating in this study you may contact Dr. Andrew Spring, Adjunct Professor, Department of Geography and Environmental Studies, Wilfrid Laurier University, (226) 772-3127, aspring@wlu.ca. If you feel you have not been treated according to the descriptions in this form, or your rights as a participant in research have been violated during the course of this project, you may contact CUREB Chair, Carleton University, ethics@carleton.ca.

I understand the information described above and consent to participate in this research:

Name: Date:

Signature:

$\underline{\text { Interview }}$ 
By initialing the statements below:

I agree to participate in this interview.

I grant permission for the researcher to use an audio recorder.

I grant permission for the researcher to use direct quotations from the interview and identify me as the source of the information.

I grant permission for the researcher to use direct quotations from the interview but NOT identify me as their source.

I do NOT grant permission for the researcher to use direct quotations from the interview

Researcher:

Name:

Date:

Signature:

\section{Interview Guide:}

\section{Questionnaire}

The following questions are intended to stimulate discussion about community strengths and assets that will help the Ka'a'gee Tu First Nation's fish composting pilot project come to fruition. These questions are intended for all participants of the fish composting focus group in Kakisa, including community members, community researchers, and the principal investigator. Some questions will be asked in the form of activities, while others will be more discussion-based.

Activity 1: As a group, brainstorm at least 6 assets that Kakisa has. These assets can be physical, economic, natural, social, cultural, or a combination of these categories. 
Afterwards, each group will be asked to share which assets they came up with. Following the discussion from each group, a community researcher will write down each asset you have come up with under one of the categories (physical, economic, natural, social, or cultural).

Question 1: Why did we decide these assets were important? What makes them community assets? How are they useful to the community?

Activity 2: EAs a group, go through each category and rank the assets from "most" to "least" relevant for fish composting. Afterwards, each person will be given an opportunity to share how they ranked each asset and why.

Activity 3: This activity will be a visual exercise to get us thinking about how the fish composting system will operate in Kakisa. On this map of the community, we have identified 3 locations of interest: the docks on Kakisa lake, the chosen fish composting site, and the greenhouses. The lake is where the fish waste will be generated. The composting site is where fish waste will be transformed into compost. The greenhouse is the final destination for finished compost. As a group, let's think through what needs to happen to move the fish waste and compost from each destination.

- What human labour is required to move fish waste from the lake to the site, and to move finished compost from the site to the greenhouse?

- What tools/equipment/machinery would be required to move fish waste and compost?

- What tools/equipment/machinery would be required to manage the fish waste at the composting site?

- How can some of the social, cultural, natural, or economic assets be used in fish composting?

Question 2: Could any of the assets ranked as "least relevant" be strengthened and made more useful to the fish composting project? 
$\underline{\text { Appendix E. } 13 \text { Moons Poster - Indigenous Food Circle }}$

Indigenous Food Circle. (2020). 13 Moons Poster. Understanding Our Food Systems. Retrieved from: https://uploadsssl.webflow.com/5da2993f20ae1b3485335ef4/5fc035b187e53784b1a4a7fb_13MOONS-30x40.pdf

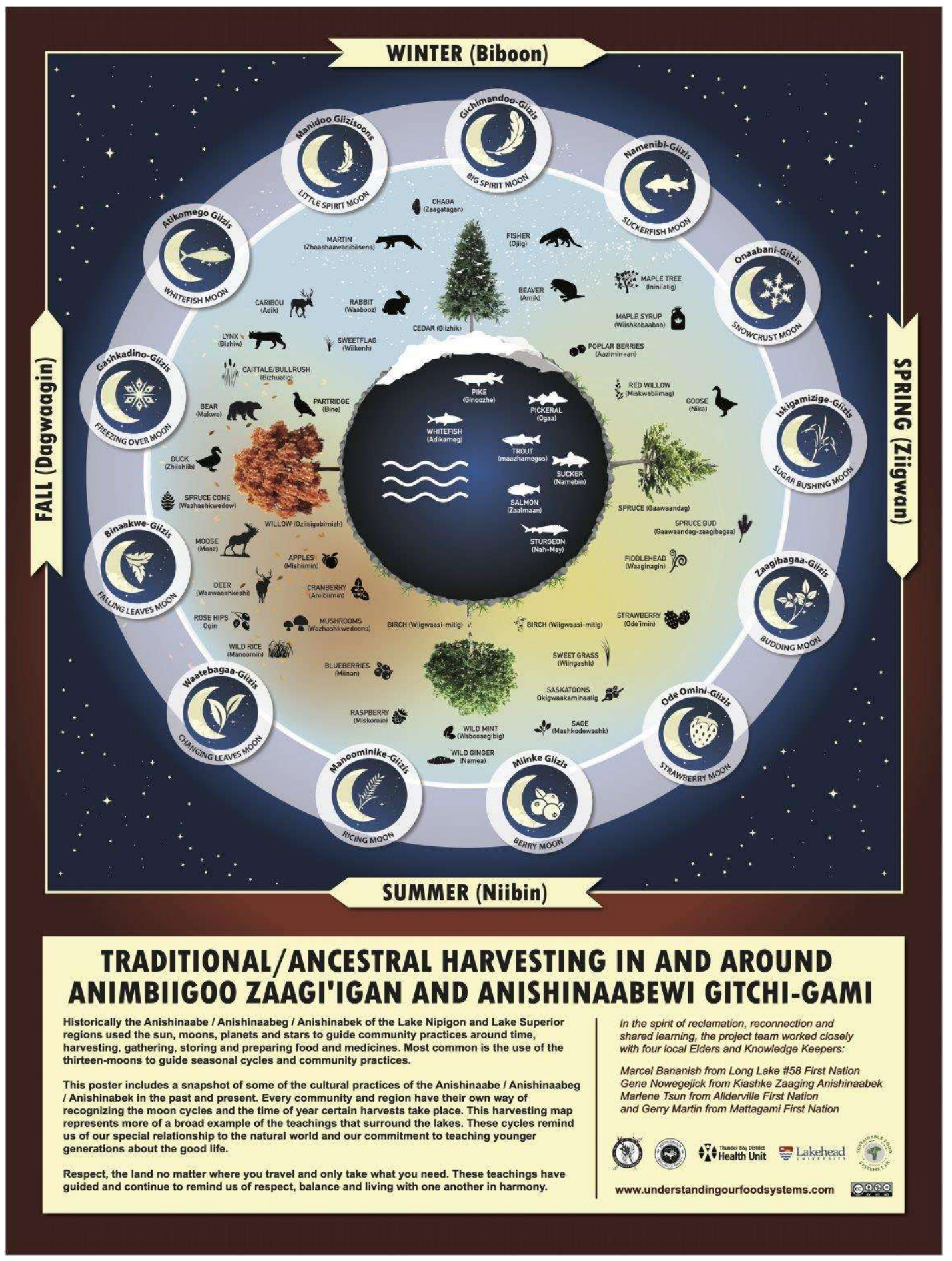


Appendix F. Kakisa Community Capitals Table (Spring et al., 2018)

Spring, A., Carter, B., \& Bay-Palmer, A. (2018). Climate change, community capitals, and food security: building a more sustainable food system in a northern Canadian boreal community. Canadian Food Studies/La Revue Canadienne des études sur l'alimentation, 5(2), 111-141.

Table 2: Summary of community capital in the food system of Kakisa as determined though community interviews, showing key elements that contribute to (+) or degrade (-) capitals

\begin{tabular}{|l|l|}
\hline Capital & Attribute \\
\hline Social & $\begin{array}{l}\text { (+) Strong social economy (food sharing) } \\
\text { (+) Small, close-knit community (bonding social capital) } \\
\text { (+) Experience with research networks outside of community (bridging social capital) } \\
\text { (-) Some issues with degradation of bonding social capital in the community. } \\
\text { (-) People leave community for education and jobs }\end{array}$ \\
\hline Cultural & $\begin{array}{l}\text { (+) Most community members maintain traditional practices and activities and a strong } \\
\text { connection to the land } \\
\text { (-) Limited time available to take part in traditional activities (for some) }\end{array}$ \\
& $\begin{array}{l}\text { (-) Language as barrier to transfer of traditional knowledge } \\
\text { (-) Some youth not as engaged in traditional foods and activities }\end{array}$ \\
\hline Natural & $\begin{array}{l}\text { (+) Abundant sources of traditional food } \\
\text { (+) Abundant access to clean water }\end{array}$ \\
\hline Financial & $\begin{array}{l}\text { (+) Concerns of impacts of development on the health of the land } \\
\text { (+) Small commercial fishery } \\
\text { (-) Limited availability of jobs in community } \\
\text { (-) High cost of living (food, gas, and supplies) }\end{array}$ \\
\hline Political & $\begin{array}{l}\text { (+) Active local government } \\
\text { (+) Pending protected area designation } \\
\text { (-) Limited decision making ability in terms of control of lands }\end{array}$ \\
\hline Human & $\begin{array}{l}\text { (+) Engaged community (active in training opportunities) } \\
\text { (-) Small population } \\
\text { (-) Time and effort needed to travel to other communities for store-bought goods. }\end{array}$ \\
\hline Built & $\begin{array}{l}\text { (+) All-weather road access } \\
\text { (+) Local school } \\
\text { (+) Community hall and culture camp } \\
\text { (-) Limited infrastructure (health, water, etc.) } \\
\text { (-) No store }\end{array}$ \\
\hline
\end{tabular}

Table as presented on page 123 (Spring et al., 2018). 